\title{
Formex \\ Configuration Processing I
}

\author{
Hoshyar Nooshin and Peter Disney
}

\author{
Space Structures Research Centre, Department of Civil Engineering, University of Surrey, \\ Guildford, Surrey GU2 7XH, United Kingdom
}

\begin{abstract}
This is the first paper in a series of papers that are intended to cover the present state of knowledge in the field of formex configuration processing. This field of knowledge has been developed during the last three decades and has now reached a level of maturity that makes it an ideal medium for configuration processing in many disciplines. In particular, it provides a rich assortment of concepts that are of great value to the engineers and architects involved in the design of space structures.
\end{abstract}

\subsection{INTRODUCTION}

Formex algebra is a mathematical system that provides a convenient medium for configuration processing. The concepts are general and can be used in many fields. In particular, the ideas may be employed for generation of information about various aspects of structural systems such as element connectivity, nodal coordinates, loading details, joint numbers and support arrangements. The information generated may be used for various purposes, such as graphic visualisation or input data for structural analysis.

The rudimentary ideas from which formex algebra has emerged were evolved in the early seventies. These embryonic concepts were published in 1975'. Experience in using the early ideas resulted in a substantial revision which was presented at a short course in 1978 and subsequently published in $1981^{2}$. The first textbook on the subject appeared in $1984^{3}$. This book provided a comprehensive account of the ideas of formex algebra as they stood at the time of the publication. The book remains a main source of information on formex algebra although new developments in the field have superseded some of the material of the book. These new developments have also enriched this field of knowledge extensively.
The objective of this paper is to introduce a skeleton of the ideas of formex algebra and the programming language Formian which is a vehicle for the practical use of formex algebra. The material presented in this paper will allow the reader to acquire a working knowledge of the elements of formex configuration processing.

The term 'configuration' is used to mean an 'arrangement of parts'. The elements of a structure, for instance, constitute a configuration and so do the component parts of an electrical network and the atoms of a protein molecule. The most common usage of the term configuration is in reference to geometric compositions that consist of points, lines and surfaces.

The term 'configuration processing' is used to mean the creation and manipulation of configurations and the term 'formex configuration processing' is used to mean configuration processing using formex algebra.

\subsection{THE CONCEPT OF A FORMEX}

Consider the configuration shown in Fig 1.2.1 and let this represent the plan view of a diagonal grid. The grid consists of two families of parallel beams that are rigidly connected together at the intersection points. This will result in 240 beam elements that are interconnected together at 136 nodes. 


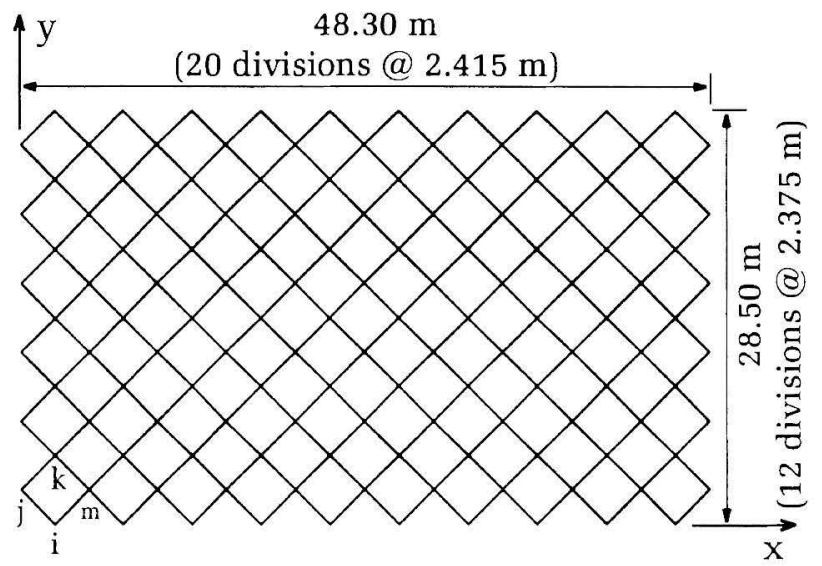

Fig 1.2.1 Plan view of a diagonal grid

Let it be required to produce data for the analysis of the grid of Fig 1.2.1. The complete set of data should include information about the constitution of the grid as well as the nodal coordinates, loading conditions, support arrangements, cross-sectional particulars of the elements and material properties. However, at the present, attention will be focused on the generation of information about the constitution of the grid.

The term 'compret' is used to refer to the constitutional aspects of a configuration. To be specific, the compret of a configuration is 'the arrangement of the component parts of the configuration'. In order to describe the compret of a configuration it is necessary to list the component parts of the configuration and to specify the interconnections between these component parts. The terms 'connectivity' and 'topology' are sometimes used instead of compret.

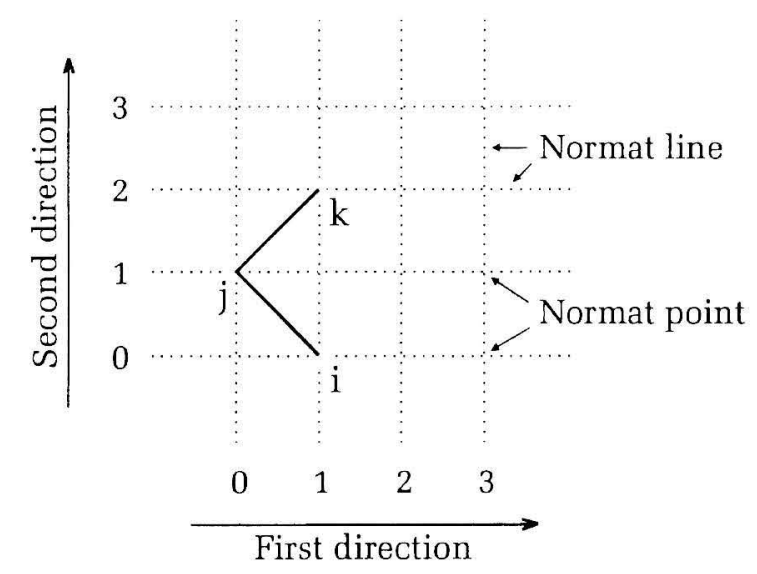

Fig 1.2.2 A normat

\subsubsection{Normats}

To specify the compret of the grid of Fig 1.2.1, one may begin by considering a small portion of the grid. This portion is chosen to consist of the elements $i j$ and $\mathrm{jk}$ at the bottom left corner of the grid. These elements are shown in Fig 1.2.2 together with a simple reference system that consists of two families of dotted lines. In terms of this reference system, element ij can be represented by the construct

$$
[1,0 ; 0,1]
$$

The first pair of numbers inside the square brackets represents node $\mathrm{i}$, since this node is at the intersection of dotted line 1 of the first direction and dotted line 0 of the second direction. Similarly, the second pair of numbers inside the square brackets represents node $\mathbf{j}$.

A graphical reference system that is used for the specification of the compret of a configuration is referred to as a 'normat'. The reference system of Fig 1.2.2 is an example of a normat consisting of 'normat lines' that intersect at 'normat points'.

\subsubsection{Uniples, Signets and Cantles}

Each number inside the square brackets in the construct

$$
[1,0 ; 0,1]
$$

represents a normat line and is referred to as a 'uniple'. Each uniple pair in the construct

$$
[1,0 ; 0,1]
$$

represents a normat point and is referred to as a 'signet', Fig 1.2.3. The semicolon between the signets indicates a connection between the specified normat points.

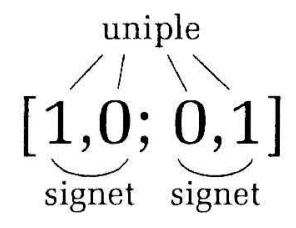

Fig 1.2.3 A cantle

The construct

$$
[1,0 ; 0,1]
$$

is a simple example of a 'formex' and an equation of the form

$$
\mathrm{E} 1=[1,0 ; 0,1]
$$

implies that El is a 'variable' whose 'value' is the formex on the right-hand side of the equation. Therefore, E1 represents the beam element ij of Fig 1.2.2. Similarly, the element jk in Fig 1.2.2 can be represented by

$$
\mathrm{E} 2=[0,1 ; 1,2]
$$


Also, the combination of elements ij and jk may be represented by

$$
\{[1,0 ; 0,1],[0,1 ; 1,2]\}
$$

This is a formex consisting of two 'cantles', Fig 1.2.4. In general, a formex may have any number of cantles and the total number of these cantles is referred to as the 'order' of the formex. Curly brackets are used to enclose the cantles of a formex. However, in the case of a formex of the first order the curly brackets are optional. Thus,

$$
\{[1,0 ; 0,1]\} \text { and }[1,0 ; 0,1]
$$

are considered to be equivalent. In addition to its meaning as a component of a formex, the term 'cantle' is used to refer to a formex of the first order.

Typically, in the context of a structural configuration

- a signet represents a node,

- a cantle represents an element and

- a formex represents a group of elements.

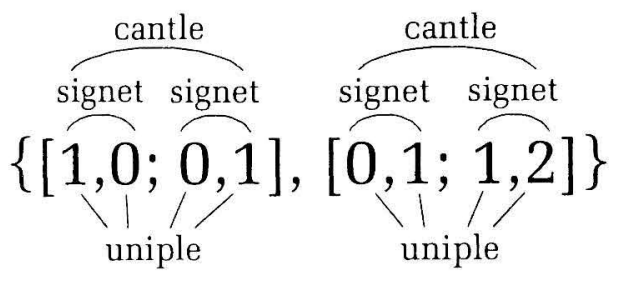

Fig 1.2.4 A formex

\subsubsection{Formex Composition}

The formex variable

$$
\mathrm{F}=\{[1,0 ; 0,1],[0,1 ; 1,2]\}
$$

that represents the combination of elements ij and $\mathrm{jk}$ in Fig 1.2.2 may also be given as

$$
\mathrm{F}=\mathrm{E} 1 \# \mathrm{E} 2
$$

where

and

$$
\mathrm{E} 1=[1,0 ; 0,1]
$$

$$
\mathrm{E} 2=[0,1 ; 1,2]
$$

The symbol \# is referred to as the 'duplus symbol'. This symbol acts as an 'operator' indicating the 'composition' of formices represented by E1 and E2. The term 'formices' is the plural of 'formex'.

Formex composition is a fundamental operation in formex algebra and is used to effect combination of entities represented by two or more formices.

The concepts of formex algebra are normally used in conjunction with a computer software. In particular, the interactive programming language 'Formian' provides a suitable medium for formex configuration processing. An overview of the basic aspects of this programming language is presented in the next section and the continuation of the formex formulation of the grid of Fig 1.2.1 will be resumed in section 1.4.

The origins of Formian date back to the late seventies and various versions of the language have been in use since then ${ }^{4-7}$. The ideas of Formian have evolved and matured over the years and the material relating to Formian in the present work is based on the current state of the language.

It is important for the reader to have access to a computer with Formian on it. The material presented in this paper may then be studied step by step with the examples being tried on the computer as progress is being made.

Formian may be downloaded from the web site: http://www.surrey.ac.uk/CivEng/research/ssrc/formian.htm

\subsection{FORMIAN: THE FIRST ENCOUNTER}

In using Formian, one normally works with a computer 'monitor' together with a 'keyboard' and a 'mouse'. These will be parts of a computing system that provides the required processing power as well as storage and input/output capabilities for the running of Formian. The term 'system' is used to refer to the entirety of the hardware and software components that are involved in running Formian on a computing system. The term 'user' is used to refer to a person who uses the system and the term 'session' is used to refer to an occasion of the use of Formian that involves a user entering Formian, carrying out some Formian operations and exiting Formian.

\subsubsection{Formian Screen}

When Formian is entered, the screen of the monitor will display a number of items, as shown in Fig 1.3.1. The particular set-up of the screen that is displayed during a Formian session is referred to as the 'Formian screen'. The main elements of the Formian screen consist of a number of 'bars' together with the editory and drawpad, as explained below:

- The 'title bar' is a narrow rectangular region that appears at the top of the screen.

- The 'menu bar' is another narrow rectangular region that is situated below the title bar and displays the names of the available 'menus'. 
- The 'tool bar' is situated below the menu bar and displays a number of 'tool buttons' each of which is for a specific activity.

- The 'editory' is a window that is situated on the left of the screen below the tool bar. The editory is used for the creation and editing of Formian instructions.

- The 'drawpad' is a window that is situated on the right of the screen below the tool bar. The drawpad is used for graphical output.

- The 'status bar' is situated under the editory and drawpad. The status bar is used by the system for the display of various kinds of information.

- The 'task bar' is situated at the bottom of the screen and is used by the Windows operating system to display buttons for switching to various applications.

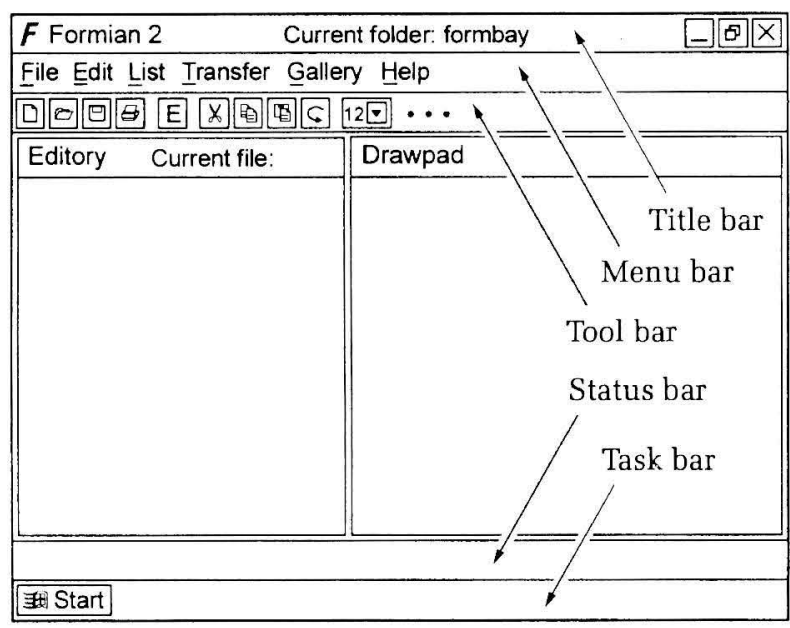

Fig 1.3.1 Formian screen

The menus that are listed on the menu bar and the tool buttons that appear on the tool bar will be discussed at various points in the sequel.

\subsubsection{Statements and Commands}

During a session, the user supplies the system with a sequence of 'instructions'. These instructions are of two kinds, namely, statements and commands.

The first type of instructions are those that are given in textual form. An instruction of this kind is referred to as a 'statement'. For example,

$$
\mathrm{E} 1=[1,0 ; 0,1] \text {; }
$$

is a statement. The effect of this statement is to associate the formex $[1,0 ; 0,1]$ with E1. That is, the statement creates a 'variable' E1 whose 'value' is the given formex.
Instructions for performance of a number of activities are provided through menus, tool buttons and keyboard shortcuts. The term 'command' is used to refer to an instruction of this kind. An example of a command is the 'exit command'. This command is 'issued' when the button on the top right-hand corner of the screen is 'clicked' using the mouse. This button has a cross appearing on it and is referred to as the 'exit button'. To 'click a button', the 'mouse pointer' is placed on the button and then the 'lefthand button' of the mouse is pressed and released immediately.

The effect of the exit command is to terminate the running of Formian and bring the session to an end. The exit command may also be issued by typing 'alt $+X$ ' from the keyboard. That is, by striking the $\mathrm{X}$-key while the alt-key is held down. This is an example of a 'keyboard shortcut'.

Statements are entered into the editory by typing from the keyboard. The statements that are placed in the editory may be subjected to execution. By 'execution' of a statement it is meant carrying out the actions that are necessary to put into effect what is specified by the statement.

For example, the typing of the sequence of characters

$$
\begin{aligned}
& \mathrm{E} 1=[1,0 ; 0,1] ; \\
& \mathrm{E} 2=[0,1 ; 1,2] ; \\
& \mathrm{F}=\mathrm{E} 1 \# \mathrm{E} 2 ;
\end{aligned}
$$

will place the sequence in the editory. The sequence of letters in this particular case gives rise to a set of three 'assignment statements'.

When an assignment statement is executed then the value of what is on the right-hand side of the 'assignment symbol', that is , the symbol $=$, is 'assigned' to the name that is on the left-hand side of the symbol. In other words, the name on the left is 'associated' with the value on the right. The establishment of this association will turn the name into a 'variable'. That is, a variable is a name which has been associated with a value. Thus, the execution of the above three assignment statements will result in the creation of three 'formex variables' E1, E2 and F.

In a programming language, as indeed in any mathematical context, a variable is simply a 'name' that represents a 'value'. However, it is a long established tradition that one talks about a variable as though it is the value itself. For instance, in relation to the formex variable $F$ discussed above, one may talk about the 'first cantle of $F$ ' where one really means the 'first cantle of the value of F'. Explicit 
reference to 'value' is sometimes made for 'extra clarity' but normally the direct reference to value is omitted.

The name used for a variable is normally chosen to reflect what the variable represents so that the name can jog the memory regarding the significance of the variable. This name must be selected from a class of names that are referred to as identifiers. An 'identifier' is any sequence of up to eight letters and digits that starts with a letter. This rule provides over $2 \times 10^{12}$ possibilities for identifiers. The letters that are used in an identifier may be upper-case or lower-case without any distinction being made between them. In fact, in all Formian constructs upper-case and lowercase letters may be used interchangeably. That is, the 'case' of the letter is always ignored.

Note that the above discussed assignment statements

$$
\begin{aligned}
& \mathrm{E} 1=[1,0 ; 0,1] ; \\
& \mathrm{E} 2=[0,1 ; 1,2] ; \\
& \mathrm{F}=\mathrm{E} 1 \# \mathrm{E} 2 ;
\end{aligned}
$$

are simply the 'formex equations' discussed before except that each equation is terminated by a semicolon. In Formian, as a general rule, every statement must be terminated by a semicolon.

Formex formulations in this work are presented in two different styles. To elaborate, when writing a formex formulation, without any direct Formian involvement, then the formulation is presented using the normal mathematical conventions, without any consideration regarding the Formian grammar. On the other hand, when a formex formulation is meant to be in terms of Formian statements, then the rules of the Formian grammar are observed. For example, a formex equation such as

$$
\mathrm{F}=\mathrm{E} 1 \# \mathrm{E} 2
$$

is not terminated by a semicolon unless it is meant to be a Formian statement.

\subsubsection{Schemes}

A group of one or more statements that are to be 'executed together' is referred to as a 'scheme'. To carry out the execution of a scheme, it is necessary to place the 'cursor' at a point of the scheme and to click the 'execution button' on the tool bar using the mouse. This will have the effect of issuing an 'execution command'.

Placing of the cursor on a scheme is done using either the mouse or the 'cursor keys' on the keyboard. The execution button is the tool button with the letter $\mathrm{E}$ appearing on it.
While a scheme is being executed, the progress of execution is represented graphically by an advancing strip of colour at the bottom of the screen on the status bar. This will provide a means of 'seeing' the progress of the execution as statements are executed one after the other. The narrow rectangular area in which the advancing strip of colour is shown is referred to as the 'progress bar', Fig 1.3.2.

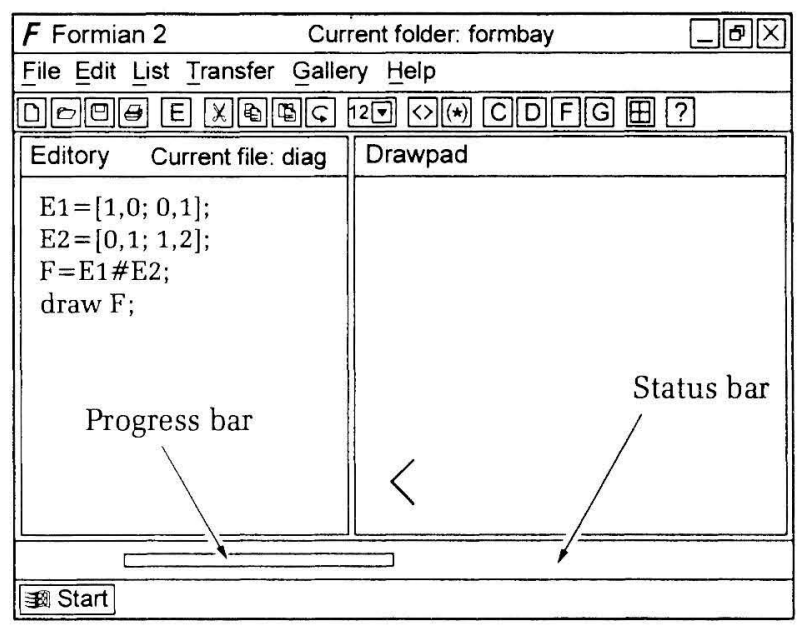

Fig 1.3.2 Execution of a scheme

Fig 1.3.2 also displays the above discussed assignment statements. These assignment statements are followed by the statement

\section{draw F;}

This is a 'draw statement' whose execution will place a plot of the value of the formex variable $F$ in the drawpad. The term 'plot' is used to refer to a graphical representation of a formex. The plot of $F$ is shown in the bottom left corner of the drawpad in Fig 1.3.2.

The effect of a draw statement may also be obtained by 'highlighting' a formex variable in the editory and clicking the 'draw tool button'. This is the tool button with the letter D appearing on it. The clicking of the draw tool button issues a 'draw command' which will effect the display of the plot of the highlighted formex variable.

The editory may contain more than one scheme. For instance, suppose that one wants to create a scheme for representation and plotting of the elements 'im' and 'mk', shown in Fig 1.3.3. The normat shown with dotted lines in this figure is identical to that shown in Fig 1.2.2.

The required scheme may be written as

$$
\begin{aligned}
& \mathrm{H}=\{[1,0 ; 2,1],[2,1 ; 1,2]\} \\
& \text { clear; }
\end{aligned}
$$


use vs(30);

draw $\mathrm{H}$;

The screen with this new scheme is shown in Fig 1.3.4. In addition to an assignment statement and a draw statement, the new scheme contains a 'clear statement' and a 'use statement'.

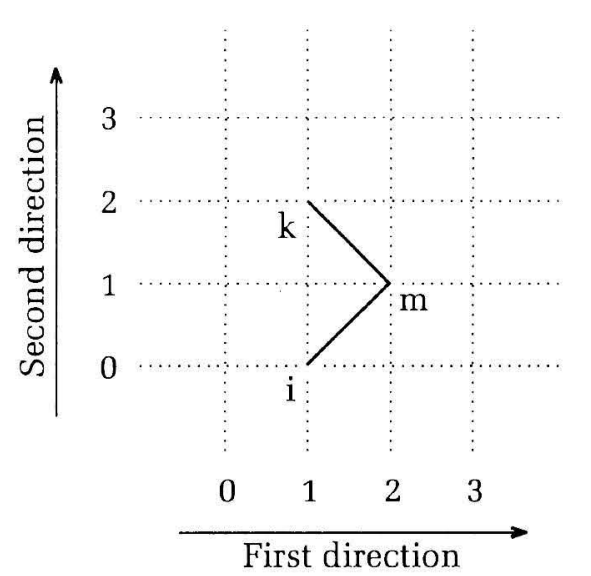

Fig 1.3.3 A part of the grid of Fig 1.2.1

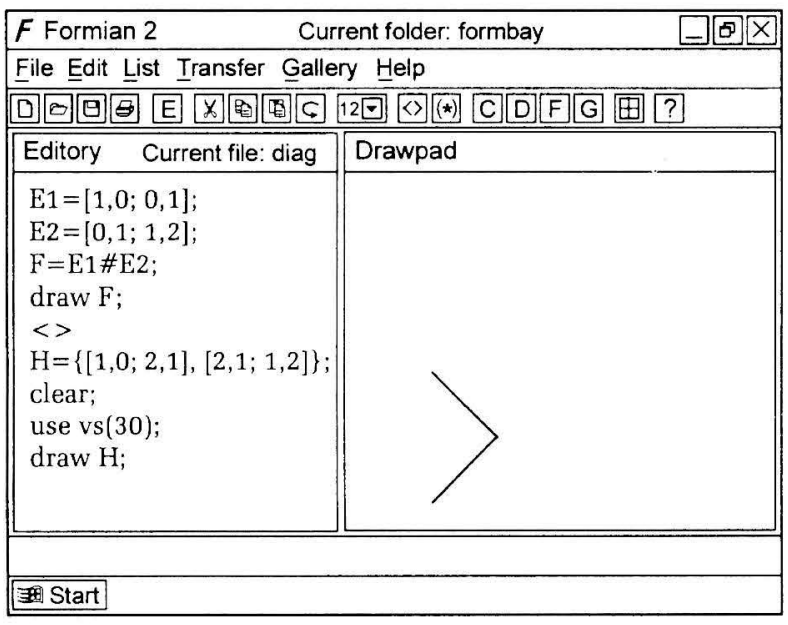

Fig 1.3.4 Formian screen with two schemes in the editory

The effect of a clear statement is to clear the drawpad. Thus, when the new scheme is executed, the plot of $\mathrm{F}$, which was created by the first scheme, will be wiped out.

The effect of a clear statement may also be obtained by a 'clear command'. This command is issued by clicking the 'clear tool button'. This is the tool button with the letter $\mathrm{C}$ appearing on it.

The effect of the statement

$$
\text { use vs(30); }
$$

is to alter the 'plotting scale'. The letters 'vs' stand for 'view scale' and the number 30 in parentheses is a measure of the plotting scale. The default value of the view scale is 10 and, therefore, the execution of the statement

$$
\text { use vs(30); }
$$

will make the scale three times larger.

Once a plotting scale is set through a use statement, it will remain in force until the end of the session unless it is changed again by another use statement.

The plot of $\mathrm{H}$ with the increased scale is shown in Fig 1.3.4. Also shown in this figure is the symbol

$$
<
$$

separating the first scheme from the second one. This symbol is referred to as the 'diamer' symbol and is obtained by typing a 'less than' symbol followed by a 'greater than' symbol.

The diamer symbol may also be obtained by clicking the 'diamer tool button'. This is the tool button with a diamer symbol appearing on it.

The diamer symbol is the 'scheme separator' and every two consecutive scheme in the editory must be separated by one or more diamer symbols.

\subsubsection{Examining the Value of a Formex Variable}

The value of a formex variable may be examined through a 'give statement'. For example, consider the scheme

$$
\begin{aligned}
& \mathrm{E} 1=[1,0 ; 0,1] \\
& \mathrm{E} 2=[0,1 ; 1,2] \\
& \mathrm{F}=\mathrm{E} 1 \# \mathrm{E} 2 ; \\
& \text { give } \mathrm{F} ;
\end{aligned}
$$

The last statement of the scheme is an example of a 'give statement'. The execution of this statement will have the effect of displaying the value of the formex variable F in a 'give box' on the screen, Fig 1.3.5.

Give statements provide a convenient mechanism for examining the values of formex variables. However, normally one would only use a give statement for displaying a formex that contains no more than a few cantles. Display of a large formex will give rise to a huge volume of numbers that are difficult to follow and scrutinise.

The effect of a give statement may also be obtained by 'highlighting' a variable in the editory and clicking the 'give tool button'. This is the tool button with the letter $\mathrm{G}$ appearing on it. The clicking of the 
give tool button issues a 'give command' which will effect the display of the value of the highlighted variable.

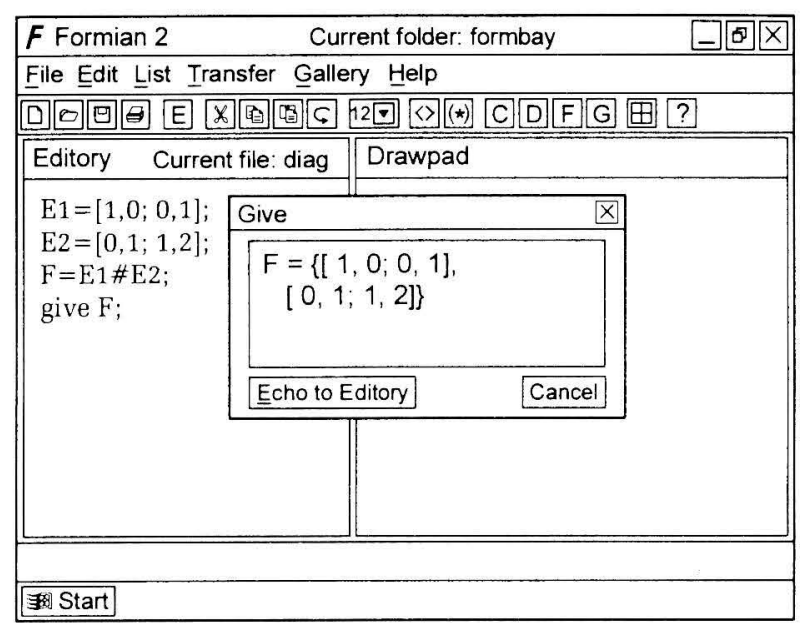

Fig 1.3.5 Execution of a give statement

\begin{tabular}{|c|c|c|}
\hline \multicolumn{3}{|c|}{$F$ Formian $2 \quad$ Current folder: formbay } \\
\hline \multicolumn{3}{|c|}{ File Edit List Iransfer Gallery Help } \\
\hline \multicolumn{3}{|c|}{ 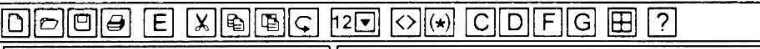 } \\
\hline \multicolumn{3}{|c|}{\begin{tabular}{ll|l} 
Editory Current file: diag & Drawpad \\
\end{tabular}} \\
\hline \multirow{4}{*}{$\begin{array}{l}\mathrm{E} 1=[1,0 ; 0,1] ; \\
\mathrm{E} 2=[0,1 ; 1,2] ; \\
\mathrm{F}=\mathrm{E} 1 \# \mathrm{E} 2 ; \\
\text { giive } \mathrm{F} ;\end{array}$} & & \\
\hline & $\frac{1}{\text { Error }}$ & \\
\hline & A syntax error & \\
\hline & OK & \\
\hline \multicolumn{3}{|c|}{$\Longleftarrow$} \\
\hline Start & & \\
\hline
\end{tabular}

Fig 1.3.6 Error indication

\subsubsection{Diagnostic Information}

Consider the scheme in the editory shown in Fig 1.3.6. An attempt to execute this scheme will prove to be unsuccessful. The system will display an "error box' with a message indicating that there is a 'syntax error' in the scheme. This implies that there is something wrong with the constitution of one of the statements and the statement that contains the error will be highlighted.

On examination, it is found that the keyword 'give' is misspelt, that is, it is spelt as 'giive' and this is the error that is causing the problem.
In general, once the system encounters an error in a statement, the execution of that statement and any remaining statements of the scheme will be abandoned and the nature of the problem, with as much details as possible, will be reported through an error box.

To proceed, one should

- dismiss the error box by clicking its 'OK button',

- correct the syntax error by editing and

- try again to execute the scheme.

In general, a scheme may be modified, enlarged or reduced in any desired manner using the available editing facilities.

\subsubsection{Editing}

In Formian, editing is performed using the normal Windows' editing conventions. The text in the editory may be edited using the edit menu, editing tool buttons and the keyboard.

The 'edit menu' is activated either by clicking 'Edit' on the menu bar or by using the keyboard shortcut 'alt+E'. Fig 1.3.7 shows the edit menu together with brief descriptions of the effects of its items.

\begin{tabular}{|c|c|}
\hline$\underline{\text { Undo }}$ & $\begin{array}{l}\text { Undo the last editing action (one level } \\
\text { only). }\end{array}$ \\
\hline Cut & $\begin{array}{l}\text { Cut the highlighted selection from the } \\
\text { editory and put it on the clipboard. }\end{array}$ \\
\hline$\underline{\text { Copy }}$ & $\begin{array}{l}\text { Copy the highlighted selection from the } \\
\text { editory and put it on the clipboard. }\end{array}$ \\
\hline$\underline{\text { Paste }}$ & $\begin{array}{l}\text { Insert the contents of the clipboard at } \\
\text { the cursor position in the editory. }\end{array}$ \\
\hline$\underline{\text { Find } . . .}$ & Find the specified text in the editory. \\
\hline Replace... & $\begin{array}{l}\text { Replace the specified text in the editory } \\
\text { with another text. }\end{array}$ \\
\hline$\underline{\text { Select all }}$ & Select the entire contents of the editory. \\
\hline
\end{tabular}

Fig 1.3.7 Editing commands

When a menu is active (that is, when it is displayed on the screen), then the effect of a 'menu item' may be obtained by:

- clicking the item using the mouse or

- touching the 'underlined letter' of the item on the keyboard or 
- highlighting the item using the cursor keys and then touching the 'return key' on the keyboard.

The editing processes of 'cutting', 'copying' and 'pasting' make use of a storage area for temporary storage of material. This storage area is referred to as the 'clipboard' and is symbolically represented by a clipboard.

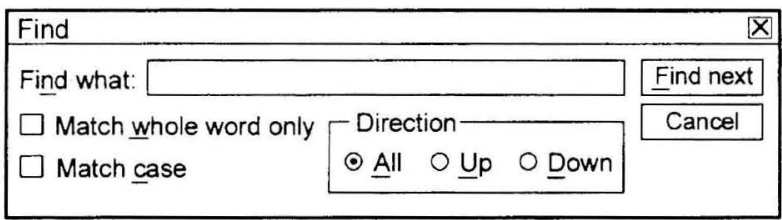

Fig 1.3.8 Find box

When a menu item is followed by three dots, it implies that the item activates a 'dialogue box'. For instance, the clicking of 'Find' on the edit menu will result in the appearance of the 'find box'. This dialogue box is shown in Fig 1.3.8. To initiate the 'find process', it is necessary to specify the text to be found. There is a rectangular 'field' in the find box into which the required text should be entered. The selection of an option in a dialogue box is achieved by

- clicking the corresponding item using the mouse or

- touching the 'underlined letter' of the corresponding item on the keyboard or

- using the tab/cursor keys on the keyboard to 'liven up' the corresponding item and then touching the 'return key' on the keyboard.

The editing tool buttons are shown in Fig 1.3.9. Also shown in this figure is a 'drop-down box' that can be used to control the 'font size' of the text in the editory.

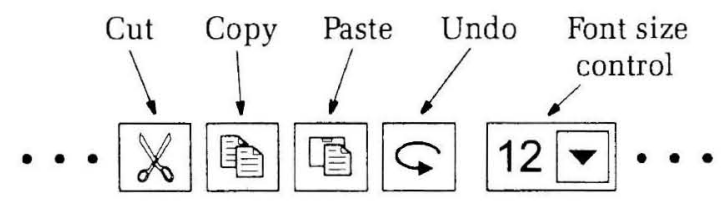

Fig 1.3.9 Editing tool buttons

\subsection{BACK TO FORMEX ALGEBRA}

Returning to the formulation of the grid of Fig 1.2.1, one can produce a description of the compret of the configuration of the grid by writing a 'longhand' formex. That is, a formex whose whole body is written out explicitly in detail. Such a formex will have 240 cantles each of which will represent an element of the grid. The formex may be of the form

$$
\begin{array}{r}
\quad\{[0,1 ; 1,0],[1,0 ; 2,1],[2,1 ; 3,0],[3,0 ; 4,1], \ldots \\
\ldots \quad[17,12 ; 18,11],[18,11 ; 19,12],[19,12,20,11]\}
\end{array}
$$

However, if one actually tries to write such a formex, one is bound to find it an extremely tedious task.

A much more convenient way of approaching the formulation is to make use of 'formex functions' that allow the generation of compretic information taking advantage of the 'regularities' of the configuration.

\subsubsection{Formex Functions}

The idea of formex functions is introduced through the simple configurations shown in Fig 1.4.1. In this figure, the combination of the elements ij and jk of the grid of Fig 1.2.1 is denoted by $F^{\prime}$. The prime (that is, the symbol '), signifies that the configuration ijk in Fig 1.4.1 is a 'plot' of the formex variable F, where

$$
\mathrm{F}=\{[1,0 ; 0,1],[0,1 ; 1,2]\}
$$

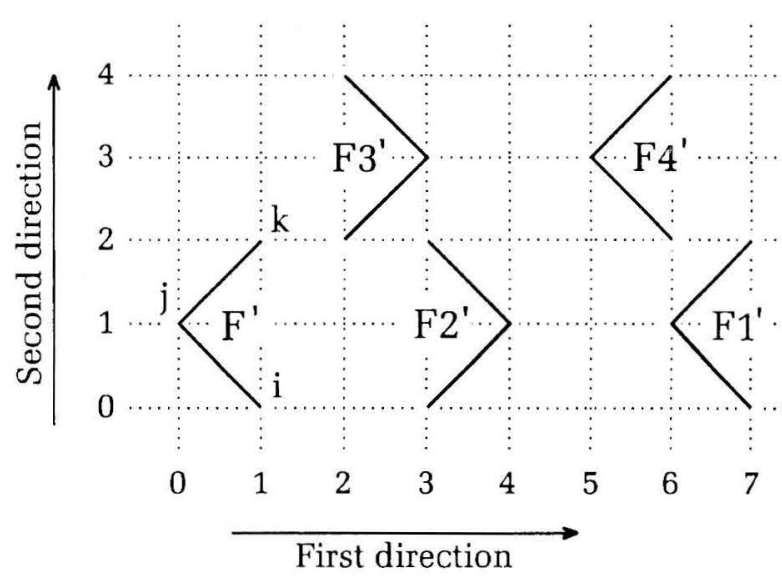

Fig 1.4.1 Some formex plots

Now, suppose that one wants to create a formex variable whose plot is the configuration denoted by $\mathrm{F} 1$ ' in Fig 1.4.1. This may be written as

$$
\mathrm{F} 1=\{[7,0 ; 6,1],[6,1 ; 7,2]\}
$$

Alternatively, the formex variable F1 may be given by the equation

$$
\mathrm{F} 1=\operatorname{tran}(1,6) \mid \mathrm{F}
$$

The construct

$$
\operatorname{tran}(1,6)
$$

is a 'formex function' that implies 'translation' in the first direction by 6 units, Fig 1.4.2. The formex variable $\mathrm{F}$ in equation

$$
\mathrm{F} 1=\operatorname{tran}(1,6) \mid \mathrm{F}
$$


is the 'argument' of the function and the symbol ' $l$ ' is used to separate the function from its argument. This symbol is referred to as the 'rallus symbol' and is read as 'of'. The rallus symbol is sometimes represented as two short vertical lines with a gap in between, that is, as ' 1 '. The form of the rallus symbol with a single vertical line is used in this paper, but the other form is also acceptable.

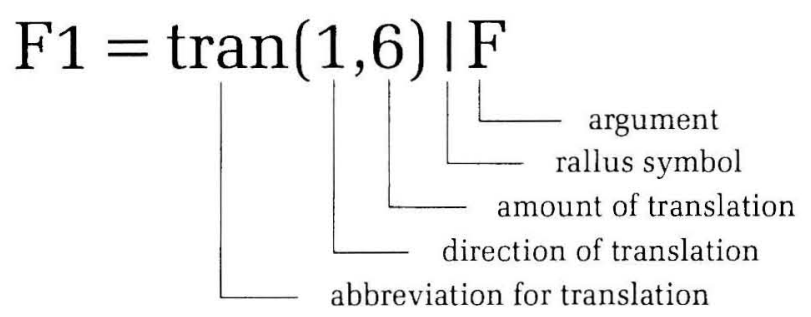

Fig 1.4.2 Translation function

The equation

$$
\mathrm{F} 1=\operatorname{tran}(1,6) \mid \mathrm{F}
$$

may be read as: F1 is (equal to) translation, in the first direction, by 6 divisions, of $F$.

A formex function represents a 'rule' for transformation of a given formex into another formex. For instance, in the above example the value of the argument $\mathrm{F}$, that is,

$$
\{[1,0 ; 0,1],[0,1 ; 1,2]\}
$$

is transformed into

$$
\{[7,0 ; 6,1],[6,1 ; 7,2]\}
$$

The rule for the transformation is to add the "amount of translation' to all the uniples that correspond to the 'direction of translation'. For the example under consideration, the first uniple of every signet is increased by 6 .

Another formex function is introduced here in terms of the configuration labelled F2' in Fig 1.4.1. This configuration may be regarded as the plot of

$$
\mathrm{F} 2=\operatorname{ref}(1,2) \mid \mathrm{F}
$$

The construct

$$
\operatorname{ref}(1,2)
$$

is a 'reflection function' implying reflection in the first direction with the plane of reflection being at normat line 2, Fig 1.4.3.

The equation

$$
\mathrm{F} 2=\operatorname{ref}(1,2) \mid \mathrm{F}
$$

may be read as: F2 is (equal to) reflection, in the first direction, with reflection plane at 2 , of $\mathrm{F}$.

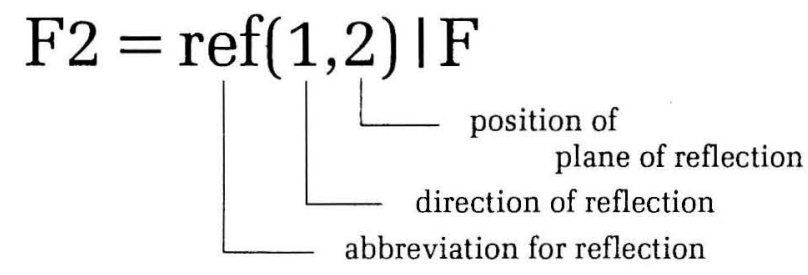

Fig 1.4.3 Reflection function

Formex functions may be used in combination. For instance, a formex variable representing the configuration labelled F3' in Fig 1.4.1 may be given by

$$
\mathrm{F} 3=\operatorname{tran}(2,2)|\operatorname{ref}(1,1.5)| \mathrm{F}
$$

It should be pointed out that the compret of a configuration can normally be formulated in many different ways. For instance, a formex variable representing the configuration F4' in Fig 1.4.1 may be given by

$$
\begin{aligned}
& F 4 & =\operatorname{ref}(1,4) \mid F 3 \\
\text { or } & F 4 & =\operatorname{tran}(2,2)|\operatorname{tran}(1,5)| F \\
\text { or } \quad & F 4 & =\operatorname{ref}(1,4.5)|\operatorname{tran}(2,2)| F 2 \ldots \text { etc. }
\end{aligned}
$$

A point regarding the usage of the term 'compret' should be explained here. Namely, when a formex is said to represent a configuration, it is meant that the formex represents the compret of the configuration. However, explicit reference to compret is often omitted, leaving it to be implied implicitly.

\subsubsection{Functions that Allow Replication}

The elements $i j$ and $\mathrm{jk}$ that are represented by formex variable $F$ are shown again in Fig 1.4.4, together with a number of other elements.

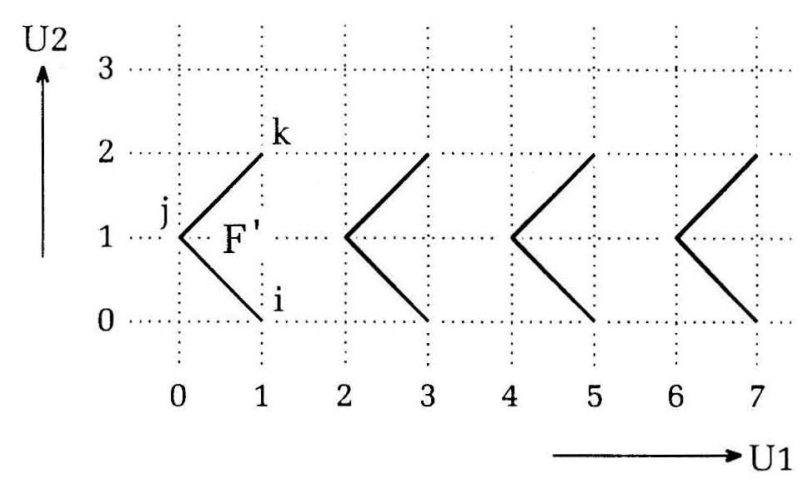

Fig 1.4.4 Translational replication

The combination of all the elements shown in Fig 1.4.4 may be represented by 


$$
\mathrm{H}=\operatorname{rin}(1,4,2) \mid \mathrm{F}
$$

The construct

$$
\operatorname{rin}(1,4,2)
$$

is a 'rindle function' implying 'translational replication' in the first direction with the number of replications being 4 and the amount of translation at each step being 2, Fig 1.4.5.

$$
\mathrm{H}=\operatorname{rin}(1,4,2) \mid \mathrm{F}
$$

Fig 1.4.5 Rindle function

Note that the number of replications is given as 4 rather than 3. That is, the number of replications includes the initial configuration which is represented by the argument. The term 'rindle' is an old English word meaning 'water course' and is adopted in formex algebra to imply translational replication.

The equation

$$
\mathrm{H}=\operatorname{rin}(1,4,2) \mid \mathrm{F}
$$

may be read as: $\mathrm{H}$ is (equal to) rindle, in the first direction, with 4 replications, in steps of 2 , of $F$.

Incidentally, a new convention that is employed in Fig 1.4.4 is that the first and second directions of the normat are indicated by $U 1$ and $U 2$, respectively, where U1 implies 'first direction uniples' and U2 implies 'second direction uniples'. This convention will be used henceforth.

Another kind of replicational effect is obtained through the lambda function. To illustrate the effect, consider the configuration in Fig 1.4.6 consisting of four elements. This configuration may be represented by

$$
\mathrm{R}=\operatorname{lam}(1,1) \mid \mathrm{F}
$$

The construct

$$
\operatorname{lam}(1,1)
$$

is a 'lambda function' implying 'reflectional replication', Fig 1.4.7.

The effect is as though $R$ is given by

$$
\mathrm{R}=\mathrm{F} \# \operatorname{ref}(1,1) \mid \mathrm{F}
$$

That is, the effect of a lambda function is to create a formex that combines the value of the argument with that of a reflection of the argument. The reason for the adoption of the name 'lambda' is the shape of the upper-case Greek letter lambda. This letter is like an upside down $\mathrm{V}$ and may be regarded as consisting of a sloping line combined with its own reflection.

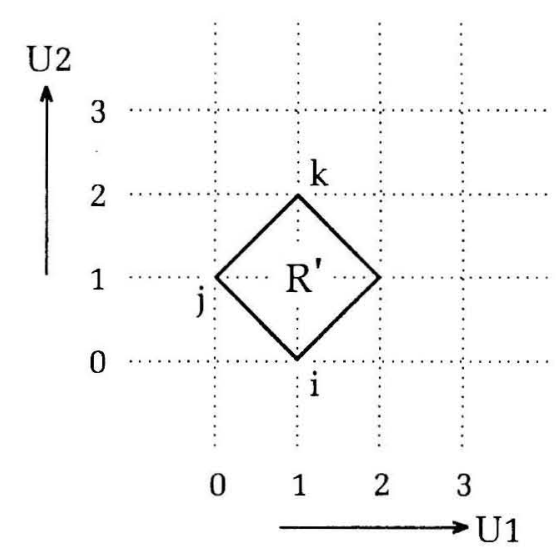

Fig 1.4.6 Reflectional replication

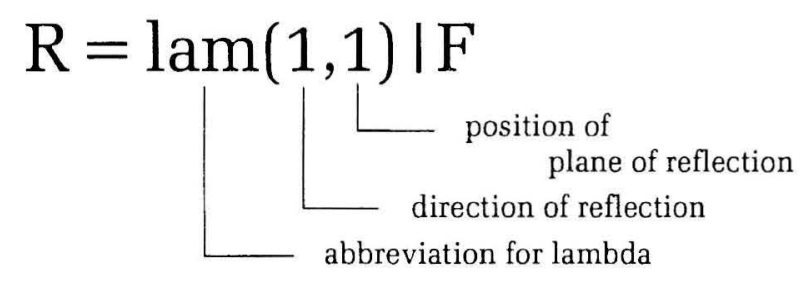

Fig 1.4.7 Lambda function

The equation

$$
\mathrm{R}=\operatorname{lam}(1,1) \mid \mathrm{F}
$$

may be read as: $\mathrm{R}$ is (equal to) lambda, in the first direction, with reflection plane at 1 , of $\mathrm{F}$.

Now, a formex variable describing the compret of the grid of Fig 1.2.1 may be given by

$$
\mathrm{G}=\operatorname{rin}(2,6,2)|\operatorname{rin}(1,10,2)| \operatorname{lam}(1,1) \mid F
$$

Here, $F$ represents the combination of elements ij and jk in Fig 1.2.1,

$$
\operatorname{lam}(1,1) \mid F
$$

represents the combination of the four elements that forms the leftmost bottom rhombus in the configuration of the grid of Fig 1.2.1,

$$
\operatorname{rin}(1,10,2)|\operatorname{lam}(1,1)| F
$$

represents all the elements forming the bottom row of rhombuses and

$$
\operatorname{rin}(2,6,2)|\operatorname{rin}(1,10,2)| \operatorname{lam}(1,1) \mid \mathrm{F}
$$

represents all the elements of the grid, as shown in Fig 1.4.8. 
The translation, rindle, reflection and lambda functions belong to a family of formex functions that are referred to as 'cardinal functions'.

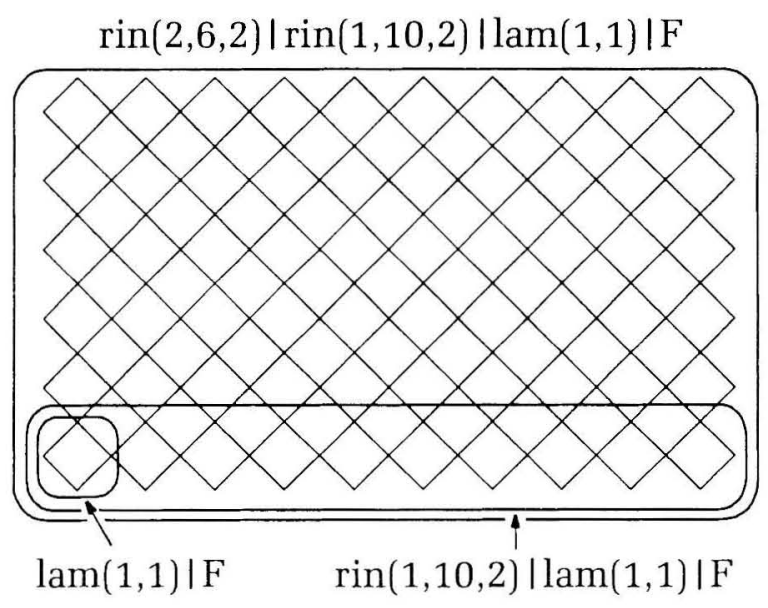

Fig 1.4.8 Stages of formulation

\subsubsection{Functions that Allow Multiple Action}

The above formulation of the compret of the grid of Fig 1.2.1 may alternatively be written as

$$
\begin{aligned}
\mathrm{G}= & \operatorname{rin}(2,6,2)|\operatorname{rin}(1,10,2)| \operatorname{lam}(2,1) \mid \\
& \operatorname{lam}(1,1) \mid[1,0 ; 0,1]
\end{aligned}
$$

This equation can also be given in the following more convenient form

$$
\mathrm{G}=\operatorname{rinid}(10,6,2,2)|\operatorname{lamid}(1,1)|[1,0 ; 0,1]
$$

The construct

$$
\operatorname{rinid}(10,6,2,2)
$$

is referred to as a 'rinid function' and is equivalent to the 'composite function'

$$
\operatorname{rin}(2,6,2) \mid \operatorname{rin}(1,10,2)
$$

Also, the construct

$$
\operatorname{lamid}(1,1)
$$

which is referred to as a 'lamid function' is equivalent to the composite function

$$
\operatorname{lam}(2,1) \mid \operatorname{lam}(1,1)
$$

The rinid function implies a 'rindle effect' (that is, translational replication) in the first direction followed by another rindle effect in the second direction, Fig 1.4.9.

The lamid function implies a 'lambda effect' (that is, reflectional replication) in the first direction followed by another lambda effect in the second direction, Fig
1.4.10. The suffix 'id' in 'rinid' and 'lamid' implies a double action involving directions one and two.

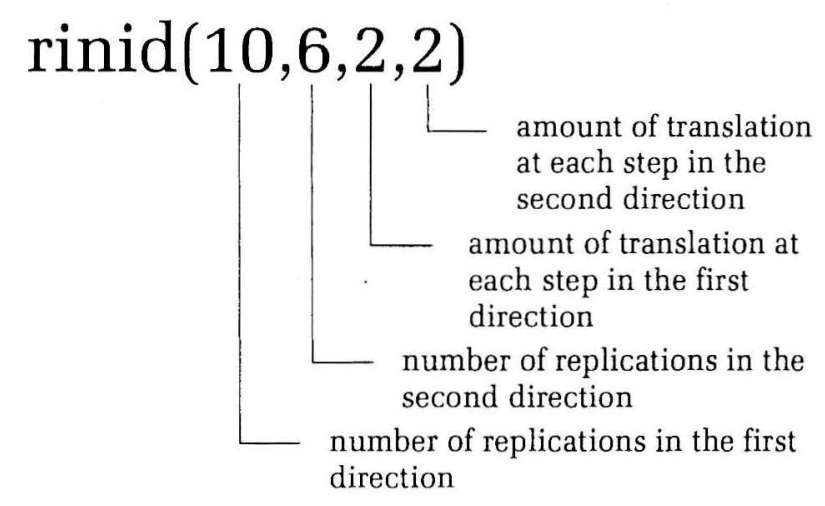

Fig 1.4.9 Rinid function

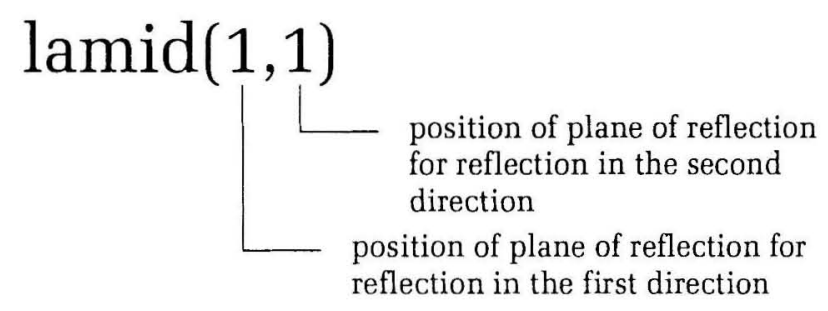

Fig 1.4.10 Lamid function

The suffix 'id' may also be used with the translation and reflection functions. Thus, the composite translation function

$$
\operatorname{tran}(2,7) \mid \operatorname{tran}(1,5)
$$

may be written as

tranid $(5,7)$

Similarly, the composite reflection function

$$
\operatorname{ref}(2,5) \mid \operatorname{ref}(1,3)
$$

may be written as

$$
\operatorname{refid}(3,5)
$$

Tranid, refid, rinid and lamid functions belong to a family of formex functions that are referred to as 'tendial functions'.

\subsubsection{Normic Properties and Retronormic Functions}

The complete specification of the compret of the grid of Fig 1.2.1 is given by

$$
\mathrm{G}=\operatorname{rinid}(10,6,2,2)|\operatorname{lamid}(1,1)|[1,0 ; 0,1]
$$

However, the information represented by $G$ is in terms of 'normat coordinates'. That is, the positions 
of the nodal points are specified relative to the simple U1-U2 normat shown in Fig 1.4.11.

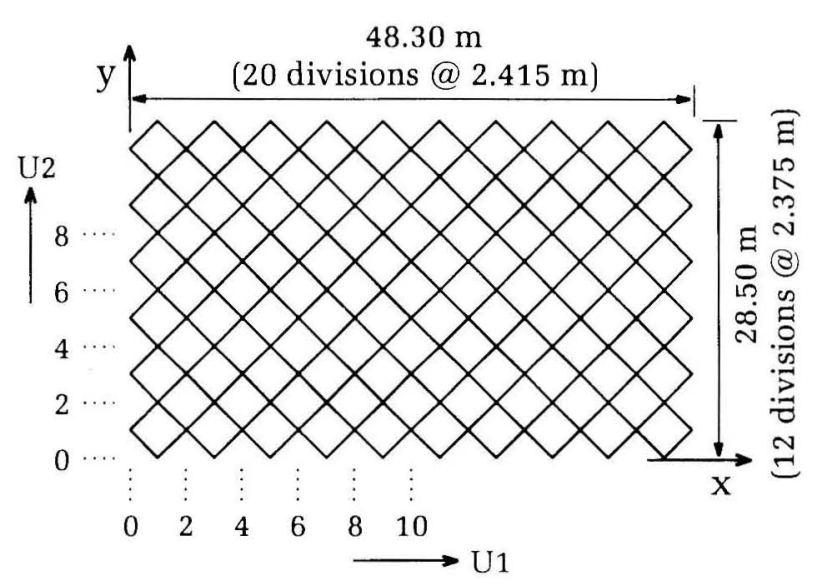

Fig 1.4.11 Grid with U1-U2 normat and $x-y$ Cartesian coordinate system

A formex that contains the description of the compret of the grid in terms of the $x-y$ coordinate system may be represented by

$$
\mathrm{G} 1=\mathrm{bb}(2.415,2.375) \mid \mathrm{G}
$$

The construct

$$
\mathrm{bb}(2.415,2.375)
$$

is a function that changes the scales along the first and second directions. The scale factors are 2.415 and 2.375 in the first and second directions, respectively. These factors are obtained from the actual dimensions of the grid, as given in Figs 1.2.1 and 1.4.11.

G1 represents a formex that contains 240 cantles each of which represents an element of the grid of Fig 1.2.1. The uniples in this formex are the actual $x$ and $y$ Cartesian coordinates of the nodes of the grid.

The first seven cantles of formices $G$ and $G 1$ are shown below for comparison:

$$
\begin{gathered}
\mathrm{G}=\{[1,0 ; 0,1],[1,0 ; 2,1],[1,2 ; 0,1],[1,2 ; 2,1], \\
[3,0 ; 2,1],[3,0 ; 4,1],[3,2 ; 2,1], \ldots\} \\
\mathrm{G} 1=\{[2.415,0 ; 0,2.375],[2.415,0 ; 4.83,2.375], \\
{[2.415,4.75 ; 0,2.375],[2.415,4.75 ; 4.83,2.375],} \\
{[7.245,0 ; 4.83,2.375],[7.245,0 ; 9.66,2.375],} \\
[7.245,4.75 ; 4.83,2.375], \ldots .\}
\end{gathered}
$$

Of course, normally, one is not concerned with the details of the numerical values inside a formex. One would work with formices as 'bundles of information' and let the system deal with the details of numerical computation.

The formex variable $G$ may be transformed in various ways to obtain different geometric effects. For example, consider the equations: and $\begin{aligned} \mathrm{GA} & =\mathrm{bb}(1.5,0.8) \mid \mathrm{G} \\ \mathrm{GB} & =\mathrm{bp}(0.75,15) \mid \mathrm{G}\end{aligned}$

Plots of GA and GB are shown in Figs 1.4 .12 and 1.4 .13 , respectively. The configurations shown in Figs 1.4.11 (1.2.1), 1.4.12 and 1.4.13 have identical compretic properties but they have different 'normic properties'.

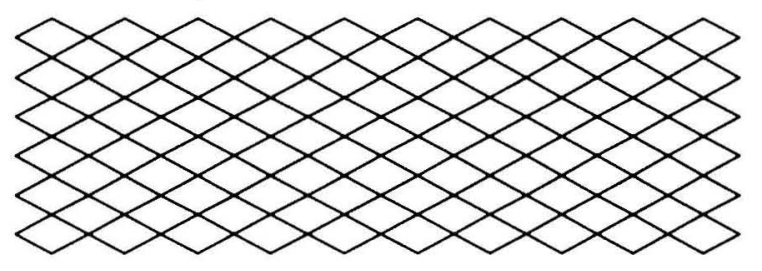

Fig 1.4.12 Plot of GA

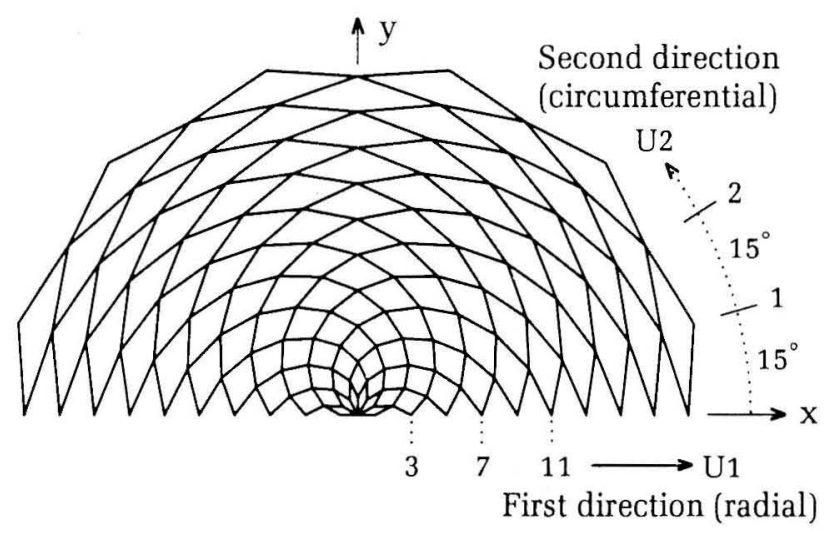

Fig 1.4.13 Plot of GB

Normic properties are those particulars of a configuration that relate to the actual dimensions of the configuration. The normic properties of a configuration are normally specified in terms of the coordinates of the nodal points of the configuration.

One way of distinguishing between the compretic and normic properties of a configuration is to imagine that the elements of the configuration are made from a freely deformable substance like rubber. The configuration may then be distorted in any conceivable manner without affecting its compret, as long as no element is added or removed and as long as the connections between the elements remain unchanged. In contrast, any distortion of the configuration will alter its normic properties.

Functions such as

$$
\text { and } \mathrm{bp}(0.75,15)
$$


are referred to as 'retronormic functions' or simply 'retronorms'. The term 'retronorm' is used to refer to any function that transforms the normat coordinates of a configuration into global Cartesian coordinates.

The function

$$
\mathrm{bb}(1.5,0.8)
$$

is a 'basibifect retronorm' effecting scaling in the first and second directions by factors 1.5 and 0.8 , respectively. A basibifect retronorm may be used for the transformation of normat coordinates into the global $x-y$ coordinates provided that the directions of the normat are the same as those of the global $x-y$ axes. For the example under consideration, this condition is satisfied.

The function

$$
\mathrm{bp}(0.75,15)
$$

is a 'basipolar retronorm' that considers the uniples of its argument as 'polar coordinates' and applies a (linear) scaling of 0.75 in the first (radial) direction and an angular scaling of $15^{\circ}$ per division in the second (circumferential) direction. The resulting polar coordinates are then transformed into global Cartesian coordinates. The positions of the U1-U2 polar normat and the global $\mathrm{x}-\mathrm{y}$ coordinate system are shown in Fig 1.4.13.

A normat may be regarded as a 'graphical retronorm'. For example, the U1-U2 normat of Fig 1.4.11 may be considered to be the graphical equivalent of the basibifect retronorm

$$
\mathrm{bb}(2.415,2.375)
$$

and the U1-U2 normat of Fig 1.4 .13 may be considered to be the graphical equivalent of the basipolar retronorm

$$
\operatorname{bp}(0.75,15)
$$

The prefix 'basi' in the word 'basibifect' implies 'uniform scaling' and the part 'bifect' refers to the first and second directions. Thus, the term 'basibifect' implies uniform scaling in the first and second directions. The term 'basipolar' implies uniform scaling in the first and second directions of a polar normat followed by the transformation of the resulting polar coordinates into Cartesian coordinates.

The use of a normat in conjunction with a global Cartesian coordinate system is convenient in practice. The idea is that while describing the compretic aspects of a configuration, one works in terms of a normat, focusing the attention on the interconnection pattern without having to worry about the actual coordinates of the points.
Subsequently, the generated configuration may be subjected to suitable retronormic transformations to obtain the actual shape. However, it should be mentioned that there are cases when the global Cartesian coordinate system itself is a suitable normat.

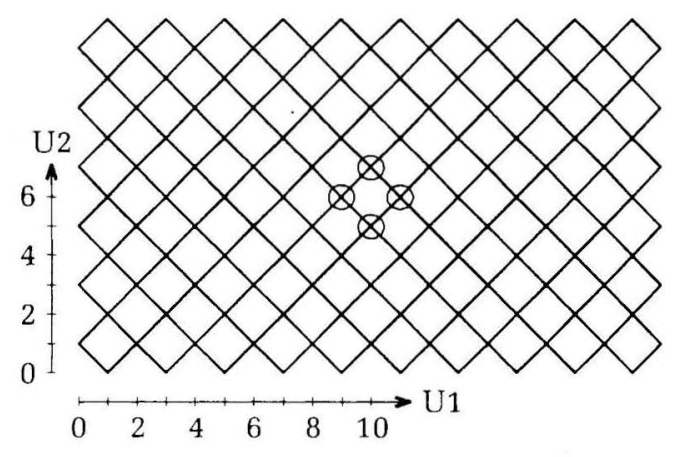

Fig 1.4.14 Plot of $\mathrm{G}$

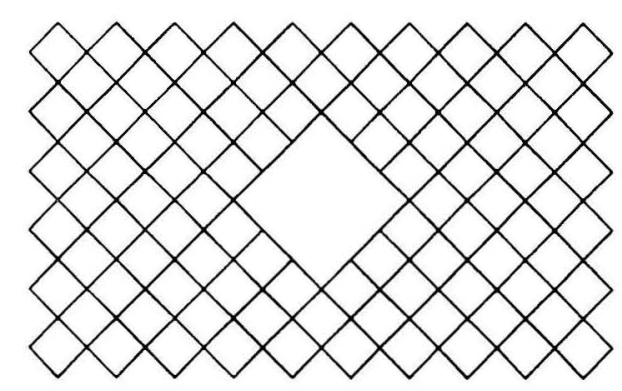

Fig 1.4.15 Plot of G1

\subsubsection{Functions that Allow Curtailment}

A plot of formex variable

$$
\mathrm{G}=\operatorname{rinid}(10,6,2,2)|\operatorname{lamid}(1,1)|[1,0 ; 0,1]
$$

is given in Fig 1.4.14. Another diagonal grid is shown in Fig 1.4.15. This configuration is seen to be the same as that in Fig 1.4.14 except for some missing elements at the middle. A convenient way of approaching the formulation of this new configuration is to take the formulation for the grid of Fig 1.4 .14 as the starting point. The formulation may then be modified to take account of the missing elements.

A formex function that can be used for this purpose is the 'luxum function'. The luxum function works by deleting all the cantles of a formex that relate to a set of specified points. The specification of the points is provided through a formex and such a formex for the case under consideration may be written as 


$$
\mathrm{Nl}=\{[9,6],[10,5],[10,7],[11,6]\}
$$

The points represented by $\mathrm{N} 1$ are indicated by little circles in Fig 1.4.14. It is seen that the removal of the elements connected to the encircled points in Fig 1.4.14 will result in the configuration of Fig 1.4.15.

A formex variable representing the configuration of Fig 1.4.15 may then be written as

$$
\mathrm{G} 1=\operatorname{lux}(\mathrm{N} 1) \mid \mathrm{G}
$$

The effect of the function is that the cantles of $G$ are examined one after the other and any one of them that has a signet identical to one of the signets of N1 is deleted. The term 'lux' stands for 'luxum' which is a Latin based word implying 'disconnected parts'.

The equation

$$
\mathrm{G} 1=\operatorname{lux}(\mathrm{N} 1) \mid \mathrm{G}
$$

may be read as: G1 is (equal to) luxum, with respect to $\mathrm{N} 1$, of $\mathrm{G}$.

The formex

$$
\mathrm{N} 1=\{[9,6],[10,5],[10,7],[11,6]\}
$$

is an example of a commonly used type of formex in which every cantle is simply a signet. A formex of this kind is referred to as an 'ingot'.

A formex variable G2 representing the configuration of Fig 1.4.16 may be obtained as follows:

$$
\begin{aligned}
\mathrm{N} 2 & =\operatorname{lamid}(10,6) \mid\{[0,1],[1,0]\} \\
\mathrm{G} 2 & =\operatorname{lux}(\mathrm{N} 2) \mid \mathrm{G} \# \\
& \operatorname{rinid}(7,2,2,12) \mid[3,0 ; 5,0] \# \\
& \operatorname{rinid}(2,3,20,2) \mid[0,3 ; 0,5]
\end{aligned}
$$

Here,

- N2 represents the eight corner nodes of the grid of Fig 1.4.14,

- $\operatorname{lux}(\mathrm{N} 2) \mid \mathrm{G}$

represents the grid with twelve comer elements removed,

- $\operatorname{rinid}(7,2,2,12) \mid[3,0 ; 5,0]$

represents the horizontal edge elements and

- $\operatorname{rinid}(2,3,20,2) \mid[0,3 ; 0,5]$

represents the vertical edge elements.

Note that the above formex formulation involves 'addition' as well as 'deletion' of elements. This is quite common in configuration processing, when one keeps on 'processing' a configuration by adding and removing parts to turn it into a desired form.

As another example of the application of the luxum function, consider the configuration shown in Fig 1.4.17. A formex variable G3 representing this configuration may be obtained as follows:

$$
\begin{aligned}
& \mathrm{N} 3=\{[5,8],[15,4]\} \\
& \mathrm{G} 3=\operatorname{lux}(\mathrm{N} 3) \mid \mathrm{G} 2
\end{aligned}
$$

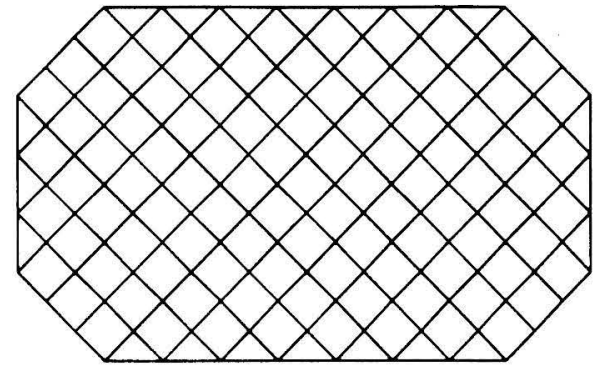

Fig 1.4.16 Plot of G2

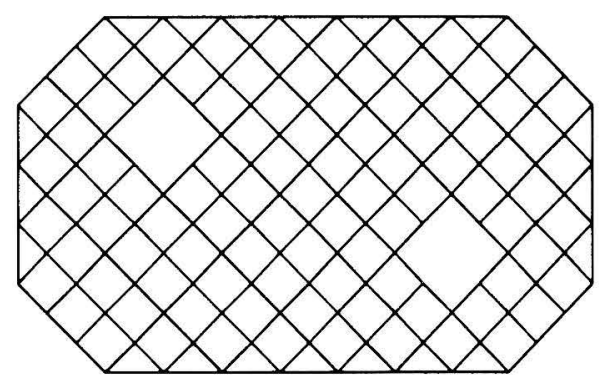

Fig 1.4.17 Plot of G3

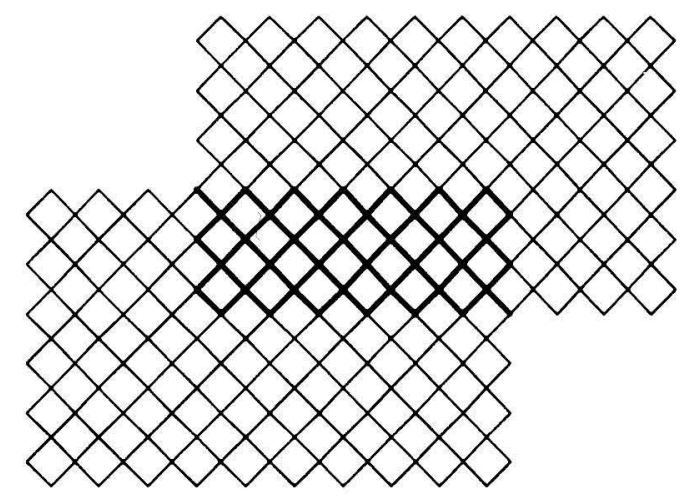

Fig 1.4.18 Plot of G4

Now, consider the configuration shown in Fig 1.4.18. This configuration may be obtained by superimposing the configuration of Fig 1.4 .14 with a displaced version of itself. A formex variable representing the configuration of Fig 1.4.18 may be written as

$$
\mathrm{G} 4=\mathrm{G} \# \operatorname{tranid}(7,7) \mid \mathrm{G}
$$

Here, a problem is encountered. Namely, some of the elements in Fig 1.4.18 correspond to two cantles of $\mathrm{G} 4$, that is, they are doubly represented. This happens in the region where the grid represented by $\mathrm{G}$ overlaps the grid represented by

$$
\operatorname{tranid}(7,7) \mid \mathrm{G}
$$


The doubly represented elements in the overlapping region are indicated by thick lines in Fig 1.4.18.

There is a formex function that can be employed to 'prune' the superfluous 'doubles' of the elements. This is the 'pexum' function that has the effect of removing every cantle of a formex which has the same signets as another cantle of the formex. Pexum is a Latin word and is adopted in formex algebra to imply 'combed out'.

Using the pexum function, a formex variable that represents the configuration of Fig 1.4.18 and has no superfluous cantles may be obtained by writing

$$
\mathrm{G} 5=\operatorname{pex} \mid \mathrm{G} 4
$$

where 'pex' stands for 'pexum'. The pexum function works by examining the cantles of a formex, one after the other, and deleting any cantle which is found to have the same signets as a previous cantle of the formex.

The equation

$$
\mathrm{G} 5=\operatorname{pex} \mid \mathrm{G} 4
$$

may be read as: G5 is (equal to) pexum of G4.

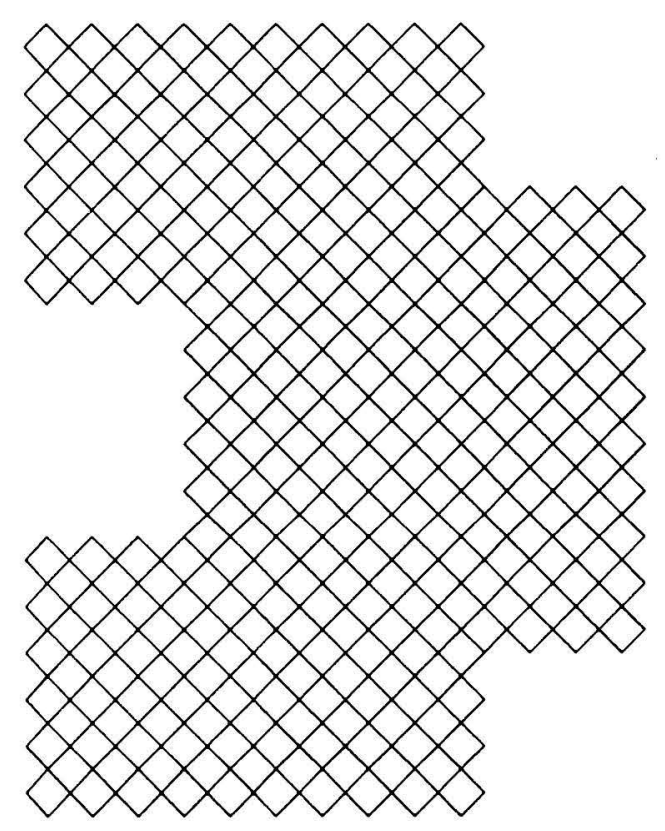

Fig 1.4.19 Plot of G6

As another example, consider the grid of Fig 1.4.19. This grid may be represented by

$$
\mathrm{G} 6=\operatorname{pex}|\operatorname{lam}(2,17)| \mathrm{G} 5
$$

The effect of the pexum function in this formulation is to eliminate the unwanted superfluous elements along a horizontal strip at the centre of the configuration of Fig 1.4.19. The above formulation is relative to the normat of Fig 1.4.14.

A question may arise regarding the reason for worrying about the doubly represented elements. Why not leaving them where they are? After all, if one looks at the plot, one will not even notice that they are there. The answer to the question is that if the creation of a 'graphical effect' is the sole purpose of the exercise, then it is not essential to discard the superfluous elements. However, formex formulations are often used for such processes as structural analysis and design. Therefore, it is important that the formex formulation of a configuration provides an accurate description of the compret of the configuration.

In general, the pexum function is frequently used in creation of complex forms by superimposing a number of simpler forms and then 'pruning' the superfluous overlapping parts.

The luxum and pexum functions belong to a family of formex functions that are referred to as 'introflection functions'.

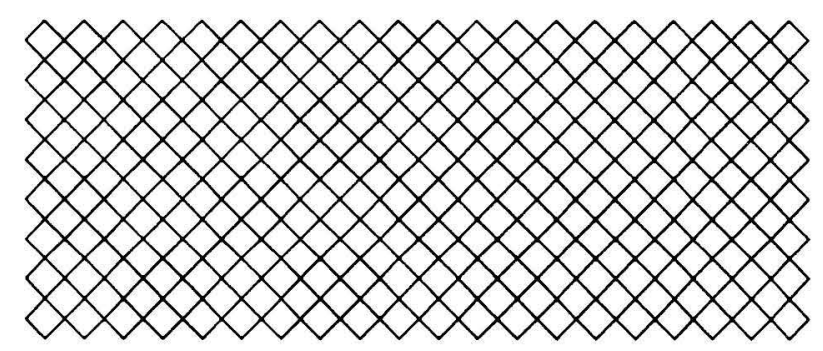

Fig 1.4.20: $m=20, n=8$

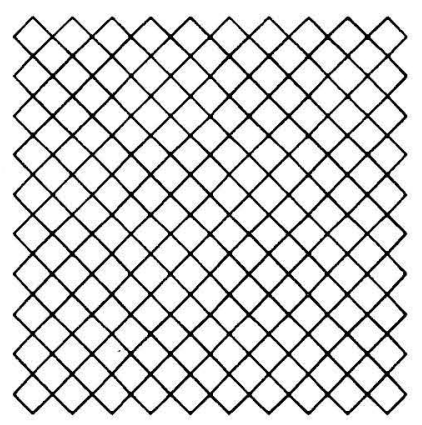

Fig 1.4.21: $m=10, n=10$

Fig 1.4.22: $\mathrm{m}=6, \mathrm{n}=18$

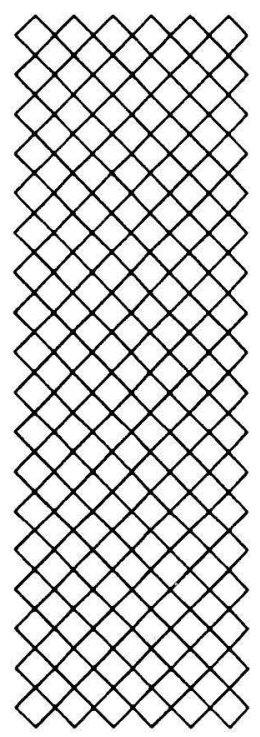




\subsubsection{Generic Formulations}

Consider the construct

$$
\operatorname{rinid}(m, n, 2,2)|\operatorname{lamid}(1,1)|[1,0 ; 0,1]
$$

This is a formulation for a configuration which has a pattern similar to that of the grid of Fig 1.2.1 and consists of an array of $m$ by $n$ rhombic units. For example,

- if $m=20$ and $n=8$ then the formulation represents the grid of Fig 1.4.20,

- if $m=n=10$ then the formulation represents the grid of Fig 1.4 .21 and

- if $\mathrm{m}=6$ and $\mathrm{n}=18$ then the formulation represents the grid of Fig 1.4.22.

A formex formulation of this type that involves 'parameters' is referred to as a 'generic formulation'.

As another example involving generic formulation, consider the configuration shown in Fig 1.4.23. This is the plan view of a three-way grid with a trapezoidal boundary shape. The grid consists of 150 beam elements of length $d$ with the triangles formed by the elements being equilateral.

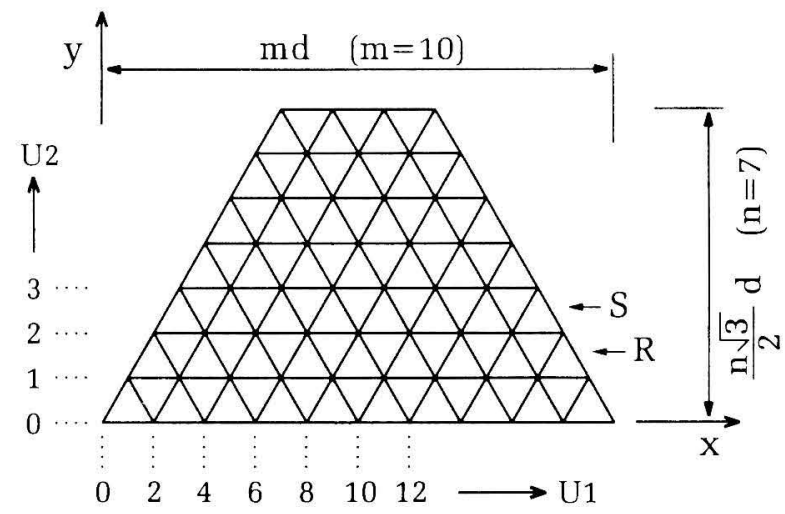

Fig 1.4.23 A three-way grid

A generic formulation for the grid of Fig 1.4.23 may be written as:

$$
\begin{aligned}
& \mathrm{E}=\{[0,0 ; 2,0],[0,0 ; 1,1],[2,0 ; 1,1]\} \\
& \mathrm{F}=\operatorname{genid}(\mathrm{m}, \mathrm{n}, 2,1,1,-1) \mid \mathrm{E} \\
& \mathrm{G}=\operatorname{rin}(1, \mathrm{~m}-\mathrm{n}, 2) \mid[\mathrm{n}, \mathrm{n} ; \mathrm{n}+2, \mathrm{n}] \\
& \mathrm{H}=\operatorname{bb}(\mathrm{d} / 2, \sqrt{3} \mathrm{~d} / 2) \mid(\mathrm{F} \# \mathrm{G})
\end{aligned}
$$

In this formulation

- E represents the group of three elements that form the leftmost bottom triangle,

- F represents all the elements of the grid other than the topmost horizontal elements, with $\mathrm{m}$ being the number of horizontal elements at the base in the first direction and $n$ being the number of rows of triangles in the second direction,
- $\mathrm{G}$ represents the topmost horizontal elements and

- $\quad$ represents all the elements of the grid.

The formex variables $\mathrm{E}, \mathrm{F}$ and $\mathrm{G}$ are relative to the $\mathrm{U} 1-\mathrm{U} 2$ normat and $\mathrm{H}$ is relative to the $\mathrm{x}-\mathrm{y}$ Cartesian coordinate system in Fig 1.4.23. The terms $d / 2$ and $\sqrt{3} d / 2$ in the basibifect retronorm

$$
b b(d / 2, \sqrt{3} d / 2)
$$

are the factors for scaling in the first and second directions.

The above generic formulation makes use of the concept of a 'genid function'. This is a mechanism for creation of non-rectangular arrays of objects. The particulars of the genid function are described in Fig 1.4.24.

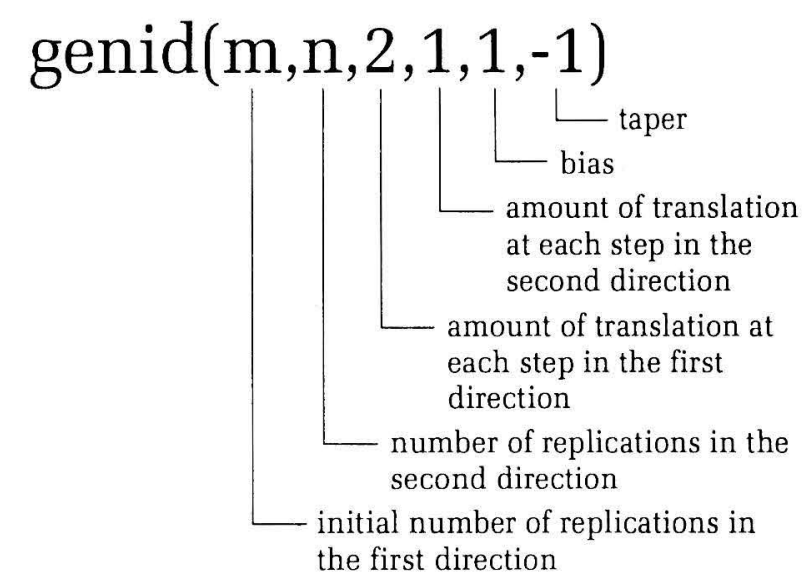

Fig 1.4.24 Genid function

The first four parameters of the genid function are similar to those of the rinid function. The remaining two parameters may be described as follows:

- 'Bias' represents the amount of translation in the first direction for every step in the second direction. Thus, if bias is denoted by ' $b$ ' then the row of triangles indicated by $\mathrm{R}$ in Fig 1.4 .23 will undergo a translation by the amount $\mathrm{b}$ in the first direction, the row of triangles indicated by $\mathrm{S}$ will undergo a translation by the amount $2 \mathrm{~b}$ in the first direction and so on.

- 'Taper' represents the increment in the number of replications for every step in the second direction. Thus, if taper is denoted by ' $t$ ' then the number of triangles in the row indicated by $\mathrm{R}$ in Fig 1.4.23 will be $\mathrm{m}+\mathrm{t}$, the number of triangles in the row indicated by $\mathrm{S}$ will be $\mathrm{m}+2 \mathrm{t}$ and so on.

The values for parameters in the above generic formulation that give rise to the grid of Fig 1.4.23 are:

$$
\mathrm{m}=10, \mathrm{n}=7 \text { and } \mathrm{d}=1
$$


The above generic formulation may be used to create a variety of trapezoidal three-way grids by using different values for parameters $m, n$ and $d$. Three such examples are shown in Fig 1.4.25, with the corresponding values of the parameters shown alongside the configurations.
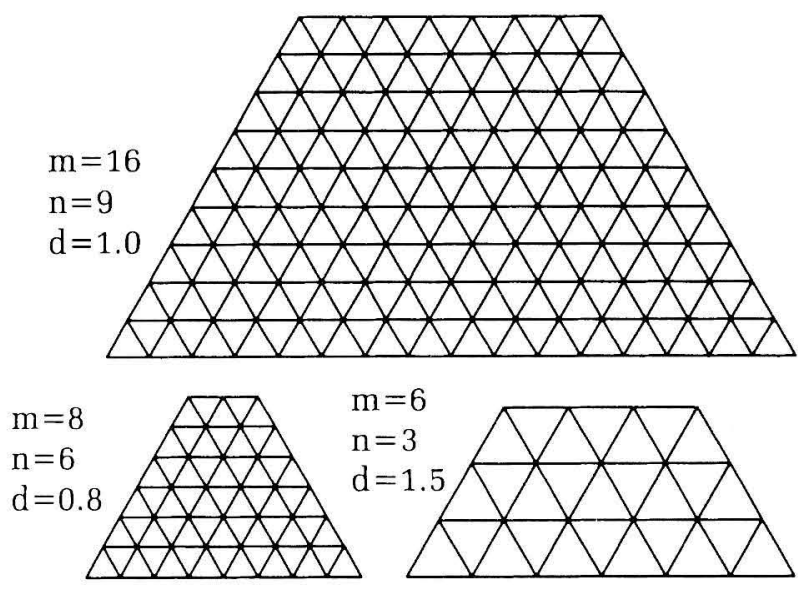

Fig 1.4.25 Three-way grids created through generic formulation

\subsubsection{Functions that Effect Rotation}

Consider the triangulated configuration in Fig 1.4.26. This is the grid of Fig 1.4.23 which is rotated by $90^{\circ}$ about the point that is encircled in Fig 1.4.26. Also shown in this figure, is the boundary of the original position of the grid together with a curved arrow that indicates the rotation.

The rotation has been effected using the equation

$$
\mathrm{H} 1=\operatorname{ver}(1,2,5,3 \sqrt{ } 3,90) ; \mathrm{H}
$$

The construct

$$
\operatorname{ver}(1,2,5,3 \sqrt{3}, 90)
$$

is a 'vertition function' and 'ver' is an abbreviation for vertition. The term 'vertition' is a Latin based word that means 'rotation'. The parameters of the above vertition function are described in Fig 1.4.27.

The first two parameters of the vertition function specify the directions that define the plane of rotation. The next two parameters specify the coordinates of the centre of rotation. In the present example, the Cartesian coordinates of the centre of rotation, from Fig 1.4.23, are

$$
x=5 d \text { and } y=3 \sqrt{ } 3 d
$$

With the value of $d$ taken as 1 , the coordinates of the centre of rotation will be

$$
x=5 \text { and } y=3 \sqrt{3}
$$

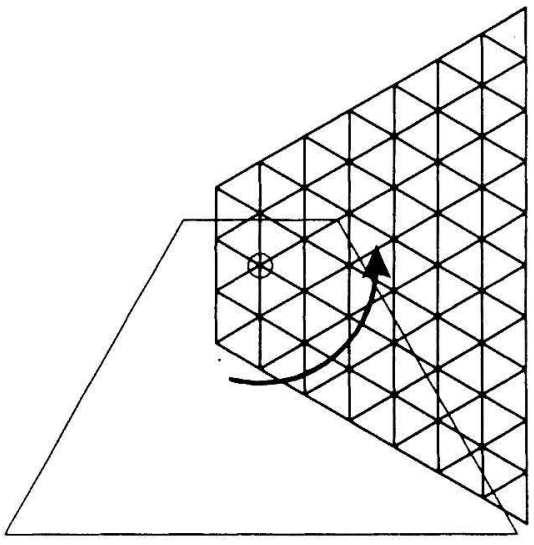

Fig 1.4.26 Effect of vertition function

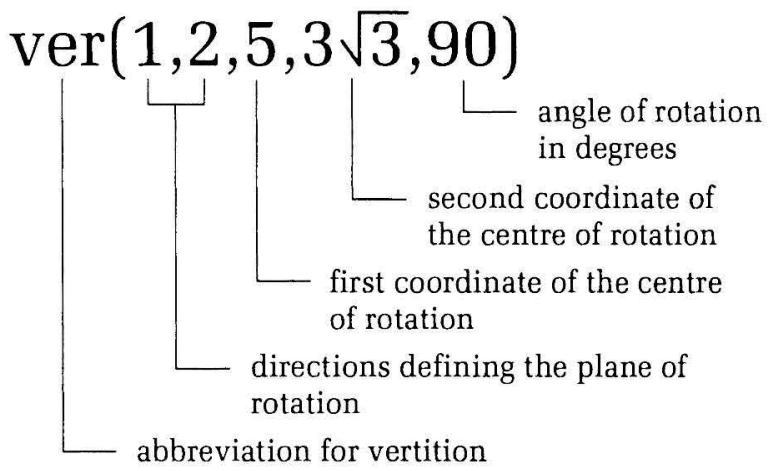

Fig 1.4.27 Vertition function

The last parameter of the vertition function specifies the angle of rotation. Actually, the presence of the last parameter of the vertition function is optional. That is, it may or may not be present. If this parameter is not given then the angle of rotation is assumed to be $90^{\circ}$.

The vertition function

$$
\operatorname{ver}(1,2,5,3 \sqrt{3}, 90)
$$

may be written in the more convenient form

$$
\operatorname{verad}(5,3 \sqrt{ } 3,90)
$$

The suffix 'ad' implies an action involving the first and second directions. In contrast, the suffix 'id' which was discussed before, implies an action in the first direction followed by a similar action in the second direction. The suffix 'id' implies a 'double' action whereas 'ad' implies a 'single' action.

Fig 1.4.28 illustrates a rotational replication effect. The configuration is obtained as a combination of the grid of Fig 1.4.23 with two rotations of itself. The angle of the first rotation is $120^{\circ}$ and that of the 
second rotation is $240^{\circ}$. The centre of rotation is shown encircled in Fig 1.4.28.

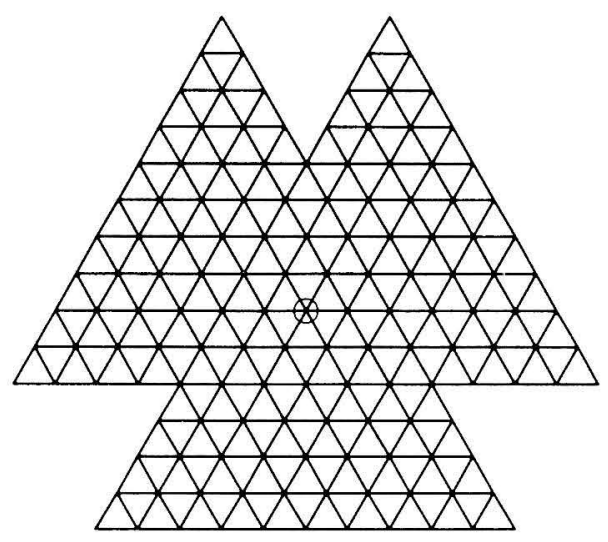

Fig 1.4.28 Rotational replication

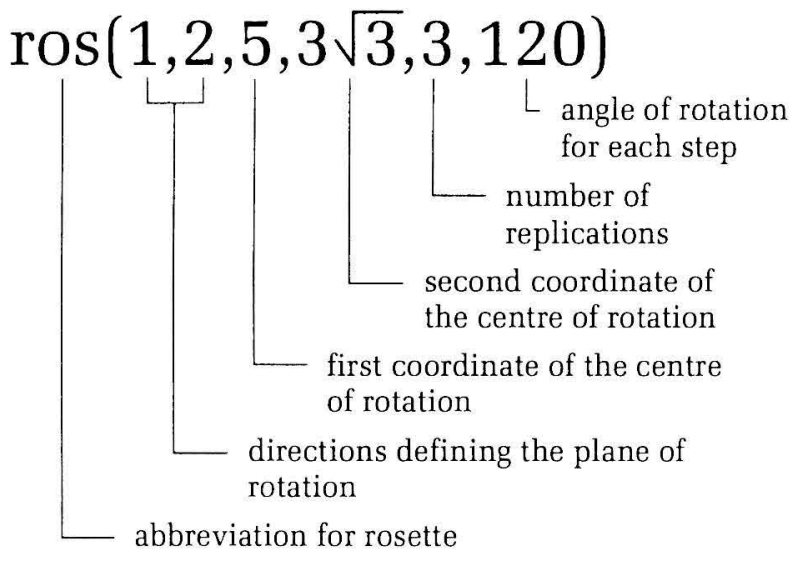

Fig 1.4.29 Rosette function

The formex that represents the configuration of Fig 1.4.28 may be written as

$$
\mathrm{H} 2=\operatorname{pex}|\operatorname{ros}(1,2,5,3 \sqrt{ } 3,3,120)| \mathrm{H}
$$

The construct

$$
\operatorname{ros}(1,2,5,3 \sqrt{3}, 3,120)
$$

is a 'rosette function' and 'ros' is an abbreviation for rosette. The rosette function provides a mechanism for rotational replication with its parameters described in Fig 1.4.29.

The first four parameters of the rosette function are similar to those of the vertition function. The remaining two parameters specify the required number of replications and the angle of rotation for each step of replication.

The last two parameters of the rosette function are optional with the 'default values' being 4 and $90^{\circ}$. That is, if the last two parameters are not given then it will be assumed that the number of replications is 4 and the angle of rotation is $90^{\circ}$.

The equation that defines the configuration of Fig 1.4.28, that is,

$$
\mathrm{H} 2=\operatorname{pex}|\operatorname{ros}(1,2,5,3 \sqrt{3}, 3,120)| \mathrm{H}
$$

involves a pexum function. This function was described earlier in relation to the examples of Figs 1.4.18 and 1.4.19. The role of the pexum function in the present case is to eliminate the superfluous elements in the central region of the configuration of Fig 1.4.28. To elaborate, the three grids that constitute the configuration of Fig 1.4.28 have a number of overlapping elements. Therefore, without the effect of the pexum function, the central part of the configuration will have a number of superfluous elements.

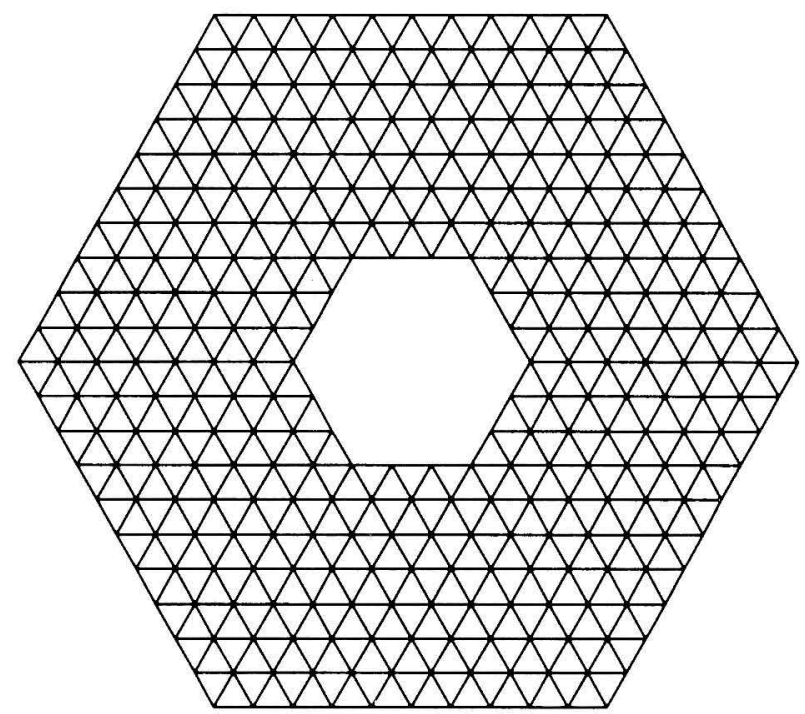

Fig 1.4.30 A rosette effect

Another rosette effect is illustrated in Fig 1.4.30. The three-way grid shown in this figure is obtained as a rotational replication of the grid of Fig 1.4.23. The configuration may be represented by

$$
\mathrm{H} 3=\operatorname{pex}|\operatorname{ros}(1,2,5,5 \sqrt{ } 3,6,60)| \mathrm{H}
$$

The effect of the pexum function in this example is to remove the superfluous elements along the edges of the 6 trapezoidal parts that constitute the grid of Fig 1.4.30.

Similar to the case of the vertition function, the rosette function

$$
\operatorname{ros}(1,2,5,5 \sqrt{ } 3,6,60)
$$

may be written in the more convenient form

$$
\operatorname{rosad}(5,5 \sqrt{3}, 6,60)
$$

where the suffix 'ad' implies an action involving the first and second directions, as described before. 


\subsection{MORE ABOUT FORMIAN}

Fig 1.5.1 shows the Formian screen with two schemes in the editory and a formex plot in the drawpad.

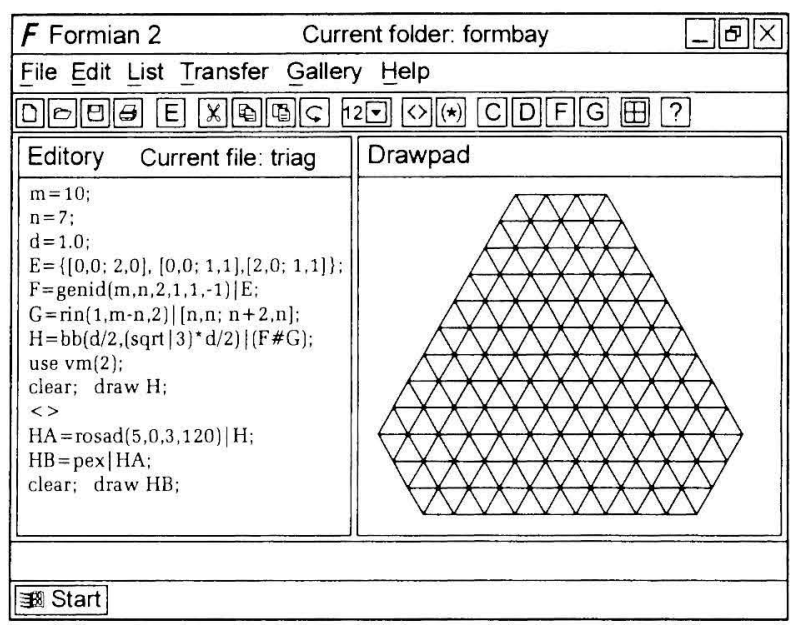

Fig 1.5.1 Processing of a three-way grid

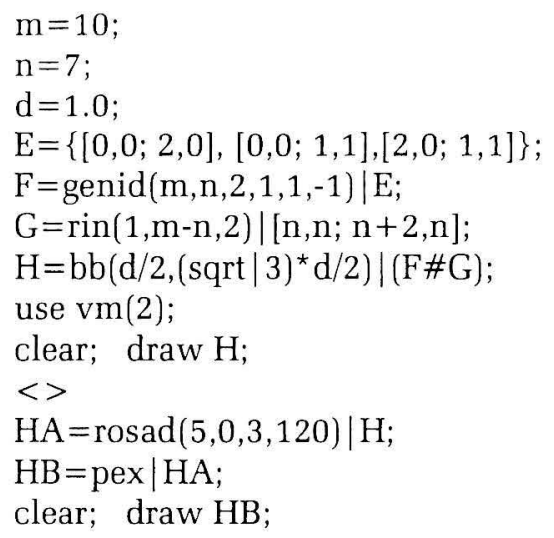

Fig 1.5.2 An editory display

The contents of the editory are also shown in a frame, with a double line at the top, in Fig 1.5.2. An arrangement of the form shown in Fig 1.5.2 is referred to as an 'editory display'. An editory display is used for displaying the whole or a part of the contents of the editory.

The term 'record' is used to refer to the textual material that constitutes the entire contents of the editory. A record normally consists of a sequence of Formian statements that may have been divided into schemes.

\subsubsection{Setting Values for Generic Parameters}

Consider the first scheme in the editory display of Fig 1.5.2. This scheme contains the generic formulation for the grid of Fig 1.4.23, as discussed in section 1.4.6. The scheme starts with the assignment statements

$$
\begin{aligned}
& \mathrm{m}=10 \\
& \mathrm{n}=7 ; \\
& \mathrm{d}=1.0
\end{aligned}
$$

These assignment statements set values of the parameters $\mathrm{m}, \mathrm{n}$ and $\mathrm{d}$ for use in the subsequent statements. This is the usual style of setting values for parameters of a generic formulation. That is, a sequence of assignment statements for setting parameter values is placed at the top of the scheme. Thereafter, the values of the parameters are adjusted by editing as required.

\subsubsection{Automatic Control of Plot Sizes}

The use statement in the first scheme of the record in the editory display of Fig 1.5.2 involves a new 'useitem'. This use-item is of the form

$$
\operatorname{vm}(2)
$$

where vm stands for 'view mode'. The effect of this use-item is to let the sizes of formex plots in the drawpad be determined automatically. To elaborate, when 'view mode 2' is 'current', then every formex plot is photographically scaled such that it just fits into the drawpad.

Once the system is put into the automatic sizing mode it will remain in this mode until the end of the session unless the mode is changed again by the user. The system may be put back into the default non-automatic sizing mode through a use statement of the form

use vm(1);

\subsubsection{Numeric Expressions and Functions}

The record in the editory display of Fig 1.5.2 contains numeric expressions such as

$\mathrm{m}-\mathrm{n}$

and

$$
(\text { sqrt } \mid 3)^{*} \mathrm{~d} / 2
$$


In general, a 'numeric expression' may appear at any position in a Formian statement where a 'number' can appear.

A numeric expression in Formian is any meaningful combination of numbers, numeric variables, arithmetic operators, numeric functions and parentheses. The arithmetic operators are

$$
+\quad * \quad / \text { and } \wedge \text { (for exponentiation) }
$$

The available set of numeric functions in Formian is similar to the usual set of standard numeric functions in common programming languages. These functions are

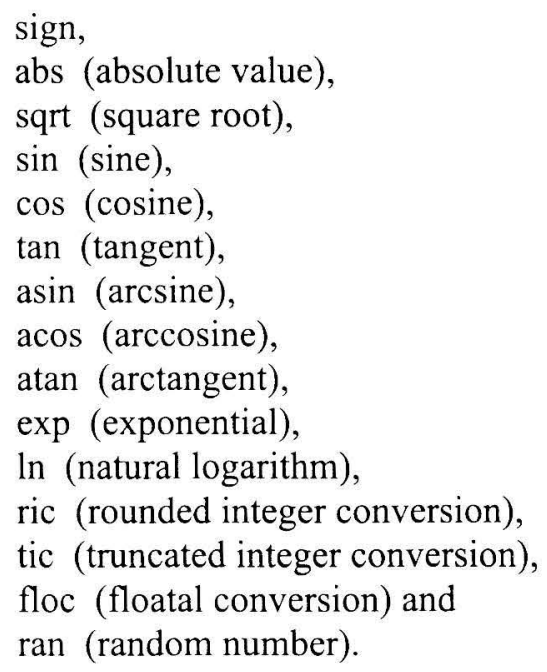

The rallus symbol is used to separate a numeric function from its argument. For example,

$$
\sin x
$$

is written as

$$
\sin \mid x
$$

Thus, the assignment statement

$$
y=\cos \mid 60
$$

will create a numeric variable y with a value of 0.5 (that is, cosine of $60^{\circ}$ ). In Formian, angles are always given in degrees.

The functions ric, tic and floc are 'conversion' functions. For example, if $\mathrm{x}=1.76$ then

$$
\begin{array}{ll}
\text { ric } \mid x & \text { is equal to } 2, \\
\text { ric } \mid-x & \text { is equal to }-2, \\
\text { tic } \mid x & \text { is equal to } 1 \text { and } \\
\text { tic } \mid-x & \text { is equal to }-1
\end{array}
$$

Also, the assignment statement

$$
y=\text { floc } \mid 6
$$

will result in the value of 6 in 'floating point form' to be assigned to $\mathrm{y}$.
Before this section is ended, attention is drawn to the differences in the styles of presentation in 'free formulations' and their corresponding 'Formian formulations'. To exemplify the point in mind, consider the formex equation

$$
\mathrm{H}=\mathrm{bb}(\mathrm{d} / 2, \sqrt{ } 3 \mathrm{~d} / 2) \mid(\mathrm{F} \# \mathrm{G})
$$

and its corresponding Formian statement

$$
\mathrm{H}=\mathrm{bb}\left(\mathrm{d} / 2,(\mathrm{sqrt} \mid 3)^{*} \mathrm{~d} / 2\right) \mid(\mathrm{F} \# \mathrm{G}) \text {; }
$$

The above formex equation is the last line of the formulation for the three-way grid configuration of Fig 1.4.23. In the case of this equation, a free mathematical style of presentation is used. However, the style of the corresponding Formian statement is compatible with the Formian grammar. In particular, the expression

$$
\sqrt{3} \mathrm{~d} / 2
$$

of the formex equation is given as

$$
\text { (sqrt } \mid 3)^{*} \mathrm{~d} / 2
$$

in the Formian statement, Fig 1.5.2.

\subsubsection{Saving Records}

Configuration processing activities are performed by executing sequences of Formian statements that are placed in the editory. It is often required to save the material in the editory for future use and further development. The current record in the editory may be saved in a 'text file' using the 'file menu'.

The file menu is activated by either clicking the item 'File' on the menu bar or by using the keyboard shortcut 'alt $+F$ '. The file menu together with brief descriptions of the effects of its items are shown in Fig 1.5.3.

When the file menu is active (that is, when it is displayed on the screen), the current record (that is, the contents of the editory) may be saved through the 'save' or 'save as' item of the file menu.

If the current record has already been saved in a text file, then the name of this text file appears on the title bar of the editory. Subsequently, if the record is modified in any way then the contents of its text file may be updated using the 'save' menu item.

The 'save as' menu item is used

- when the current record has been saved in a text file with the name of the text file appearing on the title bar of the editory and it is required to save the current record in another text file, or

- when the current record has not yet been saved and it is required to save it in a text file. 


\begin{tabular}{|c|c|}
\hline$\underline{N e w}$ & Clear the contents of the editory. \\
\hline Open... & $\begin{array}{l}\text { Place the contents of a text file } \\
\text { in the editory. }\end{array}$ \\
\hline Save & $\begin{array}{l}\text { Save the contents of the editory } \\
\text { in the currently open text file. }\end{array}$ \\
\hline Save as... & $\begin{array}{l}\text { Save the contents of the editory } \\
\text { in a text file. }\end{array}$ \\
\hline Print text... & Print the contents of the editory. \\
\hline Print picture... & $\begin{array}{l}\text { Print the picture displayed on } \\
\text { the drawpad. }\end{array}$ \\
\hline Print duet... & $\begin{array}{l}\text { Print the visible part of the } \\
\text { editory together with the picture } \\
\text { displayed on the drawpad. }\end{array}$ \\
\hline $\begin{array}{l}\underline{1} \text { triag } \\
\underline{2} \operatorname{diag}\end{array}$ & Open this file. \\
\hline Exit & Exit Formian. \\
\hline
\end{tabular}

Fig 1.5.3 File menu

In either of the above cases, the current record may be saved through the 'save as' menu item. The 'save as' menu item activates the standard Windows 'save dialogue box' that may be used to specify a file name.

It is not necessary to save the current record in a text file in every occasion. It frequently happens that the objectives of a configuration processing task are achieved through a few simple statements and there is no real need for saving the statements.

Indeed, if one tries to create a new text file for every little activity, then the accumulation of the saved files will soon become a nuisance. However, if there is any chance that the record in the editory may be of use later, then it is wise to save it.

A practical approach in this respect is as follows:

- For material that is needed for future use and further development, the related schemes may be grouped together and saved as a single record in a file (rather than saving the schemes separately in different files).

- A file may be designated for temporary storage of material (called, for instance, 'workfile'). Then, any record that is needed for only a short while can be saved in this file which will be frequently overwritten with the latest required record. If necessary, one may have more than one file for temporary storage of material (called, for instance, temp1, temp2, ... etc).

The effect of the 'new' item of the file menu is to clear the editory for creation of a new record. The use of the 'new' menu item causes the entire contents of the editory to be deleted. But, before deleting, the user is asked whether it is required to save the record in the editory.

The effect of the 'open' item of the file menu is to open a previously created 'text file' and place its contents in the editory.

The 'open' menu item activates the standard Windows 'open dialogue box' that displays the list of all the previously created files in the current 'folder'. The required file may then be selected and opened. This will cause the contents of the file to replace the current record in the editory.

In Formian, only one text file can be open at any given time. Therefore, the opening of a new file will result in the loss of the current material in the editory unless this material is saved before opening the new file. The user is appropriately prompted by the system in this regard.

The last few text files that have been opened are listed in the lower part of the file menu. For instance, in Fig 1.5.3 the latest files opened are given as 'triag' and 'diag'. Each of these files may be opened through its item on the file menu. This route for opening a file is more convenient than that through the 'open' menu item and the 'open dialogue box'.

It is good practice to have a 'folder' that contains all the text files created in Formian. This folder may then be used as the 'current folder' in Formian sessions. The name of the current folder is always displayed on the title bar of the Formian screen. In the examples given, the name of the current folder is 'formbay'. A folder may be created using standard Windows procedures.

The last item on the file menu is 'exit'. This menu item may be used to exit Formian.

The file menu has another three items that have not been referred to yet. These menu items are for printing operations and will be discussed in the next section.

The effect of some of the items on the file menu may also be obtained through tool buttons. There are four such tool buttons and theses are shown in Fig 1.5.4. 


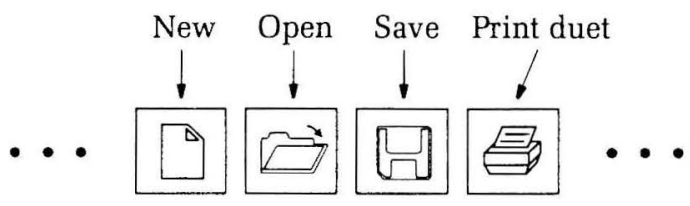

Fig 1.5.4 File tool buttons

\subsubsection{Printing}

The information generated through configuration processing activities in Formian can be outputted in two main ways, namely,

- export to structural analysis programs, draughting packages, graphics systems, numerically controlled machines, ... etc, as will be discussed in the second paper in this series, and

- printing in textual and/or graphical form.

Printing of information may be effected through the file menu. There are three items on the file menu that relate to printing operations, namely, 'print text', 'print picture' and 'print duet', Fig 1.5.3.

The 'print text' menu item may be used to print a part or the whole of the current record in the editory. The 'print text' menu item activates the 'print text box' shown in Fig 1.5.5. The entries in this box may be set as required and then the printing operation may be initiated through the OK button.

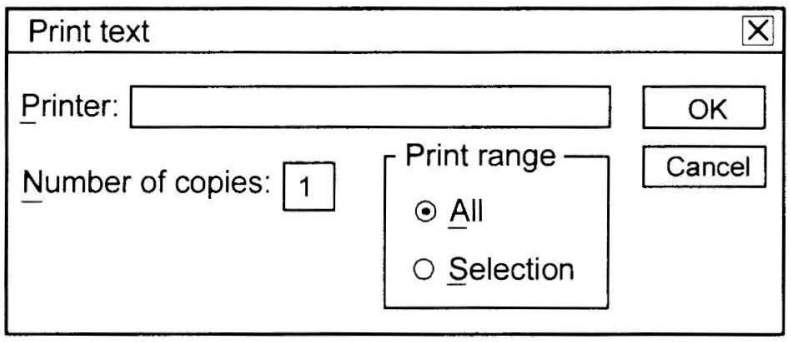

Fig 1.5.5 Print text box

The 'print picture' menu item can be used to print a copy of the contents of the drawpad. That is, all the graphic effects that are visible on the drawpad. The 'print picture' menu item activates the 'print picture box' which has a form similar to the 'print text box', shown in Fig 1.5.5. The 'print picture box' may then be used to initiate the printing operation.

A copy of the combination of the visible material of the editory and the graphic effects on the drawpad is referred to as a 'duet'. A duet may be produced through the 'print duet' item on the file menu or the 'print duet' tool button. This is the tool button with a printer symbol appearing on it, Fig 1.5.4. For instance, if the printing of a duet is initiated when the screen has the arrangement shown in Fig 1.5.1, then the printed output will be as shown in Fig 1.5.6.

\begin{tabular}{|c|c|}
\hline Editory Current file: triag & Drawpad \\
\hline $\begin{array}{l}\mathrm{m}=10 ; \\
\mathrm{n}=7 ; \\
\mathrm{d}=1.0 ; \\
\mathrm{E}=\{[0,0 ; 2,0],[0,0 ; 1,1],[2,0 ; 1,1]\} ; \\
\mathrm{F}=\operatorname{genid}(\mathrm{m}, \mathrm{n}, 2,1,1,-1) \mid \mathrm{E} ; \\
\mathrm{G}=\operatorname{rin}(1, \mathrm{~m}-\mathrm{n}, 2) \mid[\mathrm{n}, \mathrm{n} ; \mathrm{n}+2, \mathrm{n}] ; \\
\mathrm{H}=\mathrm{bb}\left(\mathrm{d} / 2,(\operatorname{sqr} \mid 3)^{*} \mathrm{~d} / 2\right) \mid(\mathrm{F} \# \mathrm{G}) ; \\
\text { use vm(2); } \\
\text { clear; draw } \mathrm{H} ; \\
<> \\
\mathrm{HA}=\operatorname{rosad}(5,0,3,120) \mid \mathrm{H} ; \\
\mathrm{HB}=\operatorname{pex} \mid \mathrm{HA} ; \\
\text { clear; draw } \mathrm{HB} ;\end{array}$ & \\
\hline
\end{tabular}

Fig 1.5.6 A duet

\subsubsection{Properties of Variables}

The list of current variables and their properties may be inspected at any time during a Formian session. This list may be displayed through the 'list menu' by

- clicking the item 'List' on the menu bar or using the keyboard shortcut 'alt $+\mathrm{L}$ ' and

- selecting the item 'variables' from a choice of three options that will be displayed.

For example, suppose that the above steps are taken following the execution of the schemes shown in Fig 1.5.1 (which are also shown in the editory display of Fig 1.5.2 and the duet of Fig 1.5.6). This will result in the display of the 'variables box' shown in Fig 1.5.7.

\begin{tabular}{|c|c|c|c|c|c|}
\hline \multicolumn{2}{|c|}{ Variables } & \multirow[b]{2}{*}{ Order } & \multirow[b]{2}{*}{ Plexitude } & \multirow[b]{2}{*}{ Grade } & \multirow[b]{2}{*}{ Size } \\
\hline Variable & Type & & & & \\
\hline$d$ & FLT & & & & $4 b$ \\
\hline $\mathrm{e}$ & INT FMX & 3 & 2 & 2 & $48 b$ \\
\hline$f$ & INT FMX & 147 & 2 & 2 & $2.4 \mathrm{~kb}$ \\
\hline$g$ & INT FMX & 3 & 2 & 2 & $48 b$ \\
\hline $\mathrm{h}$ & FLT FMX & 150 & 2 & 2 & $2.4 \mathrm{~kb}$ \\
\hline ha & FLT FMX & 450 & 2 & 2 & $7.2 \mathrm{~kb}$ \\
\hline $\mathrm{hb}$ & FLT FMX & 315 & 2 & 2 & $5.0 \mathrm{~kb}$ \\
\hline $\mathrm{m}$ & INT & & & & $4 b$ \\
\hline$n$ & INT & & & & $4 b$ \\
\hline & & & ncel & & \\
\hline
\end{tabular}

Fig 1.5.7 Variables box

The information presented in the 'variables box' is arranged in a number of columns. The first column lists all the current variables in the alphabetical order. The variables in this column are always given in lower-case letters. 
The second column of the 'variables box' shows the 'types' of the variables. The abbreviations used are as follows:

$\begin{array}{lll}\text { FLT } & \text { stands for } & \text { floatal, } \\ \text { FMX } & \text { stands for } & \text { formex and } \\ \text { INT } & \text { stands for } & \text { integer. }\end{array}$

To elaborate, two kinds of numerical values are represented in computing systems, namely, 'integer' and 'floatal'. An 'integer value' is stored in a manner that the full precision of the value is preserved. A 'floatal value' is a numerical value that is stored in a 'floating point form'. For instance, the assignment statement

$$
y=725.328
$$

will result in the number 725.328 to be assigned to $y$. The value will be stored in a 'floating point form'. This 'floatal number' may be represented by

$$
0.725328 \times 10^{3}
$$

This value may also be represented by

$$
\begin{array}{ll} 
& 0.725328 \mathrm{E} 3 \\
\text { or } & 7.25328 \mathrm{E} 2 \\
\text { or } & 72.5328 \mathrm{E} 1 \ldots \text { etc. }
\end{array}
$$

The letter $E$ in the above 'floating point representation' stands for 'exponent' and may also be given in lower-case as ' $\mathrm{e}$ '.

The range of values that can be represented by 'floatal numbers' is enormously larger than the range that can be represented by 'integer numbers'. However, unlike the 'integer form of storage', the 'floatal form of storage' does not necessarily preserve the full accuracy of the values.

The above statement is not meant to imply that the available range of integer values is too restrictive, since integer numbers with up to about 7 digits can be used. Also, the accuracy of floatal numbers is quite adequate for most practical purposes, since one can normally rely on an accuracy of 7 decimal places. This represents an accuracy better than a millimetre in a mile.

There are situations when only integer numbers can be used meaningfully, like specifying the number of nodes in a configuration. Obviously, it does not make sense to have 270.34 nodes in a configuration! On the other hand, if one wants to specify the length of a bar element, then either an integer number or a floatal number can be used. It is meaningful to refer to a ' 2 metre long bar element' or a ' 2.15 metre long bar element'.

In relation to formices, a formex is said to be an 'integer formex' provided that all of its uniples are integers. In contrast, a formex is said to be a 'noninteger formex', provided that one or more of its uniples are noninteger. For example,

$$
\{[4,2 ; 3,1],[-6,4 ;-4,2]\}
$$

is an integer formex and

$$
\{[4,2 ; 3,1],[-6,4 ;-4,2.5]\}
$$

and $\{[4.72,2.14 ; 3,1],[-6.67,4 ;-4,2]\}$

are noninteger formices.

In Formian, the uniples of an integer formex are stored as integers and the uniples of a noninteger formex are stored as floatal numbers. Hence, a noninteger formex in the context of Formian is referred to as a 'floatal formex'.

For instance, consider the assignment statements

and

$$
\mathrm{E} 1=\{[4,2 ; 3,1],[-6,4 ;-4,2]\} ;
$$

$$
\mathrm{E} 2=\{[4,2 ; 3,1],[-6,4 ;-4,2.5]\} ;
$$

The only difference between the two formices concerns the last uniple which is the integer number 2 in the first formex and the noninteger number 2.5 in the second one.

Let the execution of the above two assignment statements be followed by the execution of the give statement

give $\mathrm{E} 1, \mathrm{E} 2$;

This will result in the display of the give box shown in Fig 1.5.8.

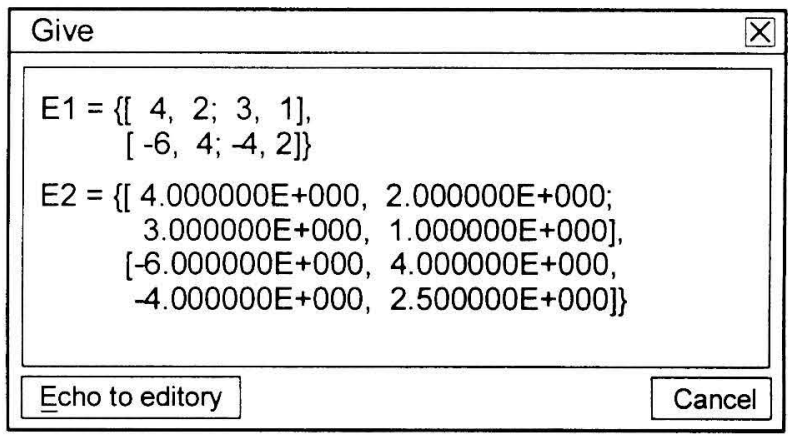

Fig 1.5.8 Integer and floatal formices

It is seen that the value of formex variable E1 is given with integer uniples but the value of E2 is given in terms of floatal uniples.

Incidentally, the give box has a button for 'echoing to editory'. The clicking of this button has the effect of placing a copy of the contents of the give box at the end of the editory. 
In the early days of formex algebra, one was very conscious of the 'integerness' and 'nonintegerness' of formices. This was mainly due to the fact that, with the available computing facilities of those days, work with integer formices was appreciably faster than that with noninteger formices. However, the attitudes in this regard have changed. The present attitude is to work with both integer and noninteger formices as the situation may demand and let the system take care of the rest.

Returning to the discussion of the 'variables box' of Fig 1.5.7, the information given in the second column indicates that

- d is a 'floatal variable',

- $\quad \mathrm{e}, \mathrm{f}$ and $\mathrm{g}$ are 'integer formex variables',

- h, ha and hb are 'floatal formex variables' and

- $\mathrm{m}$ and $\mathrm{n}$ are 'integer variables'.

The third column of the 'variables box' of Fig 1.5.7 is only relevant to formices and, therefore, it does not have any entries for the 'numeric variables' $d, m$ and $\mathrm{n}$. An entry in the third column indicates the 'order' of a formex. That is, the number of cantles of the formex.

The fourth and fifth columns of the 'variables box' of Fig 1.5.7 give information about 'plexitude' and 'grade' that are relevant to formices only. The term 'plexitude' means the number of signets in a cantle and the term 'grade' means the number of uniples in a signet.

Each one of the formex variables listed in Fig 1.5.7 represents an assembly of two-noded beam elements with each cantle of the value of the variable having two signets corresponding to the two nodes of an element. Thus, the plexitude of the formex variables in Fig 1.5.7 is given as 2. Also, the formex variables in Fig 1.5.7 are either relative to a two directional normat or a two dimensional Cartesian coordinate system with each signet consisting of two uniples. Thus, the formex variables are of grade 2, as indicated in Fig 1.5.7.

The last column of the 'variables box' gives the size of the storage area used by each of the variables. The size is given in terms of bytes, where ' $b$ ' stands for 'byte' and 'kb' stands for 'kilobyte' (1000 bytes).

\subsubsection{Concept of Tolerance}

A useful piece of information that may be deduced from the third column of the 'variables box' of Fig 1.5.7 concerns the formex variables HA (ha) and HB (hb). To elaborate, both of these formex variables represent the three-way grid shown on the drawpad in Fig 1.5.1 (and Fig 1.5.6). However, the grid represented by HA contains a number of superfluous elements whereas HB represents the grid with the superfluous elements removed, as discussed in relation to Fig 1.4.28 in section 1.4.7. The elimination of the superfluous elements is achieved through the pexum function, as shown in the second scheme of the record in the editory display of Fig 1.5.2. Now, from the third column of the 'variables box' in Fig 1.5.7, it is seen that formex HA has 450 cantles whereas formex HB has 315 cantles. This shows that there have been 135 superfluous elements that were deleted by the pexum function.

A question that may be raised regarding the working of the pexum function is as follows: Considering the approximate nature of floatal numbers, how could the equality of uniples in a floatal formex for the operation of the pexum function be checked?

To elaborate, consider the arrangement shown in Fig 1.5.9. The elements 1 and 2 in the figure are supposed to represent two coincident elements in a grid represented by a floatal formex. The elements are shown with greatly exaggerated inaccuracies in the coordinates of their end nodes. The theoretically correct position of both elements 1 and 2 is indicated by the dotted line.

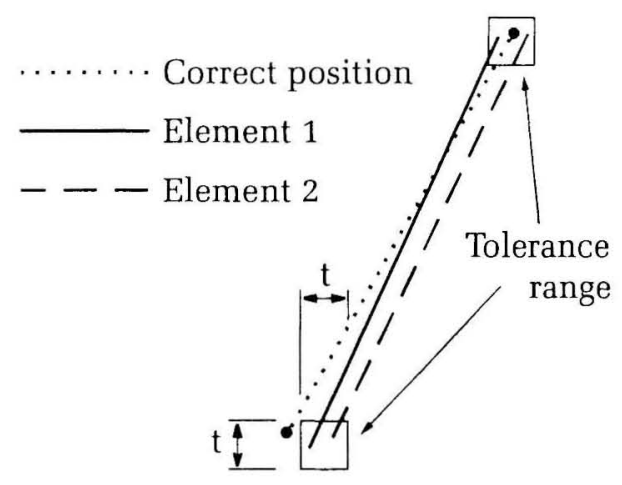

Fig 1.5.9 Tolerance range

The question is: With the inevitable presence of inaccuracies, as indicated in Fig 1.5.9, how can the pexum function detect the (theoretical) coincidence of the two elements.

The answer is that the coincidence of the elements is detected with the aid of the concept of 'tolerance'. To elaborate, in Formian, whenever two numbers $\mathrm{m}$ and $\mathrm{n}$ are to be compared for equality, then the following inequality is considered

$$
|\mathrm{m}-\mathrm{n}| \leq \mathrm{t}
$$

where, a typical value for $t$ is 0.00001 . 
The above inequality compares the value of $t$ with the absolute value of the difference between $m$ and $n$. If the inequality is satisfied then $m$ and $n$ are regarded as equal. For instance, with $t=0.00001$,

$$
4.329123 \text { and } 4.329114
$$

are regarded as equal since their difference is 0.000009 , which is less than $t$, but

\subsection{1 and 2.825642}

are regarded as unequal since their difference is 0.000011 , which is greater than $t$.

The term ' $t$ ' is referred to as 'tolerance'. The default value of $t$ is 0.00001 but this value may be changed by the user through a 'use-item' of the form

$$
\text { tol( } r)
$$

where 'tol' stands for 'tolerance' and $\mathrm{r}$ is the required tolerance. For instance, the statement

$$
\text { use tol(0.000005); }
$$

will make the tolerance equal to 0.000005 .

The effect of tolerance is illustrated graphically in Fig 1.5.9, where each of the two squares shown represents the 'tolerance range'. The elements 1 and 2 will be regarded as 'coincident' provided that their corresponding end points remain within the tolerance range at both ends.

\subsubsection{Arrangement of Statements and Inclusion of Comments}

Consider the duet shown in Fig 1.5.10. The record in the editory consists of a single scheme which is obtained by combining the two schemes of Fig 1.5.1 and changing the values of the parameters $m$ and $n$ as well as the coordinates of the centre of rotation in the rosad function. The scheme is also shown in the editory display of Fig 1.5.11.

The scheme illustrates the use of 'comments'. In Formian, a 'comment' is a sequence of characters that is enclosed between two 'comment brackets'. The 'comment bracket' is the compound symbol

\section{$(*)$}

This compound symbol is referred to as the 'floret symbol'. The 'body' of the comment that lies between the initial and terminal floret symbols may be any sequence of characters with the only restriction that it must not include a floret symbol.

A floret symbol may be either typed from the keyboard or obtained by clicking the 'floret tool button' on the tool bar. This is the tool button with a floret symbol appearing on it.

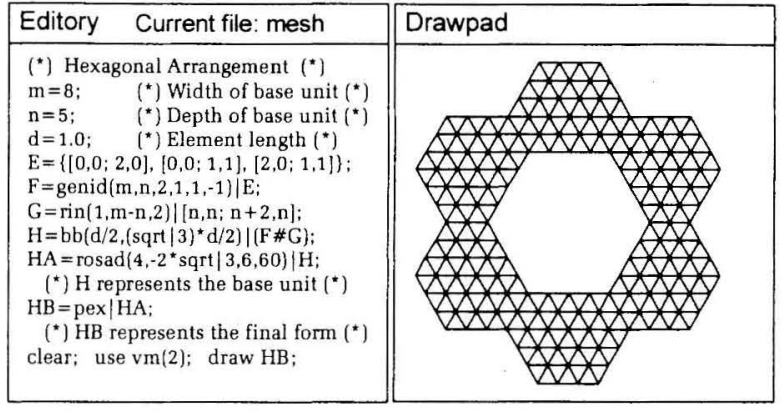

Fig 1.5.10 Inclusion of comments

(*) Hexagonal Arrangement ( ${ }^{*}$ )

$\mathrm{m}=8 ; \quad\left(^{*}\right)$ Width of base unit $\left(^{*}\right)$

$\left.\mathrm{n}=5 ; \quad{ }^{*}\right)$ Depth of base unit $\left({ }^{*}\right)$

$\mathrm{d}=1.0 ; \quad\left({ }^{*}\right)$ Element length $\left({ }^{*}\right)$

$\mathrm{E}=\{[0,0 ; 2,0],[0,0 ; 1,1],[2,0 ; 1,1]\}$;

$\mathrm{F}=\operatorname{genid}(\mathrm{m}, \mathrm{n}, 2,1,1,-1) \mid \mathrm{E}$

$\mathrm{G}=\operatorname{rin}(1, \mathrm{~m}-\mathrm{n}, 2) \mid[\mathrm{n}, \mathrm{n} ; \mathrm{n}+2, \mathrm{n}]$;

$\mathrm{H}=\mathrm{bb}\left(\mathrm{d} / 2,(\mathrm{sqrt} \mid 3)^{\star} \mathrm{d} / 2\right) \mid(\mathrm{F} \# \mathrm{G})$;

$\mathrm{HA}=\operatorname{rosad}\left(4,-2^{*}\right.$ sqrt $\left.\mid 3,6,60\right) \mid \mathrm{H}$;

$\left({ }^{*}\right) \mathrm{H}$ represents the base unit $\left({ }^{*}\right)$

$\mathrm{HB}=$ pex $\mid \mathrm{HA}$;

$\left({ }^{\star}\right)$ HB represents the final form $\left({ }^{\star}\right)$

clear; use vm(2); draw HB;

Fig 1.5.11 A scheme with comments

$\mathrm{m}=8 ; \mathrm{n}=5 ; \mathrm{d}=1.0 ; \mathrm{E}=\{[0,0 ; 2,0],[0,0 ; 1,1],[2$

$, 0 ; 1,1]\} ; \mathrm{F}=\operatorname{genid}(\mathrm{m}, \mathrm{n}, 2,1,1,-1) \mid \mathrm{E} ; \mathrm{G}=\operatorname{rin}(1$

,m-n,2) $\mid[n, n ; n+2, n] ; H=b b\left(d / 2,(\text { sqrt } \mid 3)^{*} d\right.$

/2) $\left|(\mathrm{F} \# \mathrm{G}) ; \mathrm{HA}=\operatorname{rosad}\left(4,-2^{*} \mathrm{sqrt} \mid 3,6,60\right)\right| \mathrm{H}$;

$\mathrm{HB}=$ pex $\mid \mathrm{HA}$;clear; use vm(2);draw HB;

Fig 1.5.12 A 'squashed' scheme

A comment may appear at any point of a scheme where a 'white space' can appear. The term 'white space' refers to an 'empty space' that is obtained by typing a space, newline or tab character from the keyboard. White spaces and comments may appear at any point of a scheme which is not an intermediate point of a number, an identifier, a keyword or a compound symbol.

It is good practice to include comments in the schemes. A comment may be used to give a title to a scheme, describe the purpose of the scheme, indicate the significance of a variable, ... etc. 
White spaces and comments do not affect the execution of a scheme. As far as the system is concerned, the scheme of Fig 1.5.11 is equivalent to the 'squashed' scheme shown in the editory display of Fig 1.5.12. This scheme is obtained by removing all the white spaces and comments from the scheme of Fig 1.5.11, with two exceptions. Namely, the spaces after the keywords 'use' and 'draw' are not removed. This is because a keyword must always be followed by one or more spaces.

It is good practice to arrange the statements in a scheme in a manner that the material can be easily read. There is no syntactic difference between the schemes in Figs 1.5.11 and 1.5.12. However, it is much easier for a human to follow the material as given in Fig 1.5.11.

\subsubsection{Arrangement of Schemes}

When a scheme is subjected to execution, then the statements that constitute its body are executed one after the other, starting from the first statement. The scope of the execution will be confined to the body of the scheme and will not involve any statement outside the scheme. In this sense, a scheme is an independent unit and the position of the scheme within the record has no particular significance.

However, the variables created by a scheme are not 'private' to that scheme. All the variables created are held in a 'common' storage area without any reference to the schemes that have created them. If a scheme creates a variable $\mathrm{F}$ and if the scheme that is executed next also creates a variable $\mathrm{F}$, then the new value of $F$ overwrites the value created by the previous scheme with no trace of the old value of $F$ remaining. Also, if a scheme creates a variable, then a subsequently executed scheme can make use of the value of this variable without any restriction.

The general availability of the variables for use by different schemes imply that a scheme can provide variables for use in other schemes. Therefore, if desired, the schemes may be made to depend on one another. In this case, the order of execution of the schemes should be conformable with the required order for the availability of variables. However, even in this case, the actual positions of schemes within the record remain unimportant. Although, it will be convenient to arrange the schemes in the same order as they are to be executed.

As an example, consider the editory display of Fig 1.5.13. The record shown in this figure consists of three schemes. The first scheme creates a formex variable $\mathrm{H}$ representing a trapezoidal three-way grid, based on the generic formulation that has been used in the previous examples. The second scheme uses the variable $\mathrm{H}$ to create a formex variable HEX1 whose plot is shown in Fig 1.5.14. The third scheme again uses the variable $\mathrm{H}$ to create a formex variable HEX2 whose plot is shown in Fig 1.5.15.

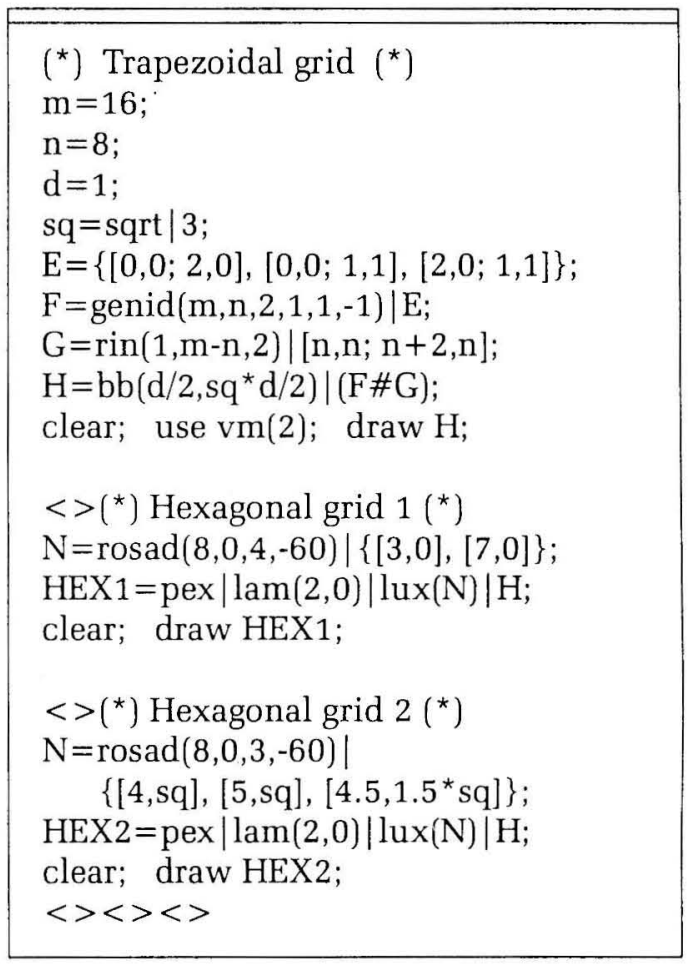

Fig 1.5.13 A record with three schemes

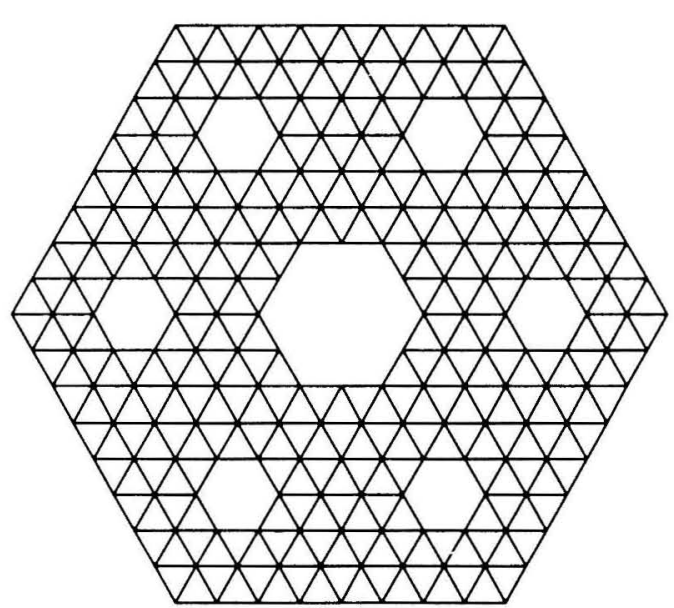

Fig 1.5.14 Plot of HEX1

In this example, the second and third schemes are both dependent on the first scheme. Therefore, it is necessary to execute the first scheme to create the formex variable $\mathrm{H}$ before the second or third scheme can be executed. However, there is no link between 
the second and third schemes and they can be executed independently.

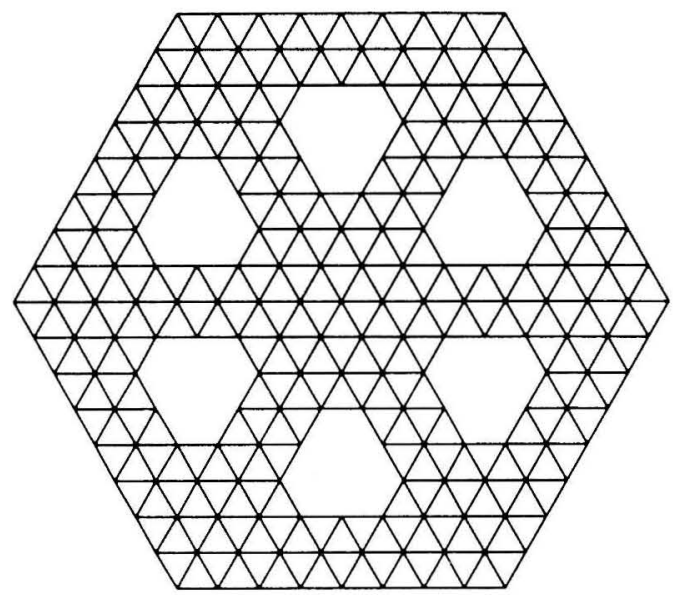

Fig 1.5.15 Plot of HEX2

Incidentally, it is a convention to use three consecutive diamer symbols to indicate the end of a record. This is shown at the end of the record in the editory display of Fig 1.5.13.

\subsubsection{Ending a Session}

A session may be brought to an end by issuing an 'exit command'. This is done by

- clicking the exit button, that is, the button on the top right corner of the screen with a cross appearing on it, or

- using the keyboard shortcut 'alt $+X$ ' or

- using the 'exit' item on the file menu.

The ending of the session will cause any material that may be in the editory as well as all the values of variables created during the session to be wiped out. However, before closing the session, if the editory contains any unsaved material, then the system will ask whether the material is required to be saved. On the other hand, as far as the variables are concerned, their values will disappear at the end of the session.

This should not raise any alarms since, usually, there is no point in holding on to the value of a formex variable beyond the end of a session. The value of a typical formex variable is a huge bundle of numbers. In contrast, the formex formulation that creates such a value is normally a few lines of text that can be incorporated in a scheme and saved in a text file. The execution of the scheme will then generate the value when required. So, what should be saved is the rule for generation of a formex value rather than the value itself.
The session may also be ended through a different mechanism. To elaborate, sometimes an error in a statement may cause the system to enter into an endless chain of operations. The user will become aware of this by the failure of the system to complete the execution of a scheme within a reasonable period of time. To get out of a situation of this kind, one may terminate the session by using the key combination 'control+alt+delete' from the keyboard.

\subsection{SPACE STRUCTURES}

The term 'space structure' refers to a structural system in which the load transfer mechanism involves three dimensions. This is in contrast with a 'plane structure', such as a plane truss, in which the load transfer mechanism involves no more than two dimensions.

The above definition is the 'formal' definition of a space structure. However, in practice, the term 'space structure' is simply used to refer to a number of families of structures that includes grids, barrel vaults, domes, towers, foldable systems and tension structures.

There are numerous examples of space structures built all over the world for sports stadiums, gymnasiums, cultural centres, auditoriums, shopping malls, railway stations, aircraft hangars, leisure centres, radio telescopes and many other purposes.

A number of single layer grid configurations were considered in the previous sections. These configurations were used as examples for explaining some basic concepts of formex configuration processing. Examples of a number of other kinds of space structure configurations will be considered in the sequel. These examples will again be used as vehicles for describing basic ideas and procedures in formex configuration processing.

\subsection{DOUBLE LAYER GRIDS}

A perspective view of a double layer grid is shown in Fig 1.7.1. In general, a double layer grid consists of two parallel layers of elements that are connected together by 'web' elements. In the double layer grid of Fig 1.7.1, the top layer has a 'square pattern' and consists of 112 elements. The bottom layer also has a square pattern with 84 elements. The number of web elements is 196. The top layer elements are shown by thick lines and the bottom layer elements as well as the web elements are shown by thin lines. The plan and elevation of the grid of Fig 1.7.1 are shown 
in Fig 1.7.2. Also shown in this figure are the dimensions of the structure together with the global Cartesian coordinate system $\mathrm{x}-\mathrm{y}-\mathrm{z}$.

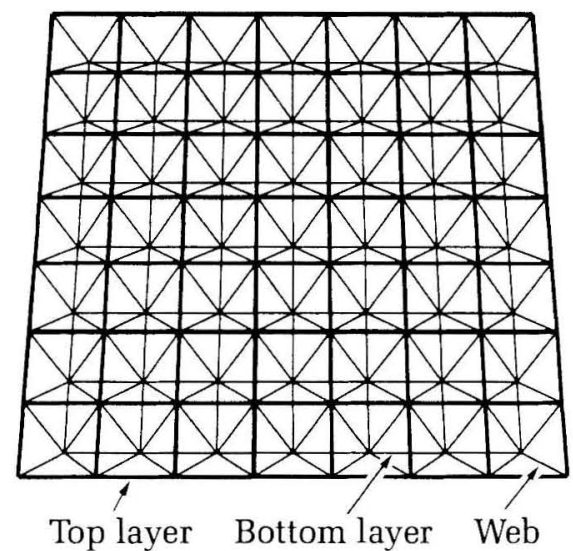

Fig 1.7.1 Perspective view of a double layer grid
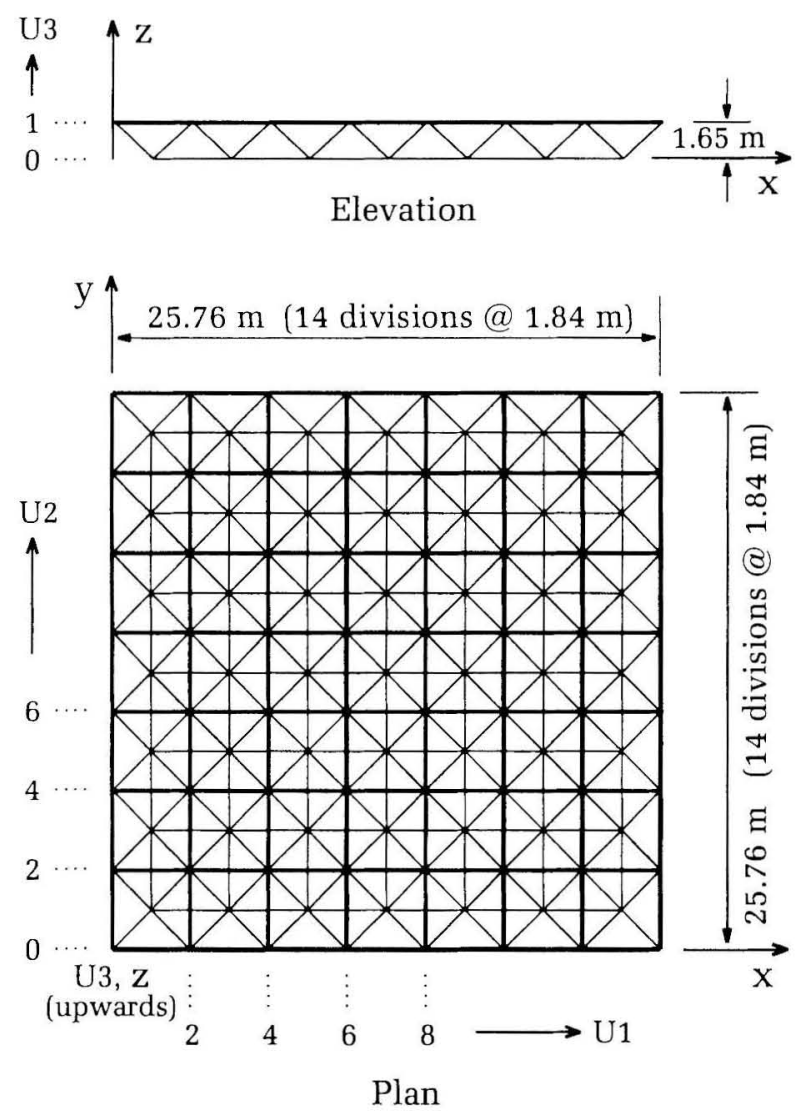

Fig 1.7.2 Plan and elevation of the double layer grid of Fig 1.7.1

The configurations in the examples of the previous sections were formulated using simple two directional normats. The same basic approach can be used for the formulation of the double layer grid of Fig 1.7.1. However, in this case it is necessary to work in terms of a 'three directional normat'. Such a normat is shown in Fig 1.7.2, with the first, second and third directions being indicated by U1, U2 and U3, respectively.

A formex formulation for the double layer grid of Fig 1.7.1 relative to the U1-U2-U3 normat of Fig 1.7.2 may be written as

$$
\begin{aligned}
\mathrm{TOP}= & \operatorname{rinid}(7,8,2,2) \mid[0,0,1 ; 2,0,1] \# \\
& \operatorname{rinid}(8,7,2,2) \mid[0,0,1 ; 0,2,1] \\
\mathrm{BOT}= & \operatorname{rinid}(6,7,2,2) \mid[1,1,0 ; 3,1,0] \# \\
& \operatorname{rinid}(7,6,2,2) \mid[1,1,0 ; 1,3,0] \\
\mathrm{WEB}= & \operatorname{rinid}(7,7,2,2)|\operatorname{rosad}(1,1)| \\
& {[0,0,1 ; 1,1,0] } \\
\mathrm{GRID}= & \mathrm{TOP} \# \text { BOT \# WEB }
\end{aligned}
$$

In this formulation

- $\operatorname{rinid}(7,8,2,2) \mid[0,0,1 ; 2,0,1]$

represents all the top layer elements that are in the first direction,

- $\operatorname{rinid}(8,7,2,2) \mid[0,0,1 ; 0,2,1]$

represents all the top layer elements that are in the second direction,

- $\operatorname{rinid}(6,7,2,2) \mid[1,1,0 ; 3,1,0]$

represents all the bottom layer elements that are in the first direction,

- $\operatorname{rinid}(7,6,2,2) \mid[1,1,0 ; 1,3,0]$

represents all the bottom layer elements that are in the second direction,

- $\operatorname{rinid}(7,7,2,2)|\operatorname{rosad}(1,1)|[0,0,1 ; 1,1,0]$

represents all the web elements and

- TOP \# BOT \# WEB

represents all the elements of the grid.

It should be noted that the rosad function used in the above formulation for the generation of the web elements, that is,

$$
\operatorname{rosad}(1,1)
$$

is an abridged form of

$\operatorname{rosad}(1,1,4,90)$

This represents 4 rotational replications by steps of $90^{\circ}$ with the centre of rotation at point $[1,1]$. The abridged form of the rosad function can be used whenever the number of replications is 4 and the rotation at each step is $90^{\circ}$, as explained in section 1.4.7. Of course, the use of this abridged form is not compulsory and one can always include the third and fourth parameters of the rosad function for the sake of clarity.

Another point to be noticed is that all the formices involved in the above formulation are of 'grade 3'. That is, all the signets of the formices consist of three uniples. This is a consequence of the fact that 
all the formices involved are relative to a three directional normat.

The formex variable GRID in the above formulation represents the compret of the configuration of the double layer grid of Fig 1.7.1 (1.7.2) relative to the U1-U2-U3 normat. A formex variable that describes the compret of the grid of Fig 1.7.1 (1.7.2) in terms of the global $x-y-z$ coordinates may be written as

$$
\text { GRIDX }=b t(1.84,1.84,1.65) \mid \text { GRID }
$$

The construct

$$
b t(1.84,1.84,1.65)
$$

is a 'basitrifect' retronorm. This function is similar to the 'basibifect' retronorm that was used for scaling two directional configurations in the previous sections. A description of the basitrifect retronorm is given in Fig 1.7.3.

$$
\operatorname{bt}(1.84,1.84,1.65)
$$

Fig 1.7.3 Basitrifect retronorm

The effect of the basitrifect retronorm is to change the proportions of a three directional configuration by using scale factors.

Another two examples of double layer grids are shown in Figs 1.7.4 and 1.7.5. A formex representing the configuration of the grid of Fig 1.7.4 relative to the U1-U2-U3 normat of Fig 1.7.2 may be obtained as follows:

$$
\begin{aligned}
& \mathrm{N}=\operatorname{rinid}(3,3,4,4) \mid[3,3,0] \\
& \operatorname{GRIDA}=\operatorname{lux}(\mathrm{N}) \mid \mathrm{GRID}
\end{aligned}
$$

In this formulation

- $\mathrm{N}$ represents nine points, specifying the positions for the removal of elements,

- the luxum function lux $(\mathrm{N})$ effects the removal of all the elements that have a connection to the points represented by $\mathrm{N}$ and

- GRID represents the compret of the grid of Fig 1.7.1 (1.7.2), as formulated before.

A formex representing the grid of Fig 1.7.5 relative to the U1-U2-U3 normat of Fig 1.7.2 may be obtained as follows:

$$
\begin{aligned}
& \mathrm{F}=\text { GRID \# tranid(6,6) } \mid \text { GRID } \\
& \mathrm{N}=\{[7,7,0],[13,13,0]\} \\
& \text { GRIDB = lux(N) } \mid \text { pex } \mid \mathrm{F}
\end{aligned}
$$

In this formulation

- F represents an overlapped combination of the grid of Fig 1.7.1 (1.7.2) with a displaced version of itself,

- the pexum function has the effect of 'pruning' the configuration by removing all the overlapped superfluous elements and

- $\operatorname{lux}(\mathrm{N})$ effects the creation of the two openings.

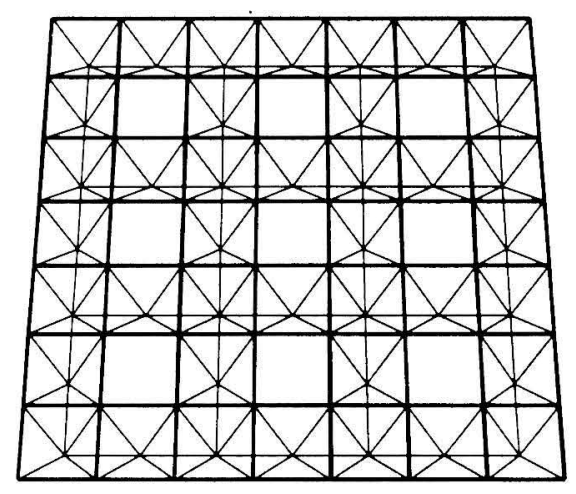

Fig 1.7.4 Perspective view of the double layer grid represented by the formex variable GRIDA

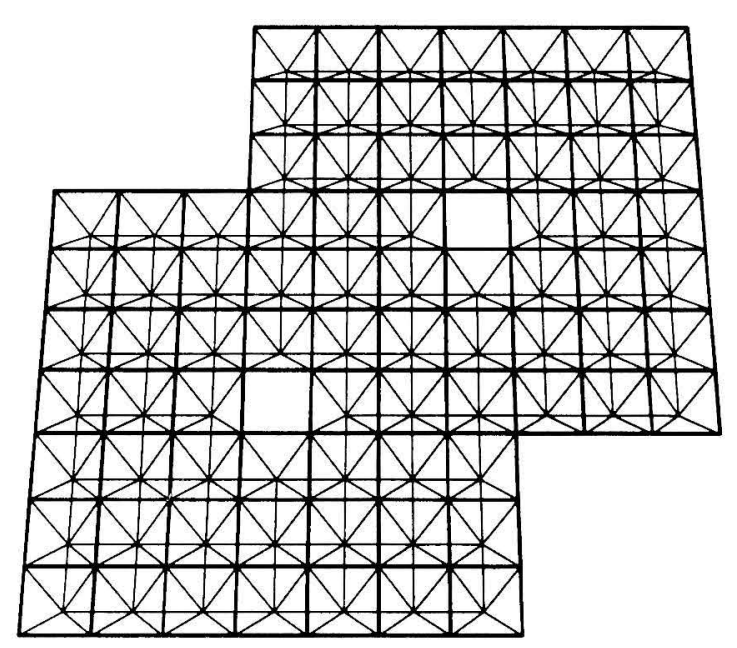

Fig 1.7.5 Perspective view of the double layer grid represented by the formex variable GRIDB

As another example, consider the double layer grid whose plan is shown in Fig 1.7.6. The top layer elements together with the web elements in this grid constitute (inverted) tetrahedral units. Also, all the triangular units in the top and bottom layers of the grid are equilateral.

A generic formulation for the grid of Fig 1.7.6 may be written as

$$
\begin{aligned}
& \mathrm{s}=\sqrt{ } 3 / 3 \\
& \mathrm{TOP}=\operatorname{genid}(\mathrm{m}, \mathrm{m}, 2,3 \mathrm{~s}, 1,-1) \mid \\
& \quad \operatorname{rosad}(1, \mathrm{~s}, 3,120) \mid[0,0,1 ; 2,0,1]
\end{aligned}
$$




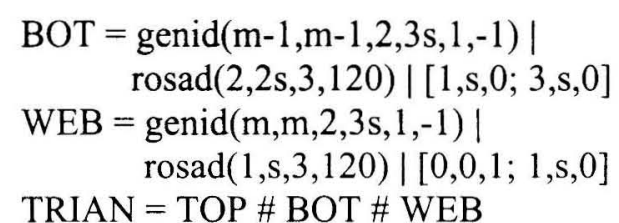

The parameter $\mathrm{m}$ in this generic formulation represents the number of tetrahedral units along each side of the grid. For the grid in Fig 1.7.6 the parameter $m$ is equal to 6 .

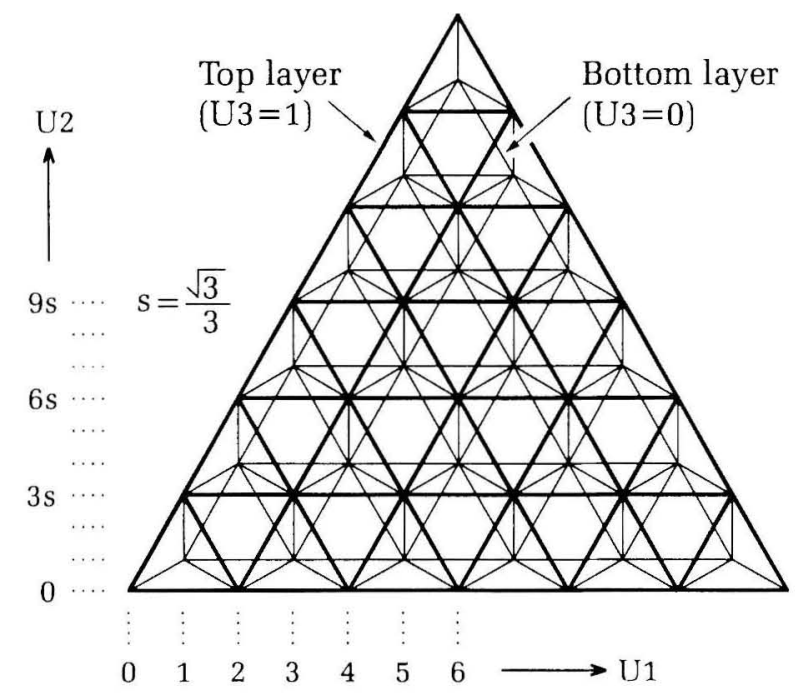

Fig 1.7.6 Plan view of a double layer grid with a triangle-on-triangle pattern

The normat in Fig 1.7.6 involves the factor

$$
s=\sqrt{ } 3 / 3
$$

which is used to obtain the correct scaling in the second direction. This example shows that normat coordinates can be noninteger. Indeed, the fact that all the normat coordinates used so far were integer numbers is incidental rather than essential.

Another point to be noticed in Fig 1.7.6 is that the actual dimensions of the grid and the $x-y-z$ coordinate system are not included. The reason for this omission is that the objective of the exercise which is the formulation of the compret of the grid is independent of the actual dimensions. And, once the compret of the grid is formulated, the actual dimensions may be taken into account easily. For this reason the actual dimensions will be omitted in most of the configurations that are considered henceforth.

As the last example in this section, the above generic formulation is extended to allow curtailing of the corners of the double layer grid of Fig 1.7.6. The extension involves two additional equations as follows:

$$
\begin{aligned}
& \mathrm{C}=\operatorname{rosad}(\mathrm{m}, \mathrm{m} \mathrm{s}, 3,120) \mid \\
& \quad \operatorname{genid}(\mathrm{n}, \mathrm{n}, 2,3 \mathrm{~s}, 1,-1) \mid\{[0,0,1],[1, \mathrm{~s}, 0]\} \\
& \text { TRIANA }=\operatorname{lux}(\mathrm{C}) \mid \text { TRIAN }
\end{aligned}
$$

where TRIAN is the formex variable representing the configuration of the double layer grid of Fig 1.7.6, as formulated above.

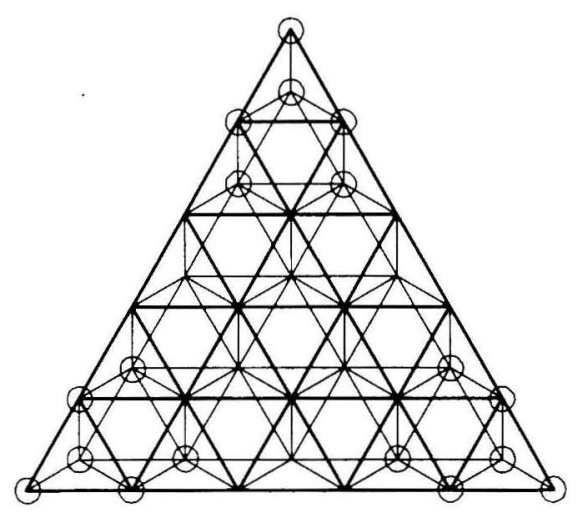

Fig 1.7.7 Positions for removal of elements for $m=5$ and $n=2$

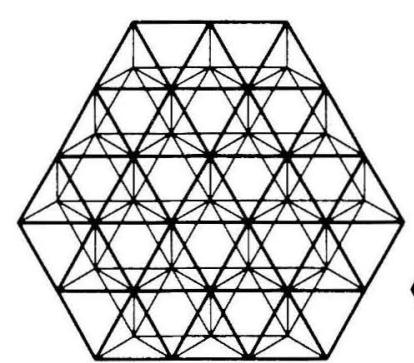

$\mathrm{m}=7, \mathrm{n}=2$

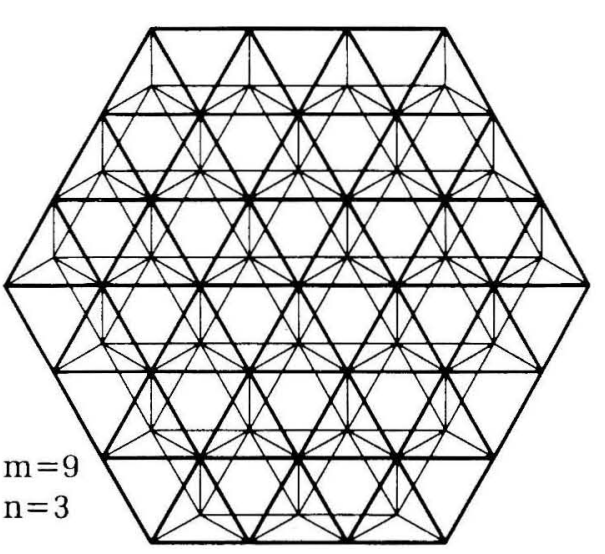

Fig 1.7.8 Three examples of corner curtailment

The formex variable $\mathrm{C}$ represents the points for the removal of elements, where

- $\mathrm{m}$ represents the number of tetrahedral units along each side of the grid of Fig 1.7.6,

- $\mathrm{n}$ indicates the extent of corner curtailment and

- $\mathrm{s}=\sqrt{3} / 3$. 
For instance, for $\mathrm{m}=5$ and $\mathrm{n}=2$, the points represented by the formex variable $\mathrm{C}$ are indicated by little circles in Fig 1.7.7.

The above generic formulation can be used to represent a variety of different double layer grids with a pattern similar to that in Fig 1.7.6 and with corner curtailment. Three such examples are shown in Fig 1.7.8 with the corresponding values of $\mathrm{m}$ and $\mathrm{n}$ shown for each case.

Consider again the formex equation

$$
\begin{aligned}
\mathrm{C}= & \operatorname{rosad}(\mathrm{m}, \mathrm{m} \mathrm{s}, 3,120) \mid \\
& \operatorname{genid}(\mathrm{n}, \mathrm{n}, 2,3 \mathrm{~s}, 1,-1) \mid\{[0,0,1],[1, \mathrm{~s}, 0]\}
\end{aligned}
$$

which is a part of the above generic formulation. In 'tracing' the effects of a formex equation such as this, one would normally work from right to left. Thus, one would first identify the points represented by

$$
\{[0,0,1],[1, \mathrm{~s}, 0]\}
$$

then, one would work out what is represented by

$$
\operatorname{genid}(\mathrm{n}, \mathrm{n}, 2,3 \mathrm{~s}, 1,-1) \mid\{[0,0,1],[1, \mathrm{~s}, 0]\}
$$

and finally, one would find out the effects of

$$
\begin{aligned}
& \operatorname{rosad}(\mathrm{m}, \mathrm{m} \mathrm{s}, 3,120) \mid \\
& \operatorname{genid}(\mathrm{n}, \mathrm{n}, 2,3 \mathrm{~s}, 1,-1) \mid\{[0,0,1],[1, \mathrm{~s}, 0]\}
\end{aligned}
$$

An example of such a tracing process is shown in Fig 1.4.8.

Double layer grids are one of the most popular forms of space structures and there are many impressive double layer grids built all over the world. The examples of double layer grids considered in this section cover a few basic forms. However, there are many other patterns that are commonly used for double layer grids in practice.

\subsubsection{Perspective views}

To acquire a 'feel' for the overall visual effect of a space structure configuration, it is often required to produce one or more perspective views of the configuration, as exemplified in Figs 1.7.1, 1.7.4 and 1.7.5. The manner in which perspective views are created in Formian is described in this section, using double layer grids as examples.

The notion of a perspective view in Formian is explained using the double layer grid of Fig 1.7.1. This grid, together with the global $x-y-z$ coordinate system, is shown in Fig 1.7.9.

The required perspective view is specified in terms of a 'view helm'. To elaborate, it is 'imagined' that the grid is viewed from a point that is referred to as the 'view point'. The line of vision is 'imagined' to be directed from the view point towards a point that is referred to as the 'view centre'. A 'vector' is 'imagined' to emanate from the view centre. This vector is referred to as the 'view rise' and its role is to specify the direction that is to become the 'vertical direction' in the required perspective view. The 'broken vector' that is shown by thick line in Fig 1.7.9 is referred to as the 'view helm'. The view helm consists of the line from the view point to the view centre and the view rise.

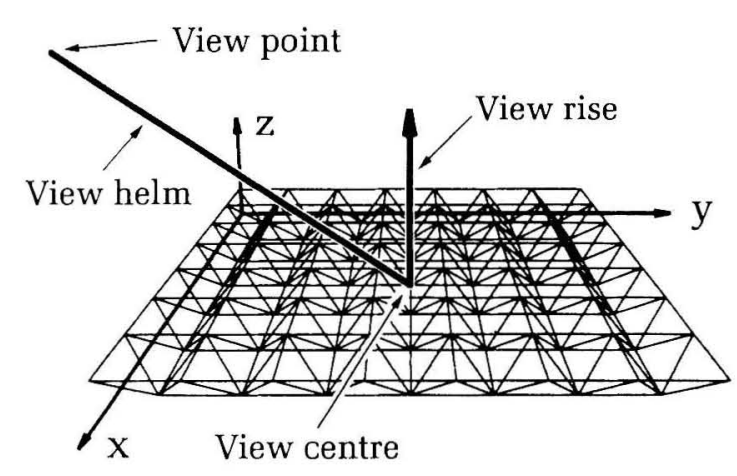

Fig 1.7.9 View helm

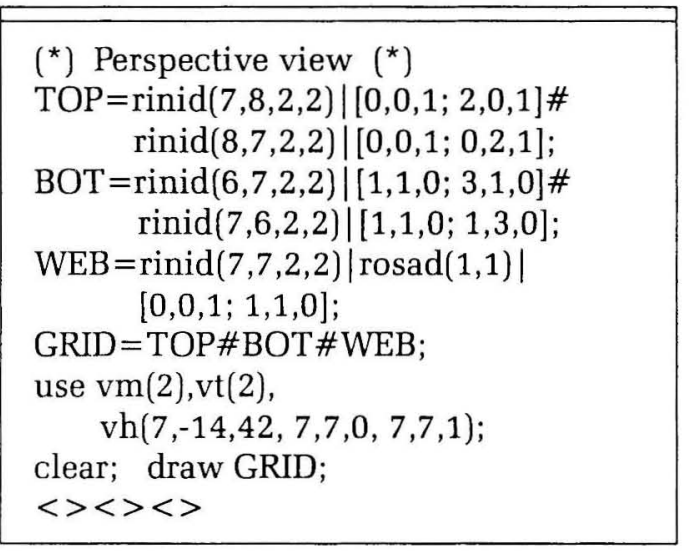

Fig 1.7.10 A scheme for obtaining a perspective view

A view helm is specified through a use-item. An example of such a use-item is given in the scheme in the editory display of Fig 1.7.10. The execution of this scheme will produce a perspective view similar to the one shown in Fig 1.7.1.

The assignment statements in the scheme of Fig 1.7.10 follow the formulation of the double layer grid of Fig 1.7.1 (1.7.2) as given in section 1.7.

The 'use statement' in the scheme of Fig 1.7.10, that is,

$$
\text { use vm(2),vt(2), } \dot{v}(7,-14,42,7,7,0,7,7,1) \text {; }
$$


contains three use-items. The first use-item, that is, $\operatorname{vm}(2)$, has the effect of putting the system in the 'automatic scaling mode', as discussed in section 1.5.2.

The second use-item, that is, $\mathrm{vt}(2)$ indicates that a 'perspective view' is required. The term ' $\mathrm{vt}$ ' is an abbreviation for 'view type'. The number in parentheses following ' $v t$ ' can be either 1 or 2 . The use-item vt(1) causes the view to be 'isometric' and the use-item vt(2) causes the view to be 'perspective'. The default setting for the view type use-item is vt(1).

The third use-item is

$$
\operatorname{vh}(7,-14,42,7,7,0,7,7,1)
$$

where 'vh' is an abbreviation for 'view helm'. The details of this use-item are described in Fig 1.7.11.

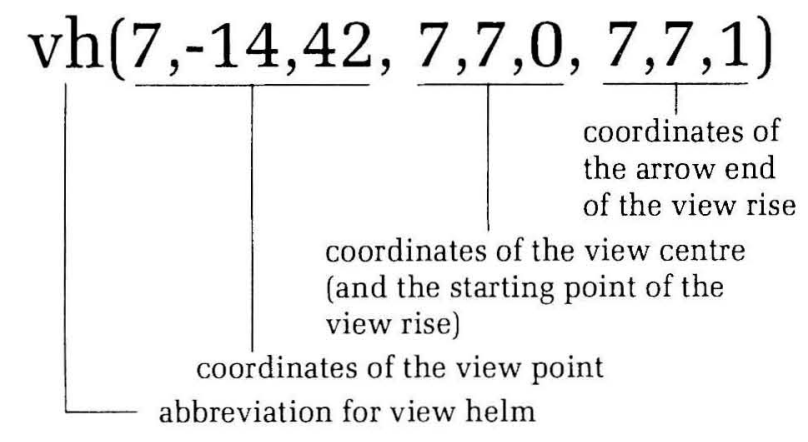

Fig 1.7.11 View helm use-item

The view helm use-item specifies

- the point from which the 'object' is viewed (that is, the view point),

- the point towards which the line of vision is directed (that is, the view centre),

- the direction that is to become the vertical direction (that is, the direction of the view rise) and

- the 'up' and 'down', with the view rise regarded as pointing 'upwards'.

An important point that needs explanation concerns the coordinate system with respect to which the view helm is to be specified. To elaborate, the coordinates of the view helm should be given relative to the coordinate system in terms of which the configuration to be viewed is given. In the present example, the formex variable GRID that represents the configuration to be viewed is relative to the U1U2-U3 normat of Fig 1.7.2. Therefore, the coordinates of the view helm in the scheme of Fig 1.7.10 are given relative to this normat.
The coordinates of a view helm must always be relative to a Cartesian-type reference system. This may be the global $x-y-z$ coordinate system or a normat such as U1-U2-U3 in Fig 1.7.2. The term 'Cartesian-type reference system' implies a reference system that has orthogonal linear axes. Thus, a curvilinear reference system is not of a Cartesiantype. The term 'curvilinear reference system' is used to imply a reference system that involves one or more curved axes (surfaces). Examples of such a system are cylindrical and spherical coordinate systems.

A minor point to be noticed in Fig 1.7.11, and elsewhere in the paper, is that the coordinates in the view helm use-items are grouped together with spaces in between. This is a useful convention that helps to separate groups of related items and is used in the specification of view helms and other entities.

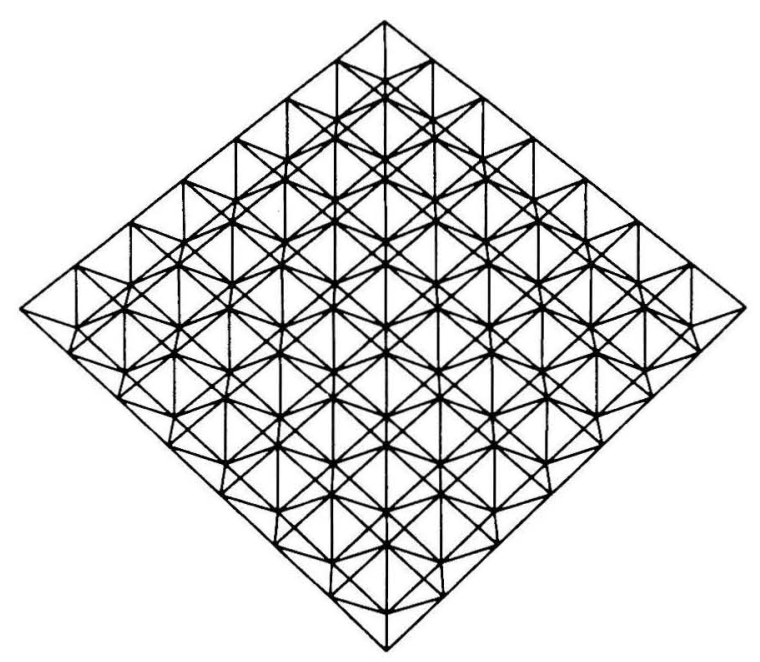

Fig 1.7.12 A perspective view with $\operatorname{vh}(-15,-15,50,7,7,0,7,7,1)$

To further exemplify the effects of the view helm, another two perspective views of the double layer grid of Fig 1.7.1 are shown in Figs 1.7.12 and 1.7.13. The view helm used for Fig 1.7.12 is

$$
\operatorname{vh}(-15,-15,50,7,7,0,7,7,1)
$$

and the view helm for Fig 1.7.13 is

$$
\operatorname{vh}(7,-10,-10,7,7,0,7,7,1)
$$

The default setting for the view helm use-item is

$$
\operatorname{vh}(0,0,1 \mathrm{E} 4,0,0,0,0,1,0)
$$

That is,

- the view point is high up on the positive side of the third axis (z-axis),

- the view centre is at the origin of the coordinate system and 
- the view rise is along the positive direction of the second axis (y-axis).

The default setting of the view helm will normally give rise to the plan view of an object.

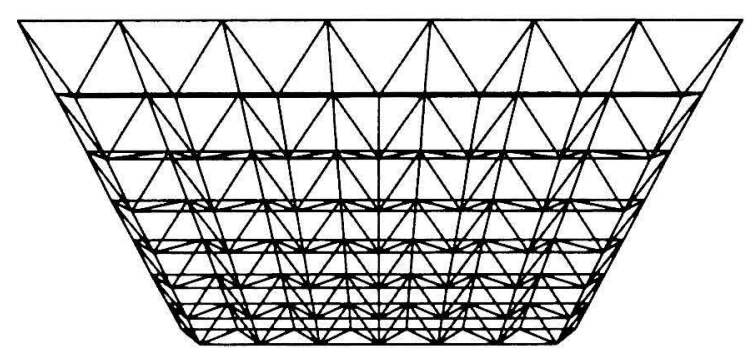

Fig 1.7.13 A perspective view with $\operatorname{vh}(7,-10,-10,7,7,0,7,7,1)$

It is not always easy to produce a good perspective view of an object and it is normal to try a number of different view helms until a satisfactory view is found.

To obtain a general view of an object, it is not always necessary to work in the 'perspective mode', that is, under the currency of the use-item vt(2). One can also obtain an 'isometric' view of an object, under the currency of vt(1), using a view helm useitem in the usual manner. A perspective view is closer to a human view of an object, as compared with an isometric view. Nevertheless, isometric views could also be quite effective and, for some purposes, they may be more appropriate than perspective views.

\subsubsection{Line Width, Style and Colour}

A feature of the examples considered in section 1.7 is the use of different line thicknesses in the plots of double layer grids for 'layer identification'. The manner in which line thicknesses may be specified in Formian is exemplified in terms of a double layer grid in the scheme shown in the editory display of Fig 1.7.14.

The assignment statements in the scheme of Fig 1.7.14 are based on the generic formulation for the triangular double layer grid of Fig 1.7.6, as given in section 1.7. The assignment statements are followed by a use statement that includes the use-item

$$
\operatorname{lw}(0.6)
$$

This is a 'line width' use-item, where 'lw' stands for 'line width' and the number in parentheses specifies the required line width in millimetres. The effect of the use-item is to change the 'current setting' for the line width to 0.6 . As a result, every line that is drawn will have a thickness of $0.6 \mathrm{~mm}$, until the setting for the line width is changed. The default setting for the line width use-item is $l w(0.3)$.

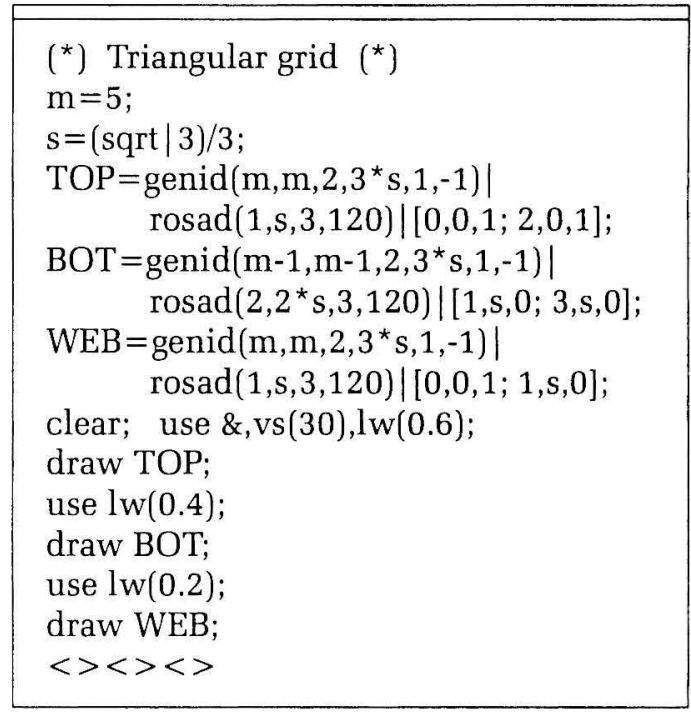

Fig 1.7.14 Line width specification

Returning to the scheme of Fig 1.7.14, the first use statement is followed by a draw statement for plotting the top layer elements. These elements will then be drawn with lines that are $0.6 \mathrm{~mm}$ thick.

The next statement in the scheme is a use statement that changes the current setting of line width to 0.4 . This is followed by a draw statement for plotting the bottom layer elements, which will be drawn with a line width of $0.4 \mathrm{~mm}$. The following two statements repeat the process for plotting the web elements using a line width of $0.2 \mathrm{~mm}$. The plotting results are shown in the duet of Fig 1.7.15.

\begin{tabular}{|c|c|}
\hline Editory Current file: work & Drawpad \\
\hline 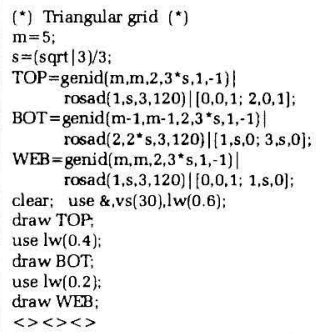 & \\
\hline
\end{tabular}

Fig 1.7.15 Line width variation

Specification of different 'line styles' is achieved using the same approach as described for the line width. The use-item for 'line style' is of the form

$\operatorname{ls}(\mathrm{n})$ 
The term 'ls' stands for 'line style' and $\mathrm{n}$ is a 'code number' indicating a style of line, where

- $\mathrm{n}=1$ indicates 'full line',

- $\mathrm{n}=2$ indicates 'dashed line' and

- $\mathrm{n}=3$ indicates 'dotted line'.

The default setting for the line style use-item is ls(1).

An effective way of 'distinguishing' between different parts of a configuration is to use colour. The approach in the scheme of Fig 1.7.14 for specifying line width is also used for specifying line colour. The 'colour' use-item is of the form

$$
c(1, n)
$$

where ' $c$ ' stands for 'colour' and where the first parameter which is given as 1 indicates that the specification is for a line.

The second parameter of the colour use-item (that is, 7) is a 'code number' for colour. There are fifty vailable colours as listed in the 'palette' (colour able). The palette may be displayed by clicking the palette tool button' which has a 'coloured window' ppearing on it. A sketch of the palette is shown in ig 1.7.16.

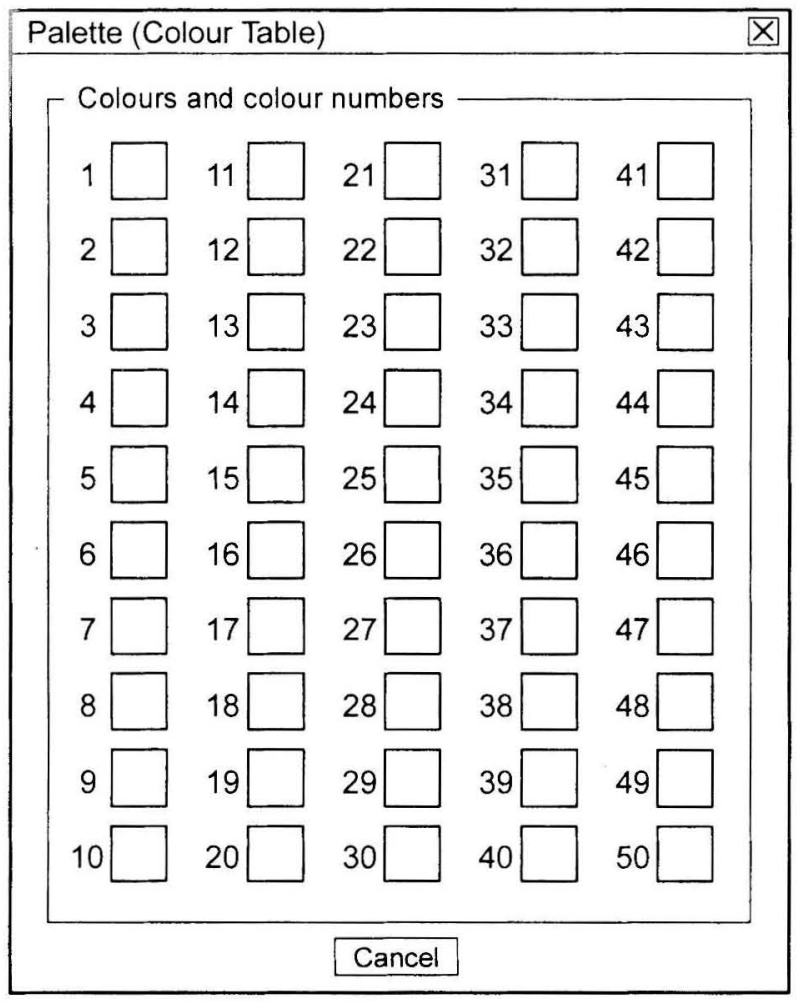

Fig 1.7.16 Palette (colour table)

Colour samples in little squares are displayed on the palette with the 'code number' for each colour appearing next to it. The first column on the palette displays the 'grey band' starting with black (colour code 1) at the top and going down to white (colour code 10) with eight shades of grey in between. The second column on the palette displays the 'red band' starting with dark red (colour code 11) at the top, followed by lighter sheds of red and with some colours in the brown and yellow ranges further down. The third, fourth and fifth columns on the palette display the 'purple band', 'green band' and 'blue band', respectively. The default setting for the line colour use-item is $c(1,23)$.

In general, when different sections of a configuration are to be plotted separately with different line thicknesses, styles and/or colours, then the system should not be in the 'automatic scaling mode'. Otherwise, each section will be scaled independently to fit the drawpad and consequently, the plots of different sections will not necessarily 'fit together' properly.

It is for this reason that the drawing of different parts, represented by formex variables TOP, BOT and WEB, in the scheme of Fig 1.7.14 is carried out with a non-automatic scaling mode.

However, the fact that the drawing operations in the scheme of Fig 1.7.14 are effected under the nonautomatic mode, that is under the currency of $\mathrm{vm}(1)$, is not immediately obvious. To elaborate, the use statement in the scheme of Fig 1.7.14 is of the form

$$
\text { use } \&, v s(30), \operatorname{lw}(0.6) \text {; }
$$

The second and third use-items here are, a view scale use-item and a line width use-item, respectively. The effects of these use-items have been explained before. However, the symbol \& that appears as the first item in the above use statement has not been discussed yet. As an item in a use statement, the symbol \& is referred to as the 'ampersand use-item' and has the effect of making the default settings of all the use-items current.

Returning to the use statement in the scheme of Fig 1.7.14, since non-automatic scaling is the default for the view mode, the effect of the ampersand use-item is to put the system in the non-automatic mode and this is the mode in which the drawing of TOP, BOT and WEB are produced.

\subsection{BARREL VAULTS}

Consider the configuration shown in Fig 1.8.1. This is a 'curved grid' with a cylindrical form. The structure consists of 178 'straight' beam elements that are connected together at 99 nodes. The nodes lie on the surface of a circular cylinder. The 'span' of the structure is $28.75 \mathrm{~m}$, the 'rise' (that is, the height 
at the centre) is $5.45 \mathrm{~m}$ and the 'length' is $39.50 \mathrm{~m}$. This is an example of a structural form that is referred to as a 'barrel vault', where the circular cylindrical surface that contains all the nodal points is referred to as the 'circumcylinder' of the barrel vault.

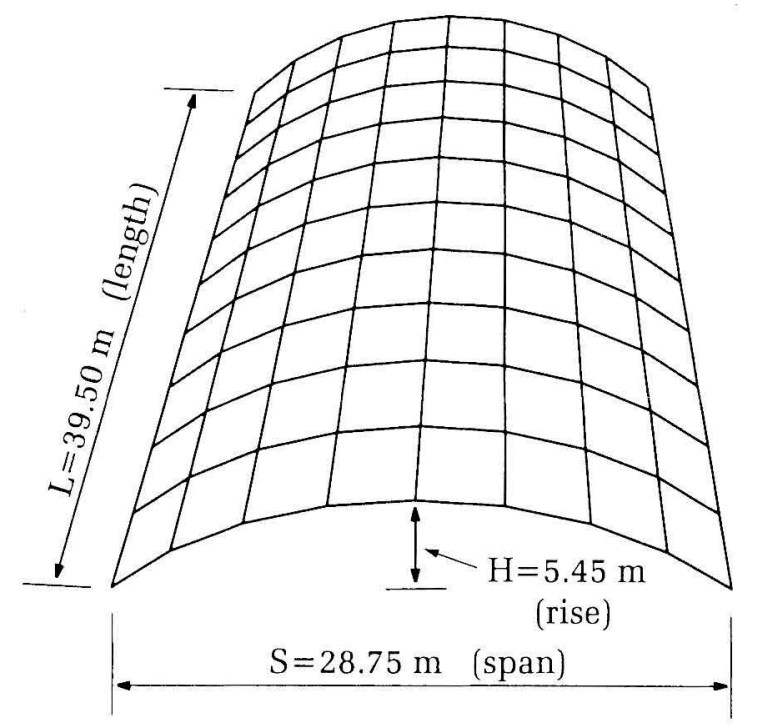

Fig 1.8.1 A barrel vault

A convenient reference system for the formulation of the configuration of the barrel vault of Fig 1.8.1 is a 'cylindrical normat', as shown in Fig 1.8.2. In this figure, the barrel vault is shown with its nodes lying on the circumcylinder. The 'origin' of the normat is at the centre of a cross-section of the circumcylinder. The first direction of the normat is along a 'radius' of the cross-section. The second direction of the normat is along the 'circumference' of the crosssection. The third direction of the normat is along the 'longitudinal axis' of the circumcylinder. The first and third directions of the normat are 'linear' and the second direction is 'angular'.

The Cartesian coordinate system corresponding to the normat is also shown in Fig 1.8.2. The $\mathrm{x}$-axis is collinear with the U1-axis and the $\mathrm{z}$-axis is collinear with the U3-axis. The $y$-axis lies in the cross-section of the circumcylinder and is perpendicular to the $x$ axis.

A corner of the barrel vault, together with the normat, is shown in Fig 1.8.3. In this normat, the length of the radius of the cross-section of the circumcylinder is chosen to be 1 and the divisions along the second and third directions are chosen to suit the positions of the nodal points of the barrel vault.

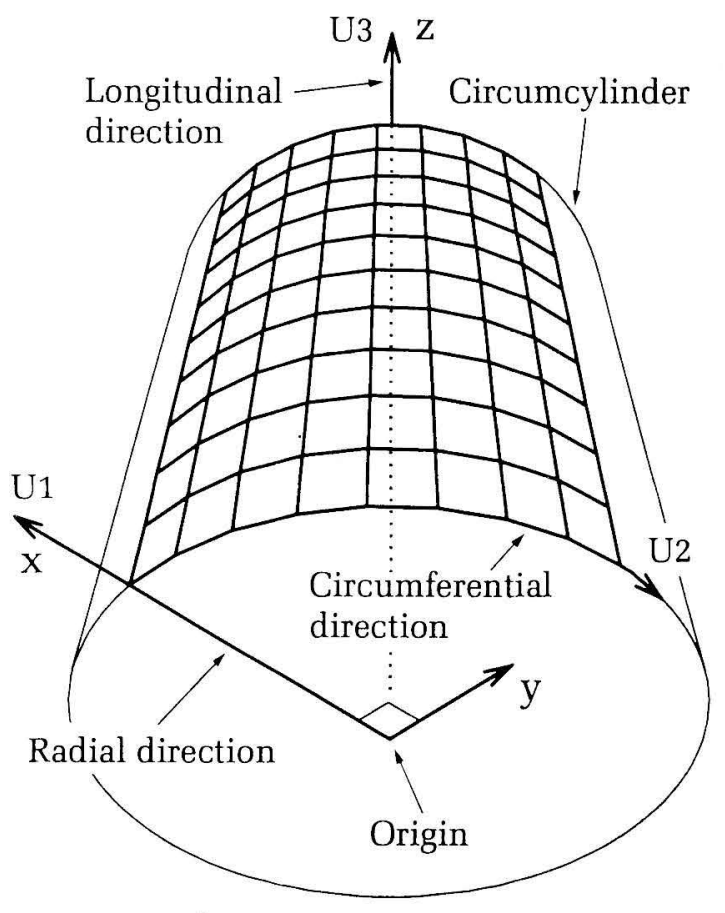

Fig 1.8.2 Cylindrical normat

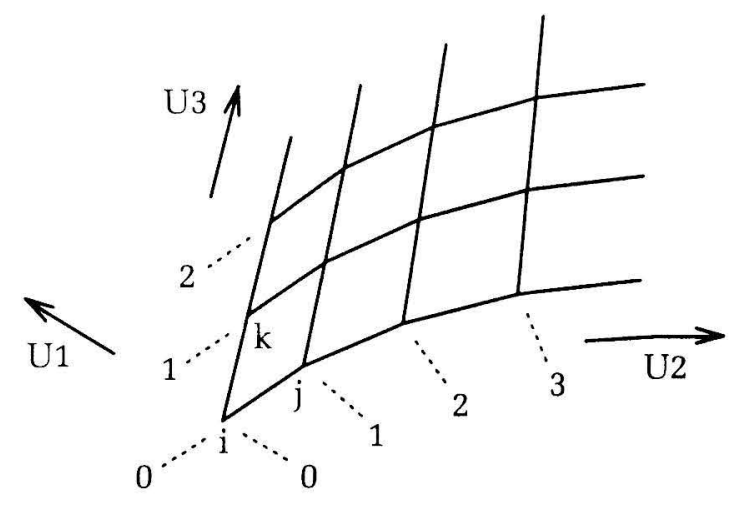

Fig 1.8.3 Corner of barrel vault of Fig 1.8.1

All the normats considered so far were of Cartesiantype (except for the polar normat discussed in section 1.4.4). However, curvilinear normats are of frequent use in formex configuration processing and the cylindrical normat is one of the commonly used curvilinear normats.

Now, focusing on the formulation of the configuration of the barrel vault of Fig 1.8.1, the compret of the configuration relative to the normat of Fig 1.8.3 may be represented by

$$
\begin{gathered}
\mathrm{E}=\operatorname{rinit}(8,11,1,1) \mid[1,0,0 ; 1,1,0] \# \\
\quad \operatorname{rinit}(9,10,1,1) \mid[1,0,0 ; 1,0,1]
\end{gathered}
$$

In this formulation

- $[1,0,0 ; 1,1,0]$ represents the element indicated by 'ij' in Fig 1.8.3, 
- $\operatorname{rinit}(8,11,1,1) \mid[1,0,0 ; 1,1,0]$ represents all the elements that are in the circumferential direction (second direction),

- $[1,0,0 ; 1,0,1]$ represents the element indicted by 'ik' in Fig 1.8.3 and

- $\operatorname{rinit}(9,10,1,1) \mid[1,0,0 ; 1,0,1]$ represents all the elements that are in the longitudinal direction (third direction).

In the above formulation, the first uniples of all the signets are equal to 1 . This is a consequence of the fact that the length of the radius of the cross-section of the circumcylinder is chosen to be 1 .

The functions

$$
\text { and } \operatorname{rinit}(8,11,1,1)
$$

in the above formulation are analogous to the 'rinid' function with the suffix 'id' replaced by 'it'. The suffix 'it' implies a double action in directions 2 and 3 (whereas, the suffix 'id' implies a double action in directions 1 and 2).

The function

$$
\text { rinit }(8,11,1,1)
$$

implies 8 translational replications in the second direction with steps of 1 followed by 11 translational replications in the third direction with steps of 1 , as shown in Fig 1.8.4.

$$
\operatorname{rinit}(8,11,1,1)
$$

Fig 1.8.4 Rinit function

All the functions with 'id' suffix have their equivalent 'it' versions, as will be seen in various examples henceforth.

The formex variable $\mathrm{E}$ in the above formulation represents the configuration of the barrel vault of Fig 1.8.1 relative to the normat of Fig 1.8.3. A formex representing the configuration relative to the $x-y-z$ coordinate system of Fig 1.8.2 may be written as

$$
\mathrm{F}=\mathrm{bc}(\mathrm{R}, \mathrm{A} / 4, \mathrm{~L} / 10) \mid \mathrm{E}
$$

where

- $\mathrm{R}$ is the radius of the cross-section of the circumcylinder, as shown in Fig 1.8.5,

- A is the 'sweep angle' of the barrel vault, that is, half the central angle of the barrel vault, as shown in Fig 1.8.5 and

- $\mathrm{L}$ is the length of the barrel vault, as shown in Fig 1.8.1.

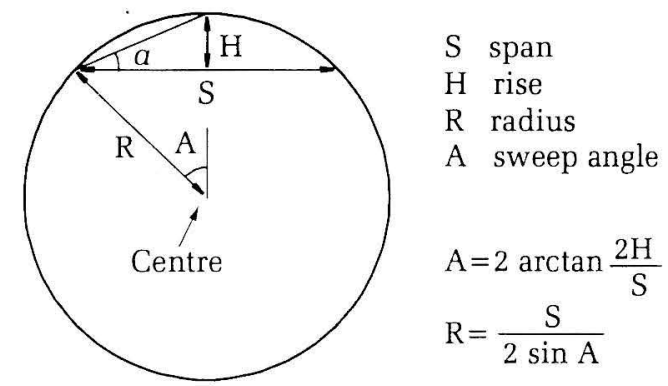

Fig 1.8.5 Cross-section of circumcylinder

The construct

$$
\mathrm{bc}(\mathrm{R}, \mathrm{A} / 4, \mathrm{~L} / 10)
$$

is a 'basicylindrical retronorm' that transforms the cylindrical normat coordinates into Cartesian coordinates. The general form of this function is shown in Fig 1.8.6.

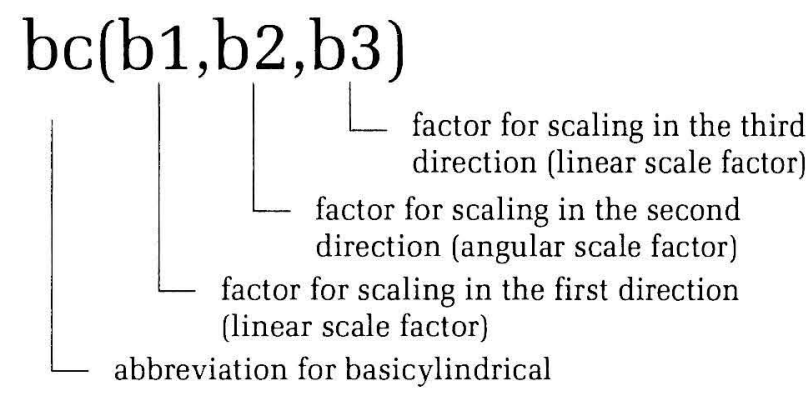

Fig 1.8.6 Basicylindrical retronorm

The first parameter of the basicylindrical retronorm is a 'linear' scale factor for scaling of the normat coordinates in the first direction. This scale factor, in the present example, should be $\mathrm{R}$ since the length of the radius of the circumcylinder in the normat was taken as 1. The second parameter of the basicylindrical retronorm is an 'angular' scale factor for scaling in the second direction. This parameter specifies the angle (in degrees) for every division along the second direction. The third parameter of the basicylindrical retronorm is a 'linear' scale factor for scaling in the third direction. The first and third parameters of the basicylindrical retronorm should 
be in a 'length unit' such as metre or millimetre, as appropriate.

The values of $\mathrm{R}, \mathrm{A}$ and $\mathrm{L}$ in

$$
\mathrm{bc}(\mathrm{R}, \mathrm{A} / 4, \mathrm{~L} / 10)
$$

may be obtained from the information given in Fig 1.8.1. The length $\mathrm{L}$ of the barrel vault is given directly in Fig 1.8.1 and the values of A and R may be obtained in terms of the span $\mathrm{S}$ and rise $\mathrm{H}$ of the barrel vault, as follows:

It may be seen form Fig 1.8.5 that

$\tan a=2 \mathrm{H} / \mathrm{S}$,

$$
\mathrm{A}=2 a
$$

and

$$
\sin \mathrm{A}=\mathrm{S} / 2 \mathrm{R}
$$

Therefore

and

$$
\mathrm{A}=2 \arctan 2 \mathrm{H} / \mathrm{S}
$$

$$
\mathrm{R}=\mathrm{S} /(2 \sin \mathrm{A})
$$

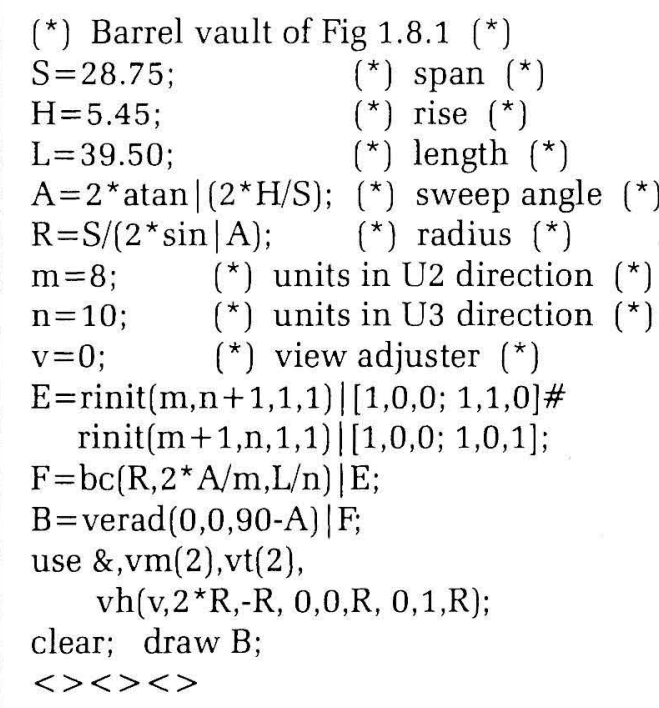

Fig 1.8.7 A generic scheme for barrel vault of Fig 1.8.1

A Formian scheme for the barrel vault of Fig 1.8.1 is shown in the editory display of Fig 1.8.7. This scheme has a generic form. That is, it is written in terms of a number of parameters. These parameters are:

- $\operatorname{span} \mathrm{S}$

- rise $\mathrm{H}$,

- length $\mathrm{L}$,

- number of units in the second direction, denoted by $m$,
- number of units in the third direction, denoted by $n$ and

- a parameter ' $v$ ' that is referred to as the 'view adjuster' and will be discussed later.

In the scheme of Fig 1.8.7, the formex variable $F$ represents the configuration of the barrel vault of Fig 1.8.1 relative to the $\mathrm{x}-\mathrm{y}-\mathrm{z}$ coordinate system of Fig 1.8.2, as discussed before.

In Fig 1.8.7, the assignment statement

$$
\mathrm{B}=\operatorname{verad}(0,0,90-\mathrm{A}) \mid \mathrm{F} \text {; }
$$

effects a rotation of the configuration in the $x-y$ plane. This rotation will place the configuration in a convenient position relative to the $x-y-z$ coordinate system, where the $\mathrm{x}$-axis is horizontal and the $\mathrm{y}$-axis is vertical, as shown in Fig 1.8.8.

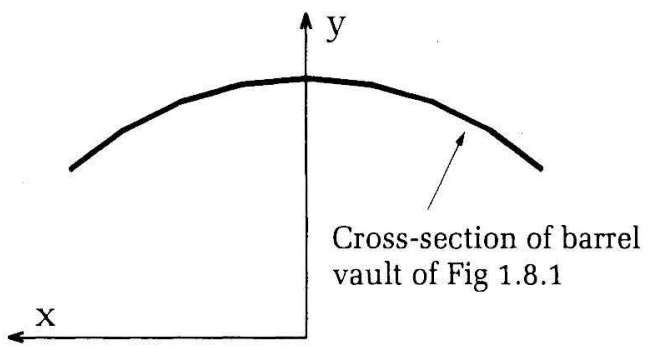

Fig 1.8.8 Rotated position of the barrel vault

When working with a cylindrical normat, a 'translation' in the second direction is equivalent to a 'rotation' in the $\mathrm{x}-\mathrm{y}$ plane. Therefore, the effect of the statement

$$
\mathrm{B}=\operatorname{verad}(0,0,90-\mathrm{A}) \mid \mathrm{F} \text {; }
$$

in the scheme of Fig 1.8.7 may also be achieved through a translation in the second direction (before the application of the basicylindrical retronorm). In this case, the statements

$$
\begin{aligned}
& \mathrm{F}=\mathrm{bc}\left(\mathrm{R}, 2^{*} \mathrm{~A} / \mathrm{m}, \mathrm{L} / \mathrm{n}\right) \mid \mathrm{E} \\
& \mathrm{B}=\operatorname{verad}(0,0,90-\mathrm{A}) \mid \mathrm{F}
\end{aligned}
$$

can be replaced by

$$
\begin{aligned}
& \mathrm{E}=\operatorname{tran}\left(2, \mathrm{~m}^{*}(90-\mathrm{A}) /(2 * \mathrm{~A})\right) \mid \mathrm{E} ; \\
& \mathrm{B}=\mathrm{bc}\left(\mathrm{R}, 2^{*} \mathrm{~A} / \mathrm{m}, \mathrm{L} / \mathrm{n}\right) \mid \mathrm{E} ;
\end{aligned}
$$

The reader may like to prove that the second parameter of the above translation function should indeed be

$$
\mathrm{m}(90-\mathrm{A}) / 2 \mathrm{~A}
$$

The setting of the view helm in the scheme of Fig 1.8.7 ensures that the $y$-axis remains vertical in all the views with the value of the 'view adjuster' $v$ determining the 'sway' of the body of the barrel 
vault. Three views of the barrel vault of Fig 1.8.1 for different values of $\mathrm{v}$ are shown in Fig 1.8.9.

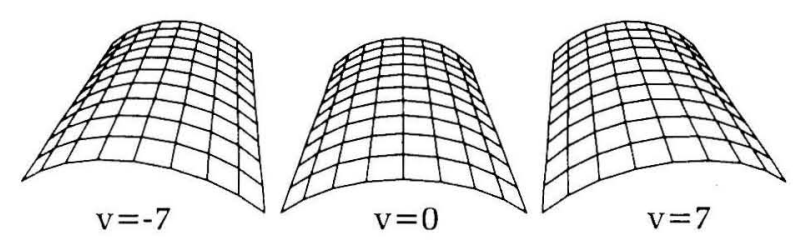

Fig 1.8.9 Effect of view adjuster

Now, suppose that the formex variable B in the scheme of Fig 1.8.7 is subjected to the transformation

$$
\mathrm{EB} 1=\mathrm{bt}(1,1.5,1) \mid \mathrm{B}
$$

where, the construct

$$
\text { bt }(1,1.5,1)
$$

is a basitrifect retronorm, as described in section 1.7. The effect of the transformation is that all the $y$ coordinates of the nodes of the barrel of Fig 1.8.1 are multiplied by 1.5 . The result is the barrel vault shown in Fig 1.8.10a. The span of this barrel vault is the same as the original barrel vault but the rise is increased by a factor of 1.5. Therefore, the crosssection of the barrel vault will assume an elliptic form. That is, the nodes of the barrel vault will lie on the surface of a cylinder with an elliptic crosssection. An ellipse that indicates the new proportions of the cross-section is shown under the barrel vault of Fig 1.8.10a.
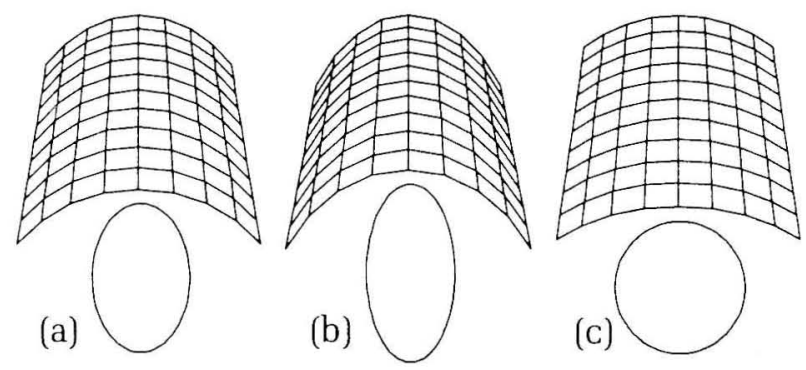

Fig 1.8.10 Elliptic barrel vaults

Another example involving the scaling of the barrel vault of Fig 1.8.1 is shown in Fig 1.8.10b. The transformation that gives rise to this configuration is given by

$$
\mathrm{EB} 2=\operatorname{bt}(1,2,1) \mid \mathrm{B}
$$

Here again the barrel vault has an elliptic form with the span being the same as the original barrel vault and the rise being increased by a factor of 2. An ellipse indicating the new proportions of the crosssection is shown under the barrel vault in Fig 1.8.10b. The configuration in Fig 1.8.10c represents the original barrel vault which is shown for comparison.

The above examples demonstrate the fact that a barrel vault configuration which is based on a circular cylinder can be easily transformed into an elliptic form. Therefore, when it is required to formulate a barrel vault configuration whose nodes lie on an elliptic cylinder, to begin with, the configuration may be formulated relative to a simple cylindrical normat. The result may then be transformed into an elliptic barrel vault.

In relation to the use of the basitrifect retronorm for obtaining the elliptic barrel vaults of Fig 1.8.10, the following points are to be noted: The basic role of a retronorm is to transform the normat coordinates into global Cartesian coordinates. However, as far as the basitrifect retronorm is concerned, it involves nothing other than simple scaling. Therefore, it may also be employed as a 'scaling function' in any formulation where simple scaling is required. An example of this type of usage is the creation of elliptic barrel vaults, as discussed above. Incidentally, to obtain the elliptic barrel vaults of Fig 1.8.10, one can also use the basibifect retronorm as a 'scaling function'. In this case, the formex variables EB1 and EB2 can be obtained as

and

$$
\mathrm{EB} 1=\mathrm{bb}(1,1.5) \mid \mathrm{B}
$$

$$
\mathrm{EB} 2=\mathrm{bb}(1,2) \mid \mathrm{B}
$$

Now, consider the configuration shown in Fig 1.8.11. This illustrates a group of four barrel vaults that are connected together along their sides. A structure of this type is referred to as a 'compound barrel vault'. The barrel vaults that constitute the compound barrel vault of Fig 1.8.11 are all identical to the barrel vault of Fig 1.8.1.

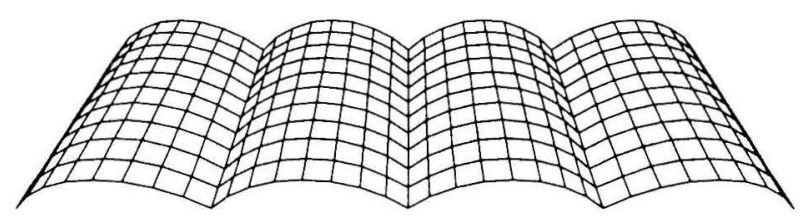

Fig 1.8.11 A compound barrel vault

A formex representing the compound barrel vault of Fig 1.8.11 may be written as

$$
\mathrm{CB}=\operatorname{pex}|\operatorname{rin}(1,4,28.75)| \mathrm{B}
$$

where $\mathrm{B}$ is the formex variable in the scheme of Fig 1.8.7 representing the barrel vault of Fig 1.8.1. The effect of the pexum function is to remove the superfluous overlapping 'valley elements'. 
Compound barrel vaults represent a popular structural form and are frequently used in practice. The individual barrel vaults that constitute a compound barrel vault need not necessarily be identical or at the same level. For instance, the structure shown in Fig 1.8.12 is a 'stepping' compound barrel vault in which the constituent barrel vaults are at different levels.

A scheme for the configuration of the stepping barrel vault of Fig 1.8.12 is shown in the editory display of Fig 1.8.13. In this scheme, the formex variable $G$ represents the part whose boundary is shown by thick lines and the formex variable $\mathrm{SB}$ represents the whole configuration. Also, the variable $\mathrm{C}$ represents the central angle of the part enclosed in thick lines and the variables $\mathrm{R}, \mathrm{D}$ and $\mathrm{T}$ represent the dimensions indicated in Fig 1.8.12.

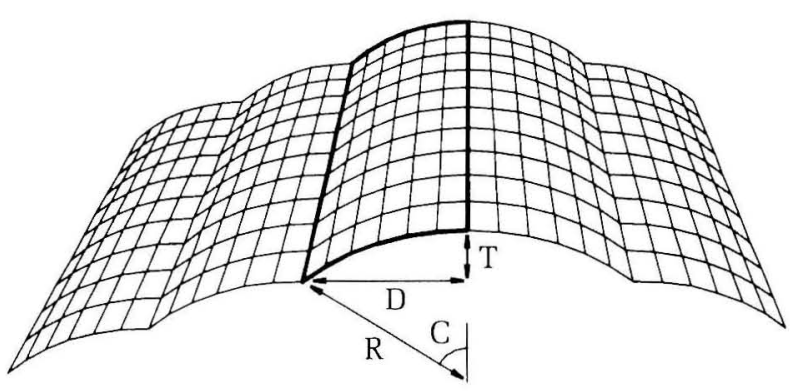

Fig 1.8.12 A stepping compound barrel vault

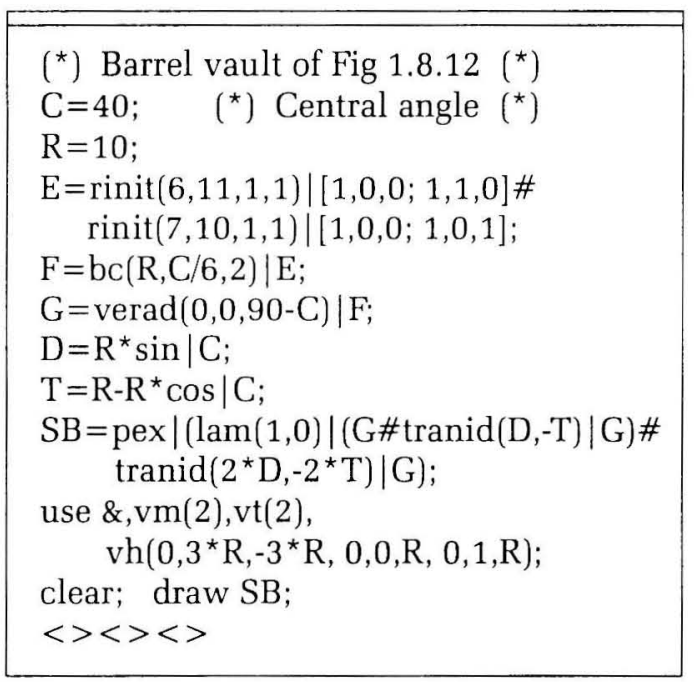

Fig 1.8.13 A scheme for the stepping barrel vault of Fig 1.8.12

The examples of barrel vaults considered so far have a 'two-way' pattern of elements. However, a barrel vault may have many other patterns. For instance, a barrel vault with a diagonal pattern is shown in Fig
1.8.14. A barrel vault with this type of pattern is referred to as a 'lamella' barrel vault.

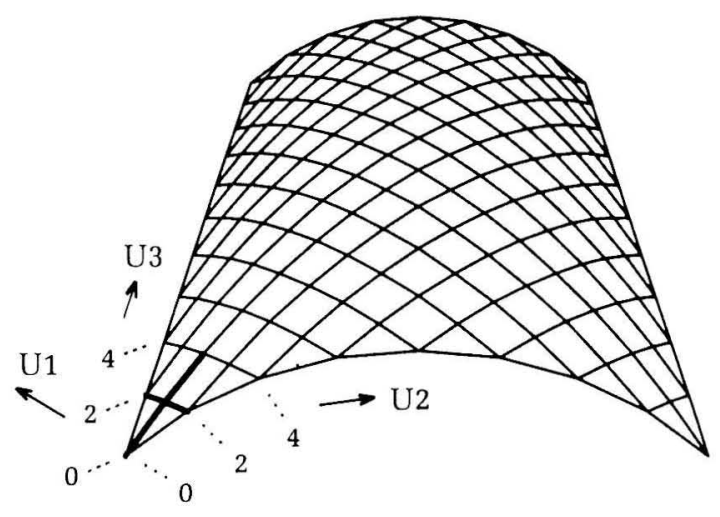

Fig 1.8.14 A lamella barrel vault

A formex variable representing the compret of the lamella barrel vault of Fig 1.8.14, relative to the indicated U1-U2-U3 cylindrical normat, may be written as

$$
\begin{aligned}
\mathrm{E}= & \operatorname{rinit}(8,10,2,2)|\operatorname{lamit}(1,1)|[1,0,0 ; 1,1,1] \# \\
& \operatorname{rinit}(8,2,2,20) \mid[1,0,0 ; 1,2,0] \# \\
& \operatorname{rinit}(2,10,16,2) \mid[1,0,0 ; 1,0,2]
\end{aligned}
$$

In this formulation,

$$
\operatorname{rinit}(8,10,2,2)|\operatorname{lamit}(1,1)|[1,0,0 ; 1,1,1]
$$

represents all the diagonal elements,

$$
\operatorname{rinit}(8,2,2,20) \mid[1,0,0 ; 1,2,0]
$$

represents the edge elements that are in the second direction, that is, in the direction of $\mathrm{U} 2$, and

$$
\operatorname{rinit}(2,10,16,2) \mid[1,0,0 ; 1,0,2]
$$

represents the edge elements that are in the third direction.

In the above formulation,

$$
\operatorname{lamit}(1,1) \mid[1,0,0 ; 1,1,1]
$$

represents the four elements that constitute the 'cross' in the front left corner of the barrel vault, shown by thick lines in Fig 1.8.14. Here, the construct

\section{$\operatorname{lamit}(1,1)$}

is a 'lamit' function. The effects of a lamit function are similar to those of a lamid function but in the second and third directions (rather than the first and second directions). To be specific, a lamit function effects a double 'lambda action' in the second and third directions.

There are many examples of actual barrel vaults that are constructed using the 'lamella' pattern. A number of other commonly used patterns for barrel vaults are 
shown in Fig 1.8.15. The formex formulations for these barrel vaults are left as exercise to be carried out by the reader.
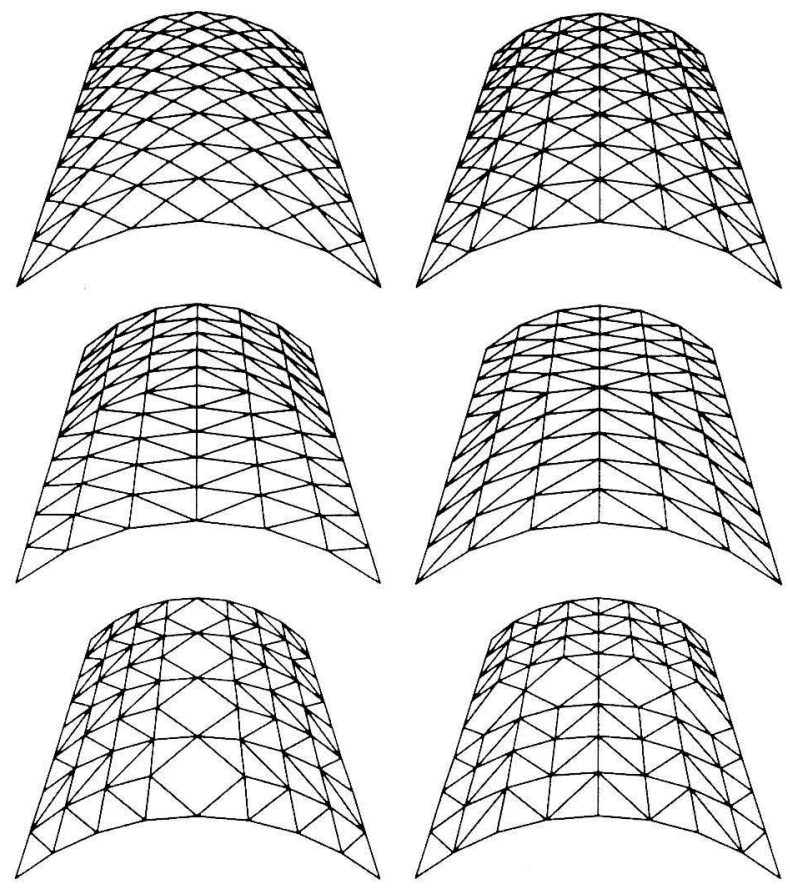

Fig 1.8.15 Some common types of barrel vault configurations

All the examples of barrel vaults considered so far have a rectangular boundary in plan. However, there are no restrictions regarding the general shape of the boundary of a barrel vault. For instance, the configuration shown in Fig 1.8.16 represents a barrel vault with a triangular boundary.

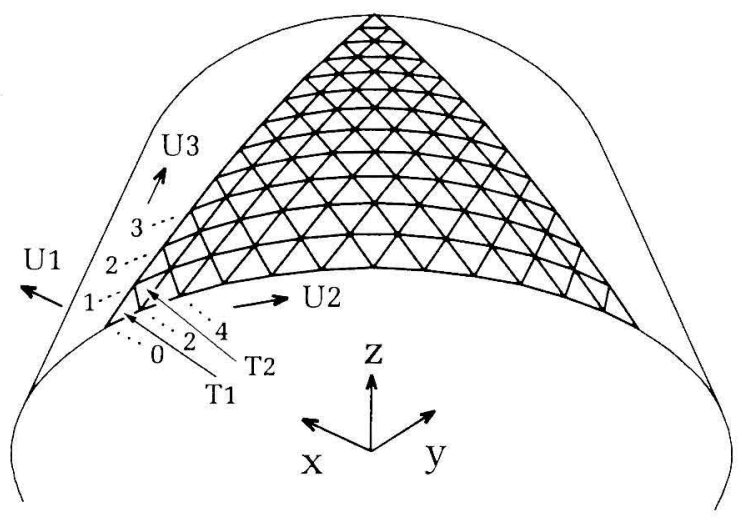

Fig 1.8.16 A finite element mesh

In addition to the shape of the boundary, the example of Fig 1.8.16 has another new feature. Namely, the configuration in Fig 1.8.16 represents a 'finite element mesh' consisting of 'triangular elements' with corner nodes. This is in contrast with all the configurations considered so far in which the elements were 'two-noded linear elements'. Therefore, unlike all the previous examples, the line segments in the configuration of Fig 1.8.16 represent the 'edges' of the triangular finite elements rather than individual line elements. The configuration of Fig 1.8.16 represents a 'cylindrically curved shell' which may alternatively be thought of as a 'continuous barrel vault'.

One may now proceed to produce a formex formulation for the finite element mesh of Fig 1.8.16. However, before attempting this, it should be made clear that the understanding of the formulation of the mesh of Fig 1.8.16 does not depend on a knowledge of the 'finite element method' of structural analysis. In this relation, all that one needs to know is that a 'finite element mesh' for a shell structure is obtained by dividing the shell into a number of 'tiles' each of which is referred to as an 'element'. Actually, subdivision of a 'surface' into an array of 'tiles' provides an effective way of graphically visualising the surface. Therefore, for a reader who is unfamiliar with the finite element method of structural analysis, the finite element mesh of Fig 1.8.16 may be simply regarded as an 'array of triangular tiles' that defines a cylindrically curved surface.

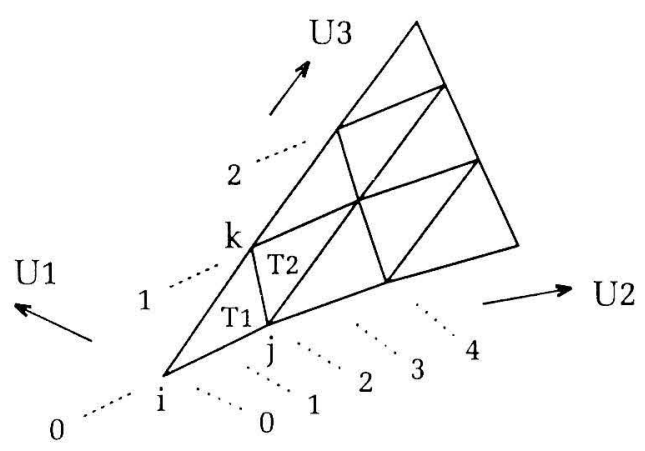

Fig 1.8.17 Corner of finite element mesh of Fig 1.8.16

A formex formulation for the finite element mesh of Fig 1.8.16 may be written as

$$
\begin{aligned}
& \mathrm{E} 1=[1,0,0 ; 1,2,0 ; 1,1,1] \\
& \mathrm{E} 2=[1,2,0 ; 1,3,1 ; 1,1,1] \\
& \mathrm{F} 1=\operatorname{genit}(12,12,2,1,1,-1) \mid \mathrm{E} 1 \\
& \mathrm{~F} 2=\operatorname{genit}(11,11,2,1,1,-1) \mid \mathrm{E} 2 \\
& \mathrm{~F}=\mathrm{F} 1 \# \mathrm{~F} 2
\end{aligned}
$$

In this formulation, the equation

$$
\mathrm{E} 1=[1,0,0 ; 1,2,0 ; 1,1,1]
$$

defines a formex variable El that represents the triangular element denoted by $\mathrm{T} 1$ in Fig 1.8.16. The 
element T1 may also be seen in Fig 1.8.17. This figure shows an enlargement of the front left corner of the mesh of Fig 1.8.16.

The cantle representing element $\mathrm{T} 1$, that is,

$$
[1,0,0 ; 1,2,0 ; 1,1,1]
$$

has three signets. The first signet, that is,

$$
1,0,0
$$

represents node i in Fig 1.8.17, where the radius in the cylindrical normat is assumed to be 1 and, therefore, the first uniple is equal to 1 . Also, the second and third signets of the above cantle represent nodes $\mathrm{j}$ and $\mathrm{k}$, respectively. Similarly, the element T2 is represented by

$$
\mathrm{E} 2=[1,2,0 ; 1,3,1 ; 1,1,1]
$$

The equation

$$
\mathrm{F} 1=\operatorname{genit}(12,12,2,1,1,-1) \mid \mathrm{E} 1
$$

in the above formulation defines a formex variable F1 that represents all the elements of the mesh of Fig 1.8.16 that are similar to T1. Also, the equation

$$
\mathrm{F} 2=\operatorname{genit}(11,11,2,1,1,-1) \mid \mathrm{E} 2
$$

defines a formex variable $\mathrm{F} 2$ that represents all the elements of the mesh that are similar to $\mathrm{T} 2$.

The constructs

and

$$
\text { genit }(12,12,2,1,1,-1)
$$

$$
\text { genit( }(11,11,2,1,1,-1)
$$

are 'genit' functions. The effects of a genit function are similar to those of a 'genid' function, as described in section 1.4.6. However, a genit function operates in the second and third directions, in contrast with the genid function that operates in the first and second directions.

The composition of formex variables F1 and F2, that is,

$$
\mathrm{F}=\mathrm{F} 1 \# \mathrm{~F} 2
$$

represents the entire mesh of Fig 1.8.16 relative to the indicated cylindrical normat. The formex variable $F$ may be transformed into a formex variable that represents the mesh of Fig 1.8.16 relative to the $x-y-z$ coordinate system using the procedure described before in relation to the barrel vault of Fig 1.8.1.

Another example of a cylindrically curved shell together with a finite element mesh is shown in Fig 1.8.18. Also, a scheme for the generation of this mesh is shown in the editory display of Fig 1.8.19. The normat used for the formulation of the mesh is the same as that shown in Fig 1.8.16.

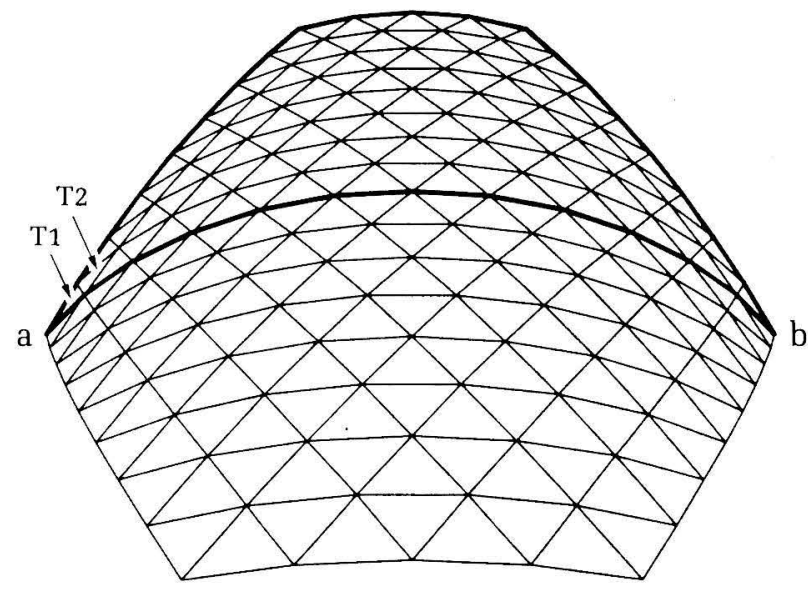

Fig 1.8.18 A finite element mesh for a cylindrically curved shell

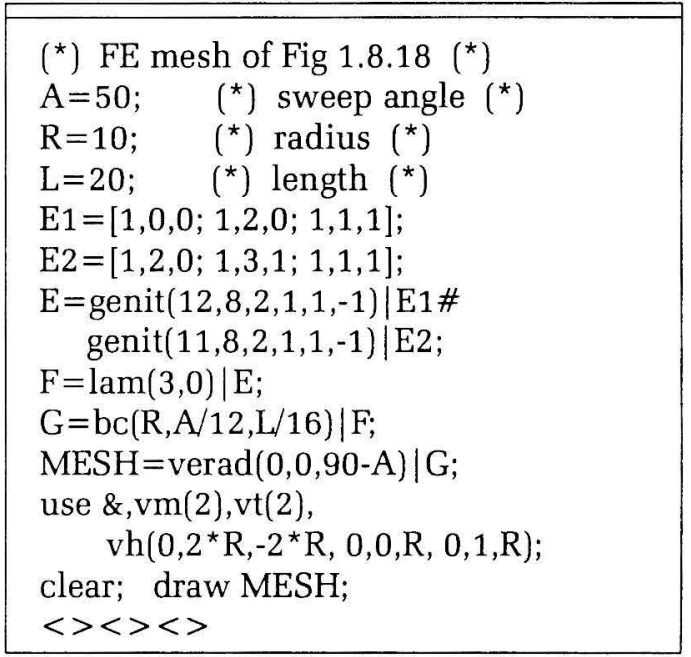

Fig 1.8.19 A scheme for finite element mesh of Fig 1.8.18

In the scheme of Fig 1.8.19,

- E1 represents the triangular element T1 in Fig 1.8.18,

- E2 represents the triangular element T2 in Fig 1.8.18,

- E represents the trapezoidal part whose boundary is shown by thick lines in Fig 1.8.18 and

- F represents the entire mesh relative to the U1U2-U3 normat (shown in Fig 1.8.16).

The formex variable $F$ is obtained from $E$ through a lambda function with the plane of reflection intersecting the circumcylinder along the curve indicated by ' $a b$ ' in Fig 1.8.18. Thus, the mesh is obtained by putting together two trapezoidal parts along the curve $a b$. However, this does not give rise to any 'overlapping' along the curve ab. The edges of the elements on the two sides of the curve $a b$ are 
'touching' each other but no part of any element 'overlaps' any other element.

The formex variable $\mathrm{G}$, in the scheme of Fig 1.8.19, represents the mesh of Fig 1.8.18 relative to the global $x-y-z$ coordinate system (shown in Fig 1.8.16). The basicylindrical retronorm used is

$$
\mathrm{bc}(\mathrm{R}, \mathrm{A} / 12, \mathrm{~L} / 16)
$$

where, $\mathrm{R}$ is the radius of the circumcylinder, $\mathrm{A}$ is the sweep angle of the mesh and $\mathrm{L}$ is the length of the mesh in the $\mathrm{z}$-direction.

The statement

$$
\text { MESH }=\operatorname{verad}(0,0,90-\mathrm{A}) \mid \mathrm{G} \text {; }
$$

in the scheme of Fig 1.8.19 creates a formex variable MESH. This represents a 'rotated' version of the mesh with the $y$-axis assuming a vertical position, as discussed before.

After the execution of the scheme of Fig 1.8.19, one may want to check the properties of the variables created by the scheme. This may be done by displaying the 'variables box', as explained in section 1.5.6. In the present example, the variables

\begin{tabular}{|c|c|c|c|c|c|}
\hline \multicolumn{6}{|c|}{ Variables } \\
\hline Variable & Type & Order & Plexitude & Grade & Size \\
\hline a & INT & & & & $4 b$ \\
\hline e & INT FMX & 128 & 3 & 3 & $4.6 \mathrm{~kb}$ \\
\hline e1 & INT FMX & 1 & 3 & 3 & $36 b$ \\
\hline $\mathrm{e} 2$ & INT FMX & 1 & 3 & 3 & $36 b$ \\
\hline$f$ & INT FMX & 256 & 3 & 3 & $9.2 \mathrm{~kb}$ \\
\hline$g$ & FLT FMX & 256 & 3 & 3 & $9.2 \mathrm{~kb}$ \\
\hline I & INT & & & & $4 b$ \\
\hline mesh & FLT FMX & 256 & 3 & 3 & $9.2 \mathrm{~kb}$ \\
\hline$r$ & INT & & & & $4 b$ \\
\hline \multicolumn{6}{|c|}{$\overline{\text { Cancel }}$} \\
\hline
\end{tabular}
box will be as shown in Fig 1.8.20.

Fig 1.8.20 Variables box after the execution of the scheme of Fig 1.8.19

Focusing on variables $\mathrm{F}, \mathrm{G}$ and $\mathrm{MESH}$, the following points may be noted:

- The 'type' of F is given as INT FMX (integer formex) and the type of G and MESH is given as FLT FMX (floatal formex). This is a reflection of the fact that $\mathrm{F}$ is relative to the cylindrical normat U1-U2-U3 with integer coordinates whereas $\mathrm{G}$ and MESH are relative to the global $x-y-z$ coordinate system with noninteger coordinates.

- The 'order' of F, G and MESH is given as 256. This indicates that the formex represented by each of these variables has 256 cantles, where each cantle represents an element of the mesh. Thus, the mesh has 256 elements.

- The 'plexitude' of F, G and MESH is given as 3 . This shows that each cantle in the formices represented by F, G and MESH has three signets. This is a reflection of the fact that, in the present example, each cantle represents a 'three-noded' finite element (triangular tile).

- The 'grade' of F, G and MESH is given as 3 . This indicates that each signet in the formices represented by $\mathrm{F}, \mathrm{G}$ and $\mathrm{MESH}$ has three uniples. This is a consequence of the fact that the cylindrical normat used has 'three directions' and the Cartesian coordinate system used has 'three dimensions'.

All the barrel vaults considered so far consisted of a single layer of elements. However, in practice, many barrel vaults are constructed with elements arranged in two or more layers. For example, consider the barrel vault shown in Fig 1.8.21.

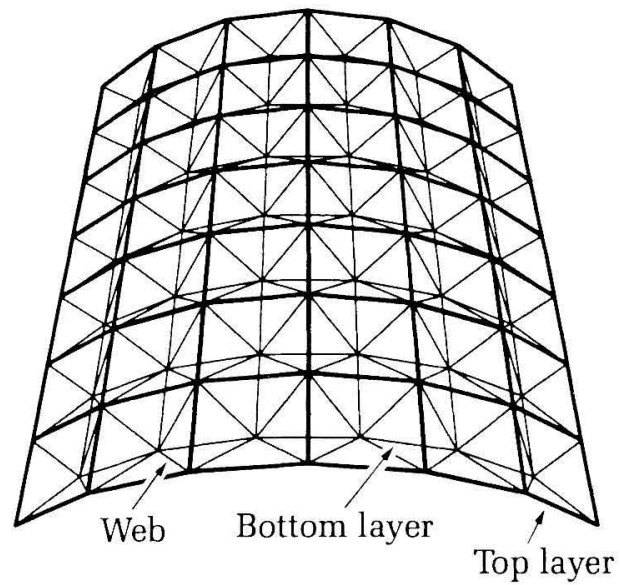

Fig 1.8.21 Perspective view of a double layer barrel vault

This barrel vault consists of

- a layer of elements that forms the 'top layer',

- a layer of elements that forms the 'bottom layer' and

- the 'web' elements that interconnect the top and bottom layers.

The top layer elements of the barrel vault in Fig 1.8.21 are shown by thick lines and the bottom layer elements as well as the web elements are shown by thin lines. All the top layer nodes of the barrel vault lie on a cylindrical surface. This surface is the 'top circumcylinder' of the barrel vault. Also, all the bottom layer nodes lie on a cylindrical surface. This is the 'bottom circumcylinder' of the barrel vault. The top and bottom circumcylinders share the same 
longitudinal axis. The plan and elevation of the barrel vault of Fig 1.8.21 are shown in Fig 1.8.22. Also shown in this figure are the dimensions of the barrel vault together with a cylindrical normat for the formulation of the compret of the configuration of the barrel vault.
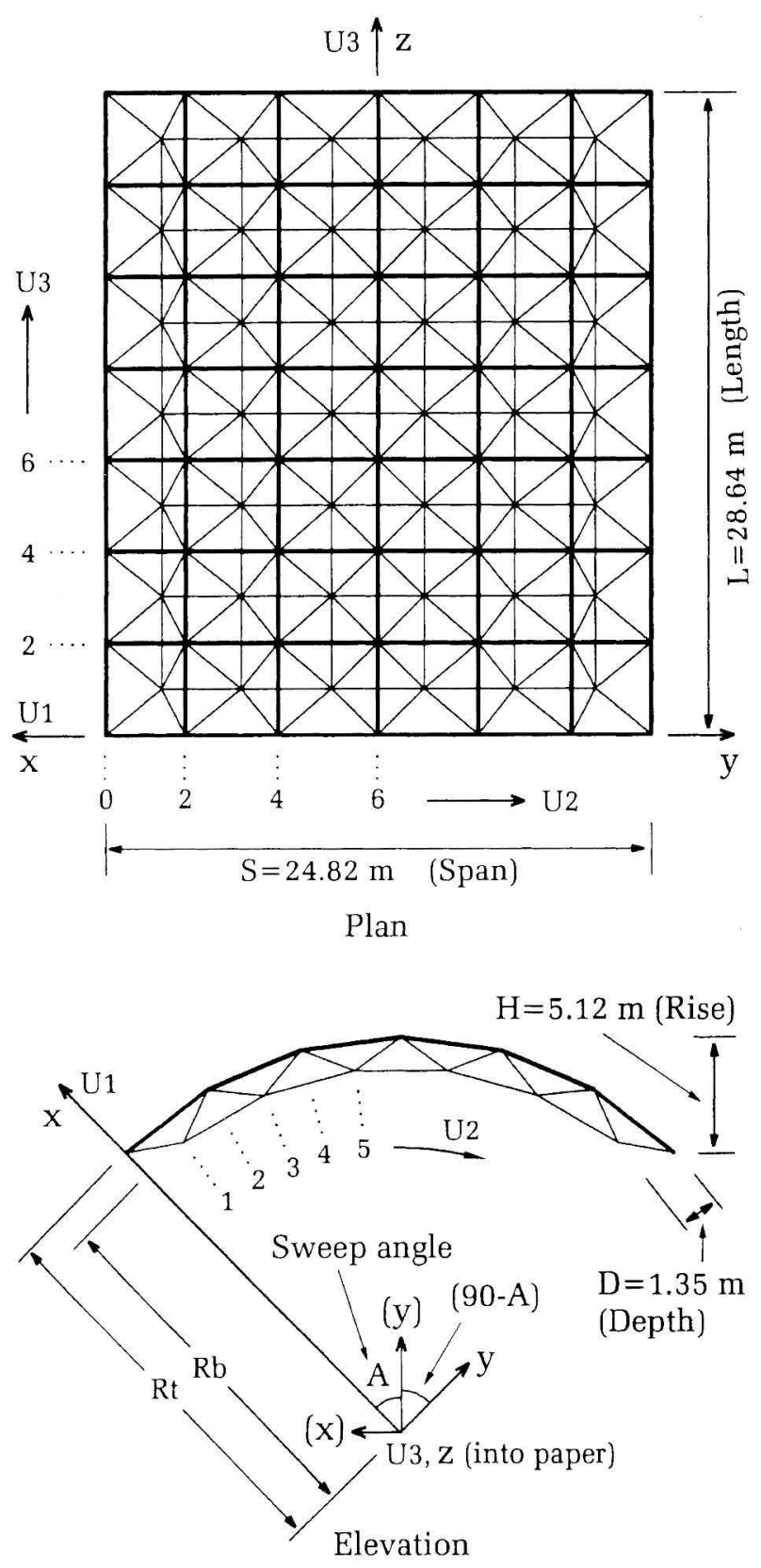

Fig 1.8.22 Plan and elevation of the double layer barrel vault of Fig 1.8.21

The 'span' of the barrel vault is $24.82 \mathrm{~m}$, its 'rise' is $5.12 \mathrm{~m}$ and its 'length' is $28.64 \mathrm{~m}$. The 'depth' of the barrel vault is $1.35 \mathrm{~m}$. The depth is the distance between the top and bottom layers. More specifically, the depth is the difference between the radii of the top and bottom circumcylinders of the barrel vault.
The compret of the barrel vault relative to the U1U2-U3 normat of Fig 1.8.22 may be represented by the following formex formulation:

$$
\begin{aligned}
& \mathrm{TOP}=\operatorname{rinit}(6,8,2,2) \mid[\mathrm{Rt}, 0,0 ; \mathrm{Rt}, 2,0] \# \\
& \operatorname{rinit}(7,7,2,2) \mid[\mathrm{Rt}, 0,0 ; \mathrm{Rt}, 0,2] \\
& \mathrm{BOT}=\operatorname{rinit}(5,7,2,2) \mid[\mathrm{Rb}, 1,1 ; \mathrm{Rb}, 3,1] \# \\
& \operatorname{rinit}(6,6,2,2) \mid[\mathrm{Rb}, 1,1 ; \mathrm{Rb}, 1,3] \\
& \text { WEB }=\operatorname{rinit}(6,7,2,2)|\operatorname{lamit}(1,1)| \\
& \text { [Rt, } 0,0 ; \mathrm{Rb}, 1,1] \\
& \mathrm{B}=\mathrm{TOP} \# \mathrm{BOT} \# \text { WEB }
\end{aligned}
$$

In this formulation

- $\operatorname{rinit}(6,8,2,2) \mid[\mathrm{Rt}, 0,0 ; \mathrm{Rt}, 2,0]$

represents all the top layer elements that are in the second direction,

- $\operatorname{rinit}(7,7,2,2) \mid[\mathrm{Rt}, 0,0 ; \mathrm{Rt}, 0,2]$

represents all the top layer elements that are in the third direction,

- $\operatorname{rinit}(5,7,2,2) \mid[\mathrm{Rb}, 1,1 ; \mathrm{Rb}, 3,1]$

represents all the bottom layer elements that are in the second direction,

- $\operatorname{rinit}(6,6,2,2) \mid[\mathrm{Rb}, 1,1 ; \mathrm{Rb}, 1,3]$

represents all the bottom layer elements that are in the third direction,

- $\operatorname{rinit}(6,7,2,2)|\operatorname{lamit}(1,1)|[\mathrm{Rt}, 0,0 ; \mathrm{Rb}, 1,1]$

represents all the web elements and

- $\quad$ TOP \# BOT \# WEB

represents all the elements of the barrel vault.

All the formex functions used in the above formulation are as introduced and discussed previously. However, the above formulation does involve a new aspect regarding the use of a cylindrical normat. To elaborate, in using the cylindrical normats so far, all the configurations formulated involved only a single cylindrical surface. However, in the present example, the configuration involves two cylindrical surfaces. Actually, there is no limit to the number of cylinders of a normat that may be involved in a formulation. A cylindrical normat has infinitely many coaxial cylinders whose radii range from 0 to $\infty$, Fig 1.8.23.

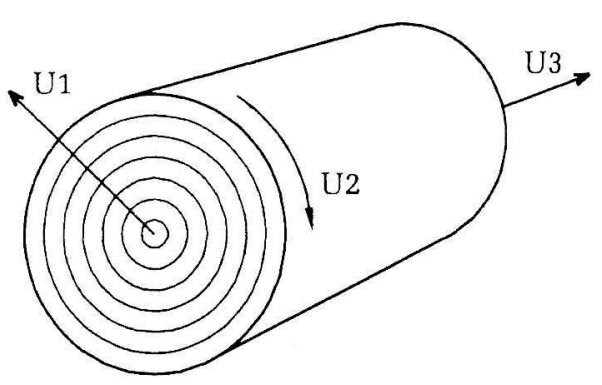

Fig 1.8.23 Coaxial cylinders of a cylindrical normat 
A Formian scheme for the barrel vault of Fig 1.8.21 is shown in the editory display of Fig 1.8.24. The scheme is generic. That is, it is written in terms of a number of parameters, where

- $\mathrm{M}$ is the number of top layer modules in the U2 direction,

- $\mathrm{N}$ is the number of top layer modules in the U3 direction,

- $\mathrm{S}$ is the span,

- $\mathrm{H}$ is the rise,

- $\mathrm{D}$ is the depth,

- $\quad \mathrm{L}$ is the length and

- $\mathrm{v}$ is the view adjuster.

$\left(^{\star}\right)$ Double layer barrel vault of Fig 1.8.21 (*)

$\mathrm{M}=6 ; \quad\left({ }^{*}\right)$ top modules along U2 $\left(^{*}\right)$

$\mathrm{N}=7 ; \quad\left({ }^{*}\right)$ top modules along U3 $\left(^{*}\right)$

$\mathrm{S}=24.82 ; \quad\left(^{*}\right) \operatorname{span}\left({ }^{*}\right)$

$\mathrm{H}=5.12 ; \quad \quad\left({ }^{*}\right)$ rise $\left({ }^{*}\right)$

$\mathrm{D}=1.35 ; \quad\left(^{*}\right) \operatorname{depth}\left({ }^{*}\right)$

$\mathrm{L}=28.64 ; \quad \quad\left({ }^{*}\right)$ length $\left(^{*}\right)$

$\mathrm{v}=0 ; \quad \quad\left({ }^{*}\right)$ view adjuster $\left({ }^{*}\right)$

$\mathrm{A}=2^{\star}$ atan $\mid\left(2^{\star} \mathrm{H} / \mathrm{S}\right) ;\left(^{\star}\right)$ sweep angle $\left({ }^{\star}\right)$

$\mathrm{Rt}=\mathrm{S} /\left(2^{\star} \sin \mid \mathrm{A}\right) ; \quad\left({ }^{\star}\right)$ top radius $\left({ }^{*}\right)$

$\mathrm{Rb}=\mathrm{Rt}-\mathrm{D} ; \quad \quad{ }^{\star}$ ) bottom radius $\left({ }^{*}\right)$

$\mathrm{TOP}=\operatorname{rinit}(\mathrm{M}, \mathrm{N}+1,2,2) \mid[\mathrm{Rt}, 0,0 ; \mathrm{Rt}, 2,0] \#$ $\operatorname{rinit}(\mathrm{M}+1, \mathrm{~N}, 2,2) \mid[\mathrm{Rt}, 0,0 ; \mathrm{Rt}, 0,2]$;

$\mathrm{BOT}=\operatorname{rinit}(\mathrm{M}-1, \mathrm{~N}, 2,2) \mid[\mathrm{Rb}, 1,1 ; \mathrm{Rb}, 3,1] \#$ $\operatorname{rinit}(\mathrm{M}, \mathrm{N}-1,2,2) \mid[\mathrm{Rb}, 1,1 ; \mathrm{Rb}, 1,3]$;

$\mathrm{WEB}=\operatorname{rinit}(\mathrm{M}, \mathrm{N}, 2,2)|\operatorname{lamit}(1,1)|$ [Rt, 0,$0 ; \mathrm{Rb}, 1,1]$;

$\mathrm{B}=$ TOP\#BOT\#WEB;

$\mathrm{B} 1=\mathrm{bc}\left(1, \mathrm{~A} / \mathrm{M}, \mathrm{L} /\left(2^{\star} \mathrm{N}\right)\right) \mid \mathrm{B}$;

$\mathrm{BV}=\operatorname{verad}(0,0,90-\mathrm{A}) \mid \mathrm{B} 1$;

use \&,vm(2),vt(2),

$\operatorname{vh}\left(\mathrm{v}, 2.75^{\star} \mathrm{Rt},-\mathrm{Rt}, 0,0, \mathrm{Rt}, 0,1, \mathrm{Rt}\right)$;

clear; draw BV;

$<><><>$

Fig 1.8.24 A generic scheme for the double layer barrel vault of Fig 1.8.21

The variable $\mathrm{A}$ in the scheme of Fig 1.8.24 represents the sweep angle of the barrel vault. The sweep angle is given by

$$
\mathrm{A}=2 \arctan (2 \mathrm{H} / \mathrm{S})
$$

as derived previously and shown in Fig 1.8.5. Also, using the information given in Fig 1.8.5, the radius of the top circumcylinder of the barrel vault of Fig 1.8.21 is found to be

$$
\mathrm{Rt}=\mathrm{S} /(2 \sin \mathrm{A})
$$

The radius of the bottom circumcylinder of the barrel vault is then given by

$$
\mathrm{Rb}=\mathrm{Rt}-\mathrm{D}
$$

The formulation of the compret of the barrel vault of Fig 1.8.21, as given in the scheme of Fig 1.8.24, is a generic version of the formex formulation given above. The last statement in this formulation creates the formex variable B that represents the compret of the barrel vault relative to the cylindrical normat U1U2-U3 of Fig 1.8.22. It should be noted that in this normat the coordinates in the $\mathrm{U} 1$ direction are based on the 'true' dimensions rather than a simplified graduation.

Graduations along normat directions are normally chosen for convenience in the formulation of configurations. However, in some situations the actual dimensions provide the most convenient graduation along a normat direction. And, this happens to be the case for the U1 direction in the example under consideration.

In the scheme of Fig 1.8.24, the configuration of the barrel vault relative to the global Cartesian $x-y-z$ coordinate system of Fig 1.8.22 is given by

$$
\mathrm{B} 1=\mathrm{bc}\left(1, \mathrm{~A} / \mathrm{M}, \mathrm{L} /\left(2^{*} \mathrm{~N}\right)\right) \mid \mathrm{B} ;
$$

The construct

$$
\mathrm{bc}(1, \mathrm{~A} / \mathrm{M}, \mathrm{L} /(2 * \mathrm{~N}))
$$

is a basicylindrical retronorm, as discussed before (Fig 1.8.6).

- The first parameter of the retronorm, which is given as 1 , is the scale factor in the U1 direction. The value is 1 since the normat graduation in this direction corresponds to the actual dimensions.

- The second parameter is the (angular) scale factor in the U2 direction and is given as $\mathrm{A} / \mathrm{M}$. This has the effect of keeping the sweep angle equal to $\mathrm{A}$ for all values of $\mathrm{M}$.

- The third parameter of the retronorm is the scale factor in the U3 direction and is given as $\mathrm{L} /\left(2^{*} \mathrm{~N}\right)$. This has the effect of keeping the length of the barrel vault equal to $L$ for all values of $\mathrm{N}$.

The statement following the basicylindrical transformation in the scheme of Fig 1.8.24 is

$$
\mathrm{BV}=\operatorname{verad}(0,0,90-\mathrm{A}) \mid \mathrm{B} 1 \text {; }
$$

The effect of this statement is to rotate the whole barrel vault around the $\mathrm{z}$ axis by $(90-\mathrm{A})^{\circ}$. As a result, with respect to the new position of the barrel vault, the $\mathrm{x}$ and $\mathrm{y}$ axes assume the directions indicated by $(x)$ and (y) in Fig 1.8.22. This rotational transformation was previously discussed in relation to the barrel vault of Fig 1.8.1, as shown in Fig 1.8.8. 
A generic scheme, such as the one in Fig 1.8.24, is a useful aid for a designer since it allows various possibilities to be examined conveniently by using different values for the parameters. For instance, the double layer barrel vault of Fig 1.8.25 is produced by the scheme of Fig 1.8.24 using the parameter values $\mathrm{M}=10, \mathrm{~N}=10, \mathrm{~S}=32, \mathrm{H}=10, \mathrm{D}=1.6$ and $\mathrm{L}=40$.

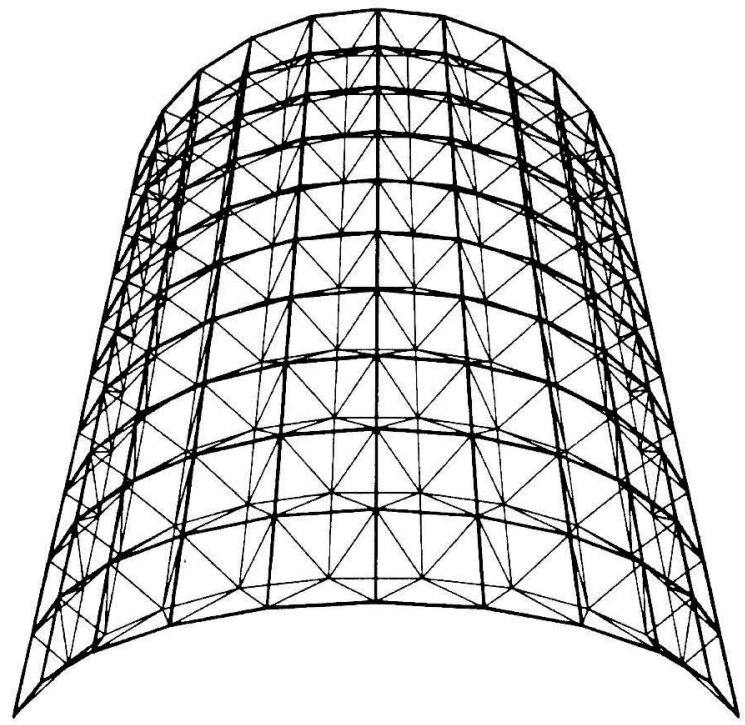

Fig 1.8.25 A double layer barrel vault generated by the scheme of Fig 1.8.24 with $\mathrm{M}=10$, $\mathrm{N}=10, \mathrm{~S}=32, \mathrm{H}=10, \mathrm{D}=1.6$ and $\mathrm{L}=40$

\subsection{DOMES}

An example of a dome configuration is shown in Fig 1.9.1. The dome has 400 elements that are connected together at 144 nodes. All of these nodes are situated on a sphere that is referred to as the 'circumsphere' of the dome.

A cross-section of the circumsphere of the dome is shown in Fig 1.9.2. Also shown in this figure is the cross-section of the dome in thick lines.

The particulars of the dome are as follows:

- The 'span' is $\mathrm{S}=36 \mathrm{~m}$.

- The 'rise' is $\mathrm{H}=7 \mathrm{~m}$.

- The 'sweep angle' is $\mathrm{A}=2 \arctan (2 \mathrm{H} / \mathrm{S})=42.501^{\circ}$

- The radius of the circumsphere of the dome is $\mathrm{R}=\mathrm{S} /(2 \sin \mathrm{A})=26.643 \mathrm{~m}$

- The 'central angle' of the dome is twice the sweep angle and is equal to $85.002^{\circ}$.

The formulae for the sweep angle $A$ and radius $\mathrm{R}$, as given above, are the same as for a cylindrical barrel vault derived previously and shown in Fig 1.8.5.

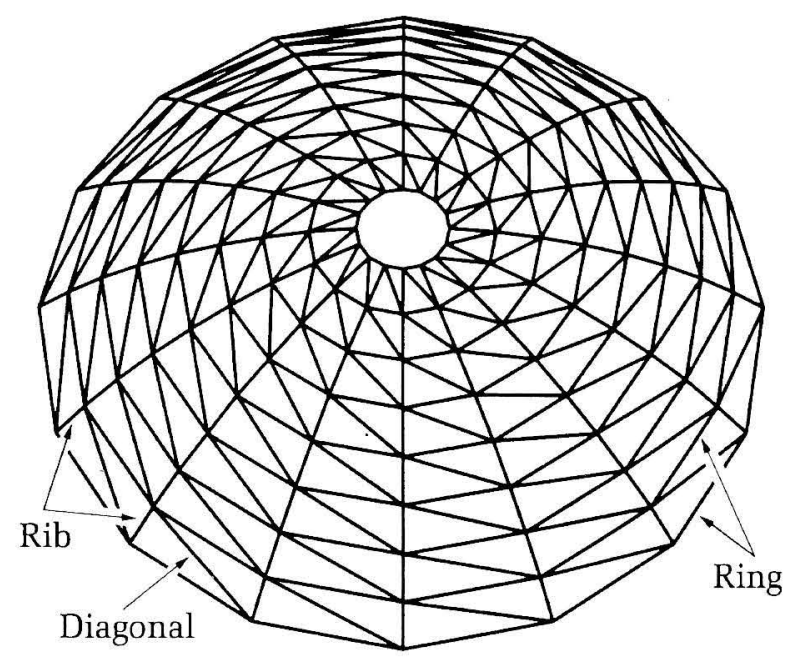

Fig 1.9.1 A dome configuration

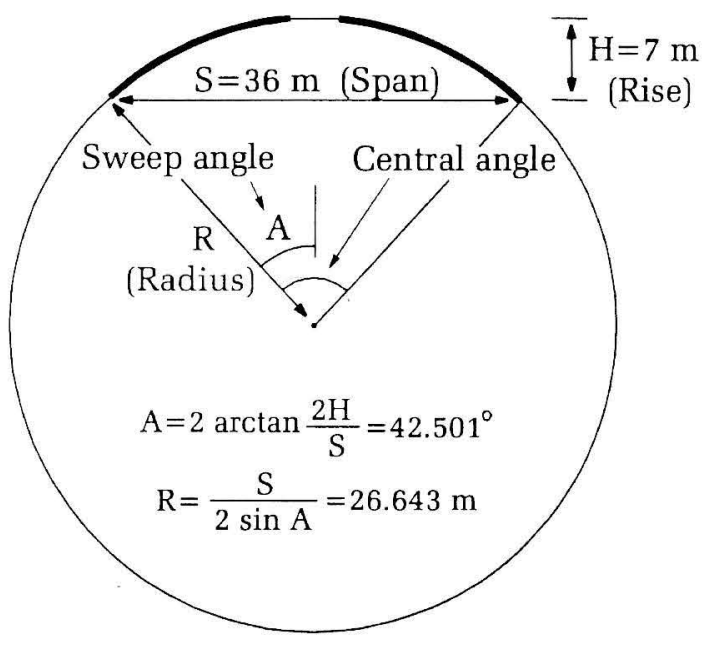

Fig 1.9.2 Cross-section of the circumsphere of the dome of Fig 1.9.1

A dome with a pattern of elements as shown in Fig 1.9.1 is referred to as a 'Schwedler dome' (after the German Engineer J W Schwedler who built a number of domes of this type in the nineteenth century). In a Schwedler dome, each group of elements that forms a horizontal polygon is referred to as a 'ring' and each individual element of a ring is referred to as a 'ring element'. Also, each group of elements that lie along a meridional line between the crown and the base ring is referred to as a 'rib' and each individual element of a rib is referred to as a 'rib element'. Finally, there are the diagonally disposed elements that are referred to as 'diagonal elements'.

The most convenient reference system for the formulation of the compret of the configuration of the Schwedler dome of Fig 1.9.1 is a 'spherical 
normat'. A spherical normat may be imagined as consisting of an infinite number of concentric spheres. The circumsphere of the dome may then be considered to be coincident with the normat sphere of radius $\mathrm{R}$, Fig 1.9.3. This sphere is imagined to have a number of 'parallels' and 'meridians' to suit the configuration of the dome. These parallels and meridians, together with a part of the dome of Fig 1.9.1, are shown in Fig 1.9.4.

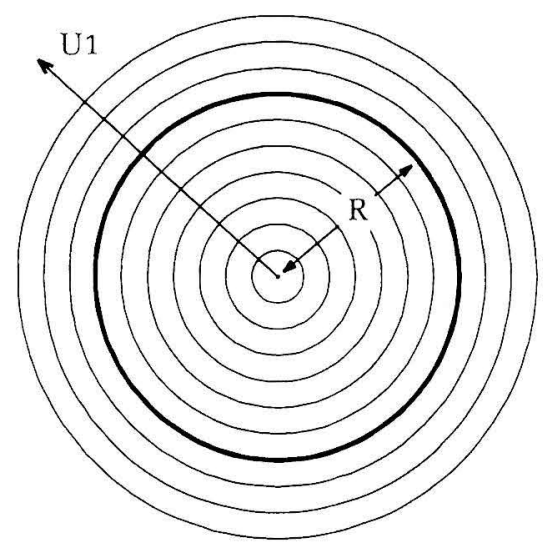

Fig 1.9.3 Concentric spheres of a spherical normat

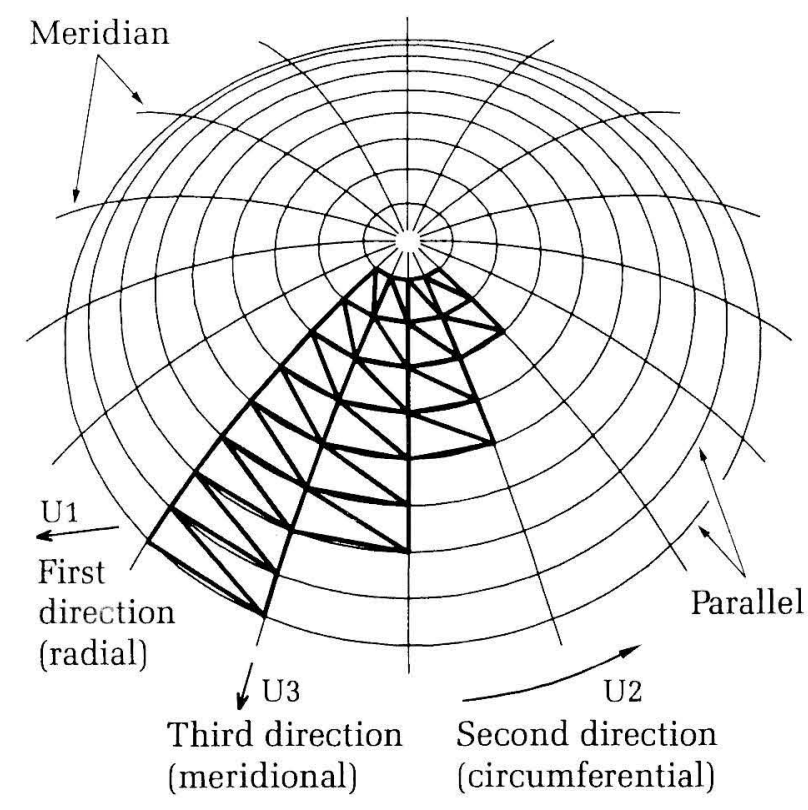

Fig 1.9.4 Parallels and meridians of a spherical normat

The normat of Fig 1.9.4 has three directions:

- 'radial' direction, denoted by U1, representing the radii of the spheres of the normat,

- 'circumferential' direction, denoted by U2, representing angles along the parallels and
- 'meridional' direction, denoted by U3, representing angles along the meridians.

A close-up of the top part of the normat of Fig 1.9.4 is shown in Fig 1.9.5. Also shown in this figure are a few elements of the dome and graduations along the second and third directions.

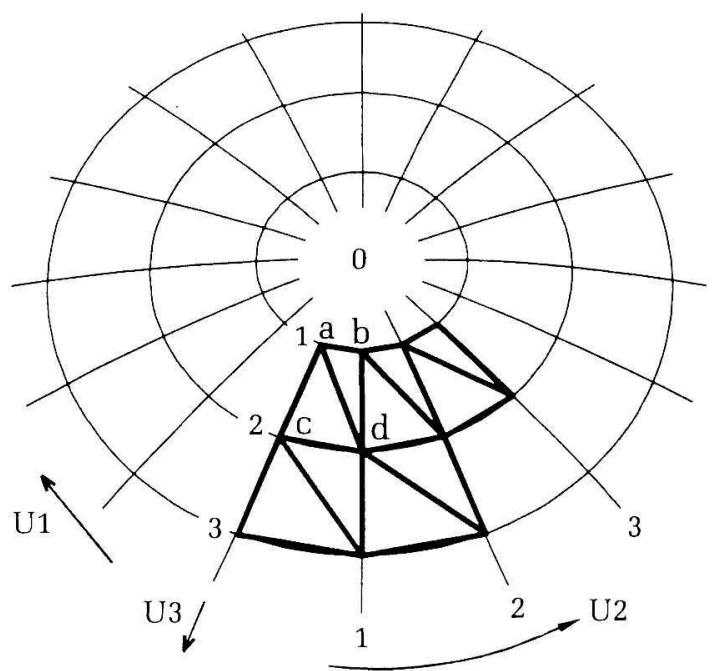

Fig 1.9.5 Normat graduation for the formulation of the compret of the dome of Fig 1.9.1

A formex formulation for the compret of the configuration of the Schwedler dome of Fig 1.9.1, relative to the normat of Fig 1.9.5, may be written as follows:

$$
\begin{aligned}
\mathrm{E}= & \operatorname{rinit}(16,8,1,1) \mid\{[\mathrm{R}, 0,1 ; \mathrm{R}, 1,1], \\
& {[\mathrm{R}, 0,1 ; \mathrm{R}, 0,2],[\mathrm{R}, 0,1 ; \mathrm{R}, 1,2]\} } \\
\mathrm{B}= & \operatorname{rin}(2,16,1) \mid[\mathrm{R}, 0,9 ; \mathrm{R}, 1,9] \\
\mathrm{D}= & \mathrm{E} \# \mathrm{~B}
\end{aligned}
$$

In this formulation

- $\quad\{[\mathrm{R}, 0,1 ; \mathrm{R}, 1,1],[\mathrm{R}, 0,1 ; \mathrm{R}, 0,2],[\mathrm{R}, 0,1 ; \mathrm{R}, 1,2]\}$ represents the elements $\mathrm{ab}$, ac and ad of the dome, as shown in Fig 1.9.5,

- $\operatorname{rinit}(16,8,1,1) \mid\{[\mathrm{R}, 0,1 ; \mathrm{R}, 1,1]$,

$[\mathrm{R}, 0,1 ; \mathrm{R}, 0,2],[\mathrm{R}, 0,1 ; \mathrm{R}, 1,2]\}$

represents all the elements of the dome other than those along the base ring,

- $\operatorname{rin}(2,16,1) \mid[R, 0,9 ; \mathrm{R}, 1,9]$

represents all the elements along the base ring and

- $\mathrm{E}$ \# B

represents all the elements of the dome.

A generic Formian scheme for the formulation of the compret of the Schwedler dome of Fig 1.9.1 is shown in the editory display of Fig 1.9.6. In this scheme

- M represents the number of elements on a ring, 
- $\mathrm{N}$ represents the number of elements on a rib,

- S represents the span and

- $\mathrm{H}$ represents the rise.

The formex formulation in the scheme of Fig 1.9.6 is a generic version of the formulation given above, with the difference that the first uniples of the formices in the scheme are given as 1 rather than R. This will be discussed later.

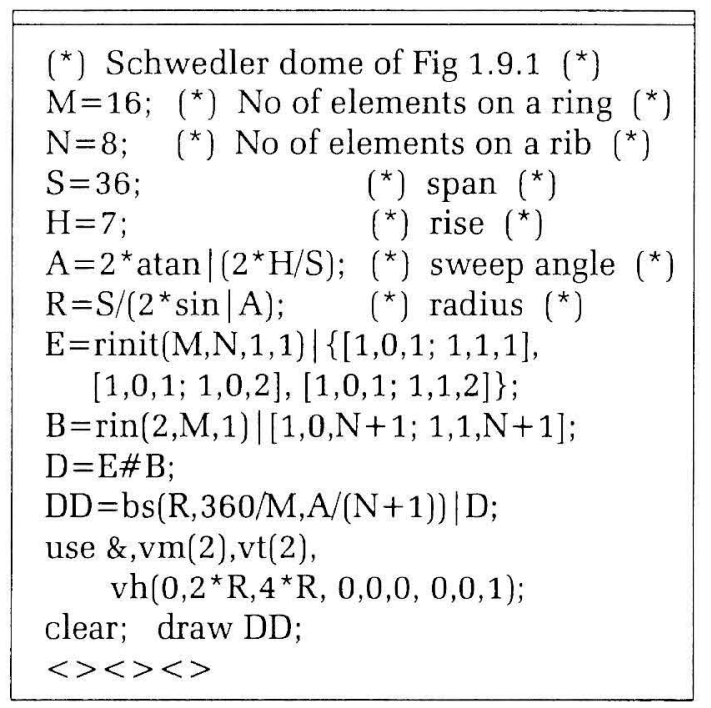

Fig 1.9.6 A generic scheme for the Schwedler dome of Fig 1.9.1

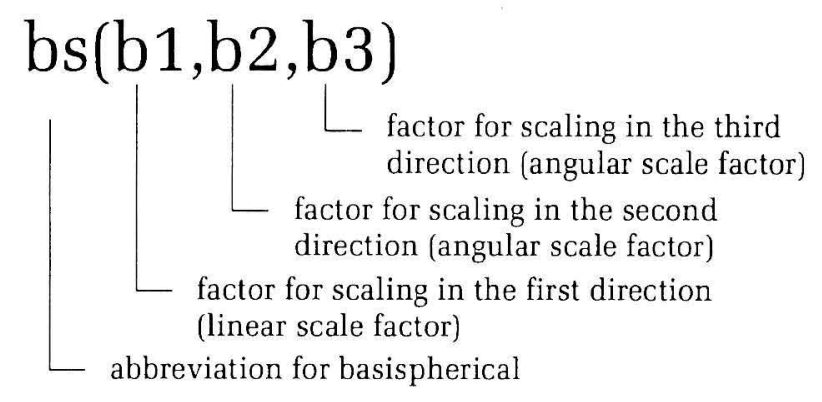

Fig 1.9.7 Basispherical retronorm

The statement following the formulation of the compret in the scheme of Fig 1.9.6 is

$$
\mathrm{DD}=\operatorname{bs}(\mathrm{R}, 360 / \mathrm{M}, \mathrm{A} /(\mathrm{N}+1)) \mid \mathrm{D} \text {; }
$$

The construct

$$
\text { bs }(\mathrm{R}, 360 / \mathrm{M}, \mathrm{A} /(\mathrm{N}+1))
$$

is a 'basispherical' retronorm. The effect of this function is to transform the spherical normat coordinates into global $x-y-z$ Cartesian coordinates. The basispherical retronorm has three parameters that act as scale factors, as explained in Fig 1.9.7.
The first parameter $b 1$ is a scale factor in the radial direction along $\mathrm{U} 1$, the second parameter $\mathrm{b} 2$ is an angular scale factor for the circumferential direction along $\mathrm{U} 2$ and the third parameter b3 is an angular scale factor for the meridional direction along U3.

In the scheme of Fig 1.9.6, the first parameter of the retronorm is given as $\mathrm{R}$. This implies that every first uniple of the value of the formex variable $\mathrm{D}$ will be multiplied by R. Thus, all the nodal points of the dome will assume their correct positions on the normat sphere of radius R. Alternatively, the formex variables $\mathrm{E}$ and $\mathrm{B}$ in the scheme could have been given as

$$
\begin{gathered}
\mathrm{E}=\operatorname{rinit}(\mathrm{M}, \mathrm{N}, 1,1) \mid\{[\mathrm{R}, 0,1 ; \mathrm{R}, 1,1], \\
\quad[\mathrm{R}, 0,1 ; \mathrm{R}, 0,2],[\mathrm{R}, 0,1 ; \mathrm{R}, 1,2]\} ; \\
\mathrm{B}=\operatorname{rin}(2, \mathrm{M}, 1) \mid[\mathrm{R}, 0, \mathrm{~N}+1 ; \mathrm{R}, 1, \mathrm{~N}+1] ;
\end{gathered}
$$

In this case, the first parameter $\mathrm{b} 1$ of the retronorm in the scheme should be given as 1 rather than $\mathrm{R}$.

The second parameter b2 of the basispherical retronorm in the scheme of Fig 1.9.6 is given as

\section{$360 / \mathrm{M}$}

This implies that every second uniple of the value of the formex variable $\mathrm{D}$ will be multiplied by $360 / \mathrm{M}$. The effect is that, for any value of $\mathrm{M}$, the elements on a ring cover $360^{\circ}$ and create a closed polygon.

The third parameter b3 of the retronorm in the scheme is given as

$$
\mathrm{A} /(\mathrm{N}+1)
$$

This implies that every third uniple of the value of the formex variable $\mathrm{D}$ will be multiplied by $\mathrm{A} /(\mathrm{N}+1)$. Consequently, for any value of $\mathrm{N}$, the sweep angle of the dome will remain equal to $\mathrm{A}$.

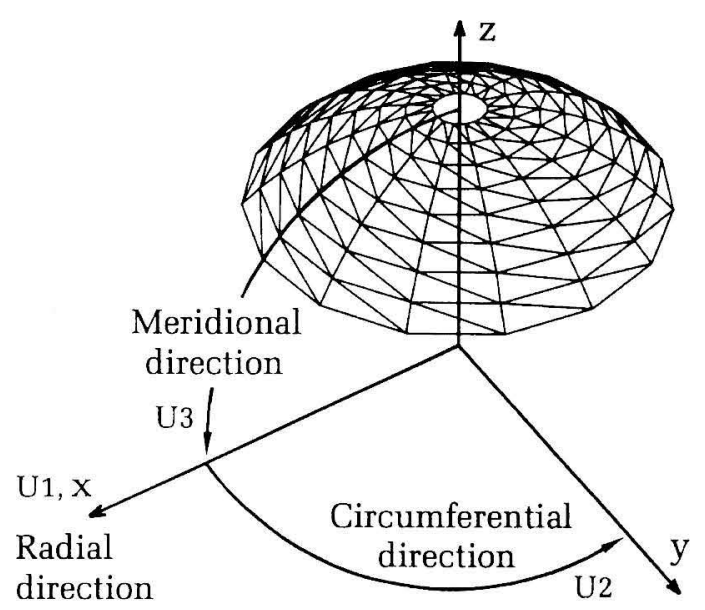

Fig 1.9.8 Relationship between the U1-U2-U3 spherical normat and the global $x-y-z$ Cartesian coordinate system 
In the scheme of Fig 1.9.6, both formex variables D and DD represent the compret of the Schwedler dome of Fig 1.9.1. However, D represents the compret of the dome relative to the spherical normat of Fig 1.9.5, whereas DD represents the compret of the dome relative to the global $x-y-z$ Cartesian coordinate system. The relationship between these two reference systems is shown in Fig 1.9.8.

If a typical signet of the formex variable $D$ is represented by

$$
[\mathrm{U} 1, \mathrm{U} 2, \mathrm{U} 3]
$$

and if the corresponding signet of DD is represented by

$$
[\mathrm{x}, \mathrm{y}, \mathrm{z}]
$$

then the basispherical retronorm

$$
\text { bs(b1,b2,b3) }
$$

will transform [U1,U2,U3] into $[\mathrm{x}, \mathrm{y}, \mathrm{z}]$ using the equations

$$
\begin{aligned}
& x=b 1 \times U 1 \times \cos (b 2 \times U 2) \times \sin (b 3 \times U 3) \\
& y=b 1 \times U 1 \times \sin (b 2 \times U 2) \times \sin (b 3 \times U 3) \\
& z=b 1 \times U 1 \times \cos (b 3 \times U 3)
\end{aligned}
$$

These equations are based on the standard formulae for transformation of spherical coordinates into Cartesian coordinates.

To conclude the discussion of the scheme of Fig 1.9.6, reference should be made to the 'use', 'clear' and 'draw' statements at the end of the scheme. These statements effect the setting up of the viewing particulars and the drawing of the dome. The details of these statements have been discussed in the previous sections.

Another example of a Schwedler dome is shown in Fig 1.9.9. This dome has 10 rings and 24 ribs. However, some of the ribs have been 'trimmed' back at the top and the arrangement of the elements in the central part has been altered.

An operation of this kind on the configuration of a dome is referred to as 'trimming' and the resulting dome is referred to as a 'trimmed' dome. Trimming may be carried out in many different ways and applied to different types of domes.

The reason for trimming is to avoid 'element cluttering' in the central region of a dome. To elaborate, consider the Schwedler dome shown in Fig 1.9.10. This configuration is generated using the scheme of Fig 1.9.6 with $\mathrm{M}=24$ (number of elements on a ring) and $\mathrm{N}=9$ (number of elements on a rib).

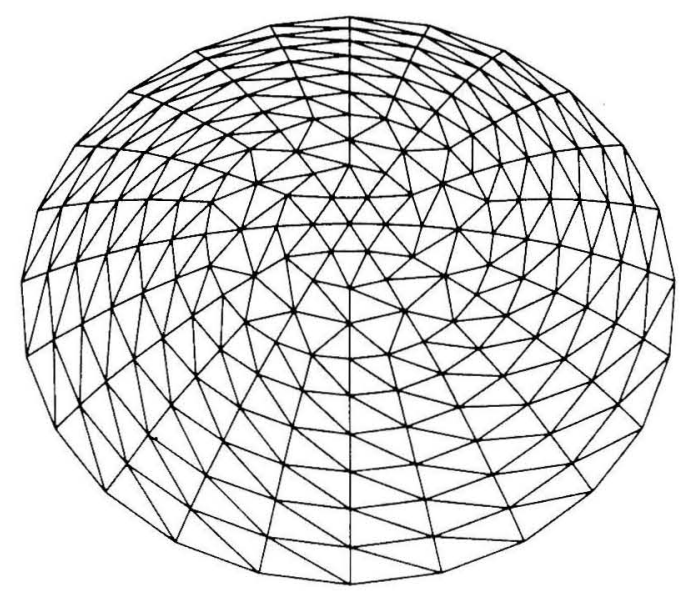

Fig 1.9.9 A trimmed Schwedler dome

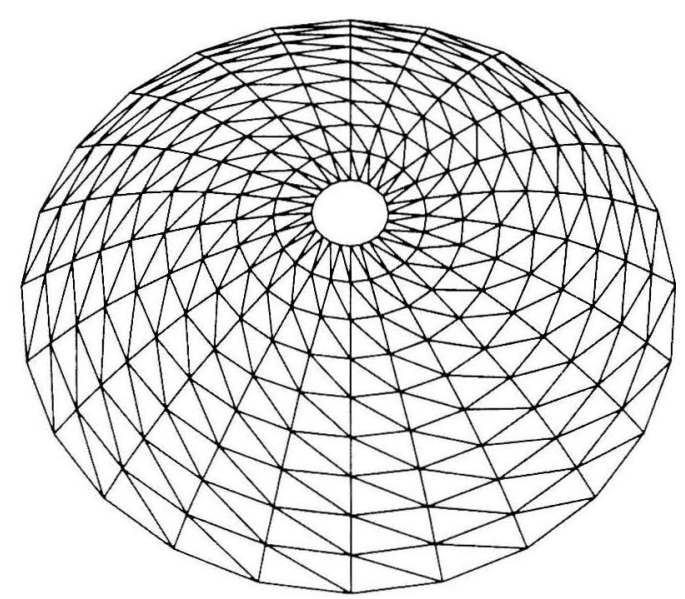

Fig 1.9.10 A Schwedler dome generated by the scheme of Fig 1.9.6 with $\mathrm{M}=24$ and $\mathrm{N}=9$

The main bodies of the domes in Figs 1.9.9 and 1.9.10 are similar but their central regions have different patterns. In the central region of the dome of Fig 1.9.10 there is, evidently, an undesirable cluttering of the elements. However, this problem has been overcome by trimming in the dome of Fig 1.9.9.

A Formian scheme for the generation of the configuration of the dome of Fig 1.9.9 is shown in Fig 1.9.11. In this scheme

- the formex variable Ec represents the elements in the central region of the dome,

- the formex variable $\mathrm{Eb}$ represents the elements in the main body of the dome excluding the ones on the base ring,

- the formex variable B represents the elements on the base ring and

- the formex variable D represents all the elements of the dome. 


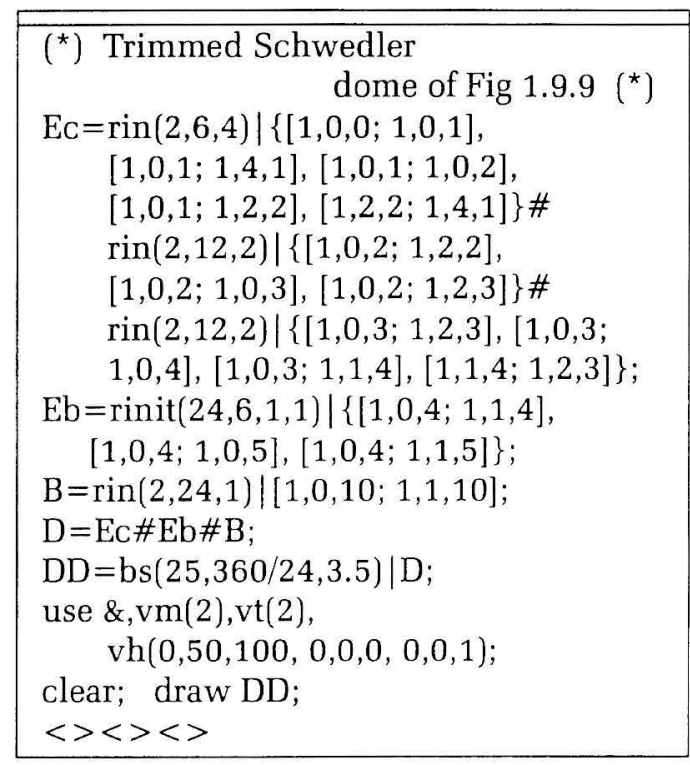

Fig 1.9.11 A scheme for the trimmed Schwedler dome of Fig 1.9.9

In the scheme of Fig 1.9.11, the statement

$$
\mathrm{DD}=\mathrm{bs}(25,360 / 24,3.5) \mid \mathrm{D} \text {; }
$$

has the effect of transforming $\mathrm{D}$, representing the compret of the dome relative to a spherical normat, into $\mathrm{DD}$, representing the compret of the dome relative to the global $x-y-z$ coordinate system.

In the basispherical retronorm

$$
\text { bs }(25,360 / 24,3.5)
$$

- The first parameter sets the circumradius of the dome equal to 25 units (the term 'circumradius' means the 'radius of the circumsphere').

- The second parameter sets the angular scale factor for the circumferential direction equal to $(360 / 24)^{\circ}$, so that, with 24 circumferential divisions, the rings will close.

- the third parameter sets the angular scale factor in the meridional direction equal to $3.5^{\circ}$. This will result in the sweep angle of the dome being equal to $35^{\circ}$ (since there are 10 divisions on each meridian from the crown to the base of the dome).

It is to be noted that in the case of the scheme of Fig 1.9.11, the circumradius and the sweep angle of the dome are given directly, rather than being calculated in terms of the span and the rise (as in the previous example). However, if required, the span and the rise of the dome can be obtained using the relations given in Fig 1.9.2. To be specific, the span is obtained as

$$
\mathrm{S}=2 \mathrm{R} \sin \mathrm{A}=28.679 \text { units }
$$

and the rise is obtained as

$$
\mathrm{H}=(\mathrm{S} \tan (\mathrm{A} / 2)) / 2=4.521 \text { units }
$$

Note that here the values for the span $\mathrm{S}$ and rise $\mathrm{H}$ are given in terms of 'units (of length)', rather than a specific unit such metre or millimetre. The reason is that, in the present context, the discussion concerns the arrangement and the proportions of the elements rather than the actual sizes. In such a context, one may choose to use the general term 'unit' instead of a specific unit of length. This emphasises the fact that the discussion is independent of the actual sizes. Fundamentally, the information contained in a formex is in terms of an arrangement of 'pure' numbers without any inherent association with specific units of length, angle, time, force, ... etc. The association of units with the information in a formex is effected by a 'human' to suit the context in which the formex is used.
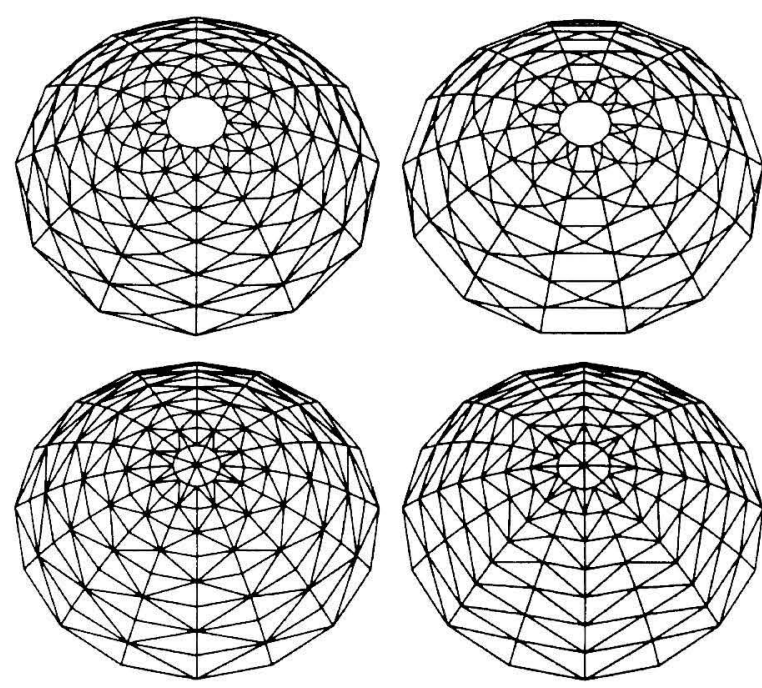

Fig 1.9.12 Some varieties of Schwedler dome
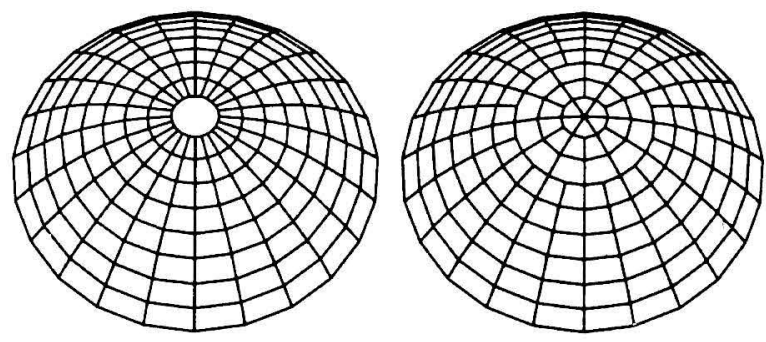

Fig 1.9.13 Examples of ribbed domes

Further examples of dome configurations are shown in Figs 1.9.12 to 1.9.14. The domes in Fig 1.9.12 are examples of various types of Schwedler domes. Examples of a different family of dome configurations are shown in Fig 1.9.13. These are 
referred to as 'ribbed' domes, with the one on the right being a 'trimmed ribbed' dome.

The basic characteristic of a Schwedler dome configuration is that it consists of rib, ring and diagonal elements. In contrast, a ribbed dome configuration (mainly) consists of rib and ring elements. There is another major family of dome configurations in which the elements are (mainly) ring and diagonal elements. Examples of this family of domes are shown in Fig 1.9.14. These are referred to as 'lamella' domes. Also, the bottom right dome in Fig 1.9.14 is a 'trimmed lamella' dome.
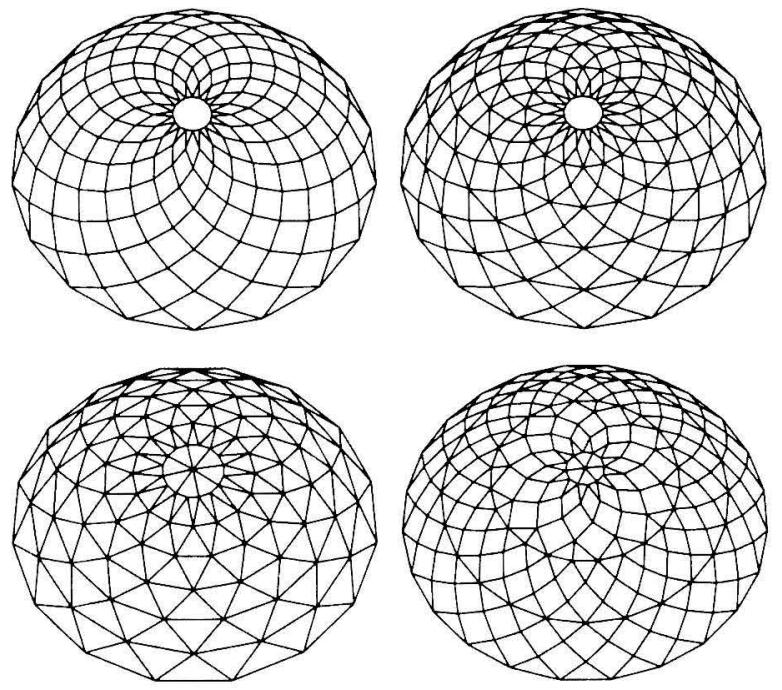

Fig 1.9.14 Examples of lamella domes

A lamella dome configuration may contain a few rib elements, as in the bottom dome configurations in Fig 1.9.14. Also, ribbed domes may sometimes involve a few diagonal elements.

The formex formulations for the domes in Figs 1.9.12 to 1.9 .14 are left for the reader to carry out as exercise.

Spherical dome configurations may be transformed into ellipsoidal domes using simple scaling in a manner similar to that discussed in relation to barrel vaults in section 1.8. For example, let $\mathrm{D}$ be a formex variable representing a trimmed Schwedler dome of the type shown in Fig 1.9.9 relative to the global coordinate system. A plan view of this dome is shown in Fig 1.9.15(a). The formex variable

$$
\mathrm{DD}=\mathrm{bb}(1,1.25) \mid \mathrm{D}
$$

will then represent an ellipsoidal dome whose dimensions in the y direction are 1.25 times greater than those in the original dome. The plan view of the dome represented by DD is shown in Fig 1.9.15(b).
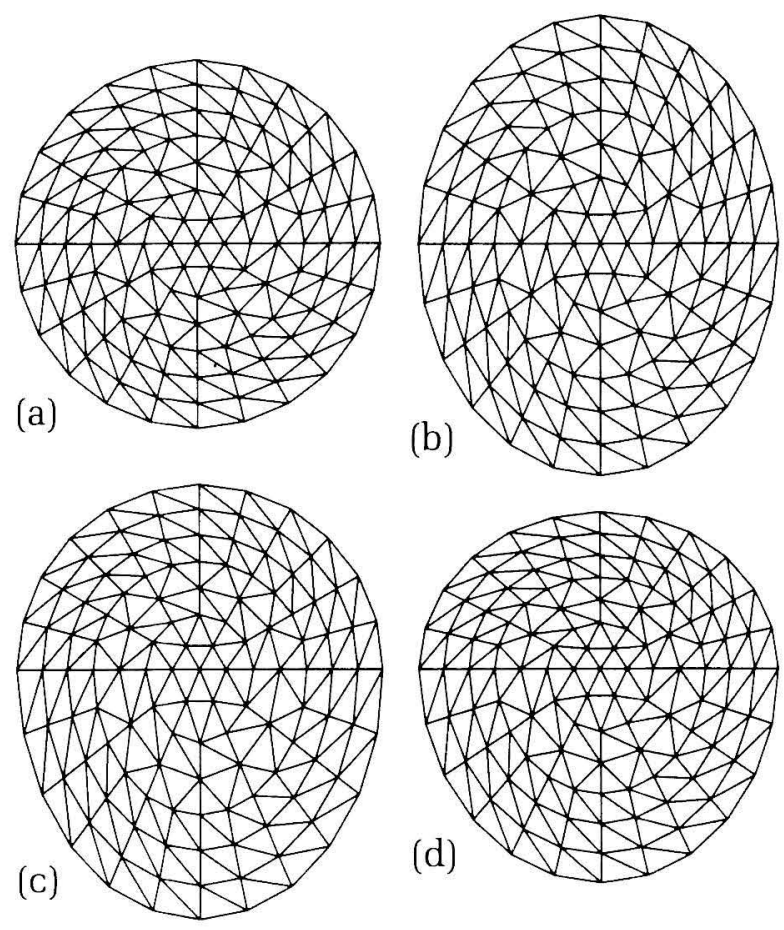

Fig 1.9.15 Examples of ellipsoidal and ovate domes

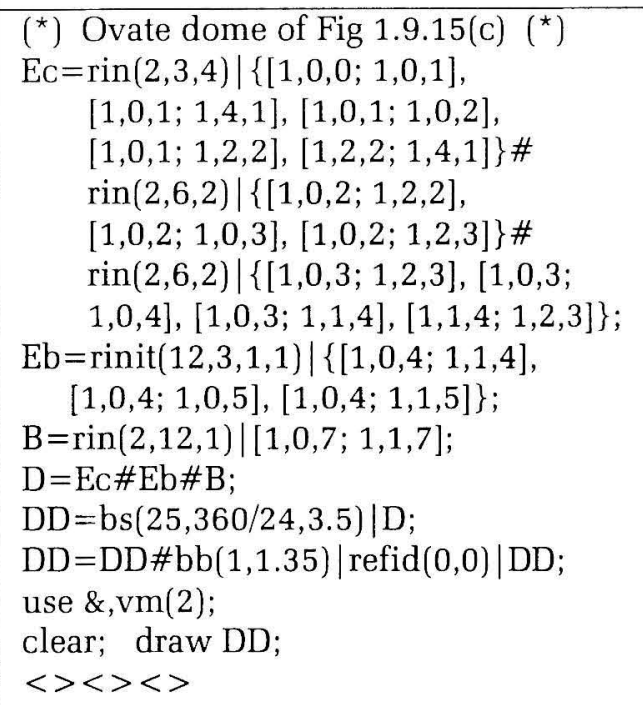

Fig 1.9.16 A scheme for the ovate dome of Fig 1.9.15(c)

Simple scaling may also be used to create 'ovate' (egg-shaped) domes of various forms. For example, Fig 1.9.15(c) shows the plan view of an ovate dome obtained by putting together half of the spherical dome of Fig 1.9.15(a) with half of an ellipsoidal dome. A scheme for the generation of the compret of this ovate dome in shown in the editory display of 
Fig 1.9.16. Fig 1.9.15(d) shows the plan view of another ovate dome that is obtained by putting together two half ellipsoidal domes.

As the last example in this section, consider the double layer dome of Fig 1.9.17. This is a circular canopy structure with a large opening at the middle. The dome has 324 top layer elements, 252 bottom layer elements and 576 web elements. In Fig 1.9.17, the top layer elements of the dome are shown by thick lines and the bottom layer elements as well as the web elements are shown by thin lines. A section through the centre of the dome is shown in Fig 1.9.18.

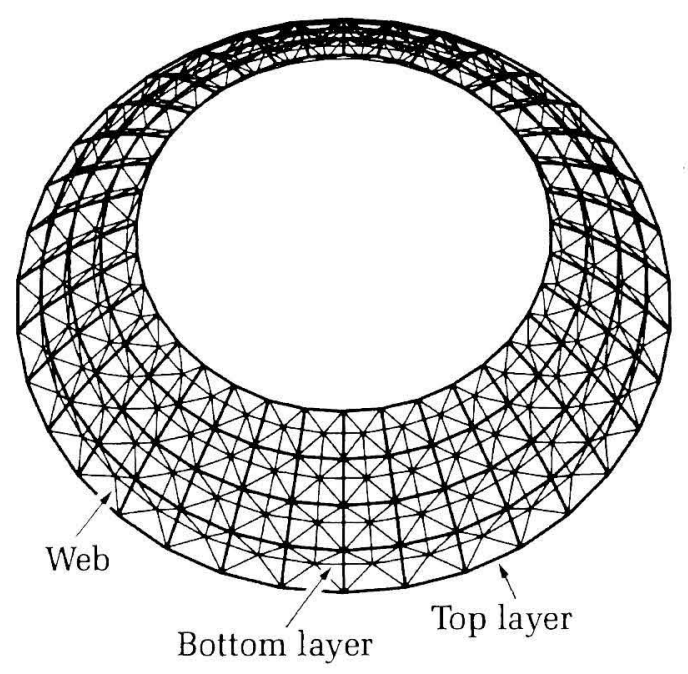

Fig 1.9.17 Perspective view of a double layer canopy dome

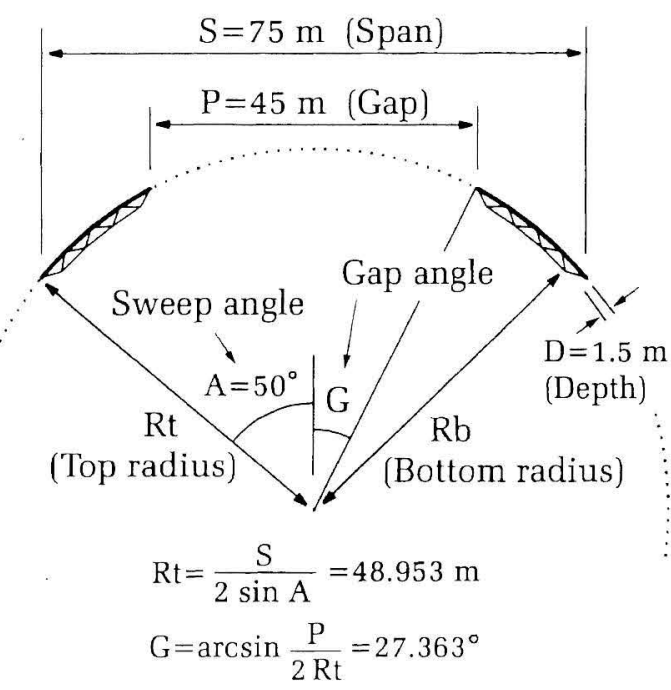

Fig 1.9.18 A section through the centre of the double layer dome of Fig 1.9.17
The span of the dome, that is, the diameter of the base ring of the top layer, is $\mathrm{S}=75 \mathrm{~m}$ and the 'gap' at the middle, that is, the diameter of the central ring of the top layer is $\mathrm{P}=45 \mathrm{~m}$.

The position of the circumsphere of the top layer of the dome is indicated by a dotted circle in Fig 1.9.18. Also shown in this figure is the 'depth' of the dome which is equal to $1.5 \mathrm{~m}$. This is the difference between the circumradii of the top and bottom layers of the dome.

The sweep angle of the dome is given as $50^{\circ}$, as shown in Fig 1.9.18. The circumradius of the top layer is then obtained as

$$
\mathrm{Rt}=\mathrm{S} /(2 \sin \mathrm{A})=48.953 \mathrm{~m}
$$

where $\mathrm{S}$ is the span and $\mathrm{A}$ is the sweep angle. The derivation of this equation has been discussed previously (Fig 1.8.5).

To obtain the 'gap angle' $\mathrm{G}$, one may write

$$
\begin{aligned}
& (\mathrm{P} / 2) / \mathrm{Rt}=\sin \mathrm{G} \\
& \mathrm{G}=\arcsin (\mathrm{P} /(2 \mathrm{Rt}))=27.363^{\circ}
\end{aligned}
$$

$\left(^{\star}\right)$ Double layer dome of Fig 1.9.17 (*) $\mathrm{M}=36 ;\left(^{\star}\right)$ No of elements on a ring $\left(^{\star}\right)$ $\mathrm{N}=4 ;\left(^{*}\right)$ No of elements on a top rib $\left({ }^{*}\right)$ $\mathrm{S}=75 ; \quad \quad\left(^{*}\right) \operatorname{span}\left({ }^{*}\right)$

$\left.\mathrm{P}=45 ; \quad \quad{ }^{*}\right) \operatorname{gap}\left({ }^{*}\right)$

$\left.\mathrm{D}=1.5 ; \quad \quad{ }^{*}\right)$ depth $\left({ }^{*}\right)$

$\mathrm{A}=50 ; \quad \quad\left(^{*}\right)$ sweep angle $\left({ }^{*}\right)$

$\mathrm{Rt}=\mathrm{S} /\left(2^{*} \sin \mid \mathrm{A}\right) ; \quad\left({ }^{*}\right)$ top radius $\left({ }^{*}\right)$

$\left.\mathrm{Rb}=\mathrm{Rt}-\mathrm{D} ; \quad \quad{ }^{*}\right)$ bottom radius $\left({ }^{*}\right)$

$\mathrm{G}=\operatorname{asin} \mid\left(\mathrm{P} /\left(2^{\star} \mathrm{Rt}\right)\right) ; \quad\left(^{\star}\right)$ gap angle $\left({ }^{\star}\right)$

$\left.\mathrm{i}=(\mathrm{A}-\mathrm{G}) /\left(2^{\star} \mathrm{N}\right) ; \quad \quad{ }^{\star}\right)$ increment $\left({ }^{\star}\right)$

$\mathrm{TOP}=\operatorname{rinit}\left(\mathrm{M}, \mathrm{N}+1,2,2^{\star} \mathrm{i}\right) \mid[\mathrm{Rt}, 0, \mathrm{G} ; \mathrm{Rt}, 2, \mathrm{G}] \#$ $\operatorname{rinit}\left(\mathrm{M}, \mathrm{N}, 2,2^{\star} \mathrm{i}\right) \mid\left[\mathrm{Rt}, 0, \mathrm{G} ; \mathrm{Rt}, 0, \mathrm{G}+2^{\star} \mathrm{i}\right]$;

$\mathrm{BOT}=\operatorname{rinit}\left(\mathrm{M}, \mathrm{N}, 2,2^{\star} \mathrm{i}\right) \mid[\mathrm{Rb}, 1, \mathrm{G}+\mathrm{i} ; \mathrm{Rb}, 3, \mathrm{G}+\mathrm{i}] \#$ $\operatorname{rinit}\left(\mathrm{M}, \mathrm{N}-1,2,2^{*} \mathrm{i}\right) \mid\left[\mathrm{Rb}, 1, \mathrm{G}+\mathrm{i} ; \mathrm{Rb}, 1, \mathrm{G}+3^{*} \mathrm{i}\right]$;

WEB $=\operatorname{rinit}\left(M, N, 2,2^{*} \mathrm{i}\right)|\operatorname{lamit}(1, \mathrm{G}+\mathrm{i})|$

[Rt, $0, \mathrm{G} ; \mathrm{Rb}, 1, \mathrm{G}+\mathrm{i}]$;

$\mathrm{DD}=\mathrm{TOP} \# \mathrm{BOT} \# \mathrm{WEB}$;

$\mathrm{DD}=\mathrm{bs}\left(1,360 /\left(2^{*} \mathrm{M}\right), 1\right) \mid \mathrm{DD}$;

use \&,vm(2),vt(2), $\operatorname{vh}\left(0,2^{*} \mathrm{Rt}, 4^{\star} \mathrm{Rt}, 0,0,0,0,0,1\right)$;

clear; draw DD;

$<><><>$

Fig 1.9.19 A generic scheme for the double layer dome of Fig 1.9.17

A generic scheme for the dome of Fig 1.9.17 is given in Fig 1.9.19. The initial data, namely, $\mathrm{S}=75, \mathrm{P}=$ $45, \mathrm{D}=1.5$ and $\mathrm{A}=50$ are given as parameters in the scheme and the values of the circumradii Rt and 
$\mathrm{Rb}$ and the gap angle $\mathrm{G}$ are then obtained in terms of the parameters. Also given as parameters in the scheme are

- $\mathrm{M}$, denoting the number of elements on a top or bottom layer ring, and

- $\mathrm{N}$, denoting the number of elements on a top layer rib.

A spherical normat for the formulation of the compret of the dome is shown in Fig 1.9.20. In this figure, the normat coordinates in the third direction (meridional direction) are given in terms of the gap angle $G$ and an increment

$$
\mathrm{i}=(\mathrm{A}-\mathrm{G}) /(2 \mathrm{~N})
$$

The normat coordinates in the third direction are actual angular values, starting from the gap angle $G$ at the central ring of the top layer, incrementing towards the base ring of the top layer, reaching the sweep angle $\mathrm{A}$.

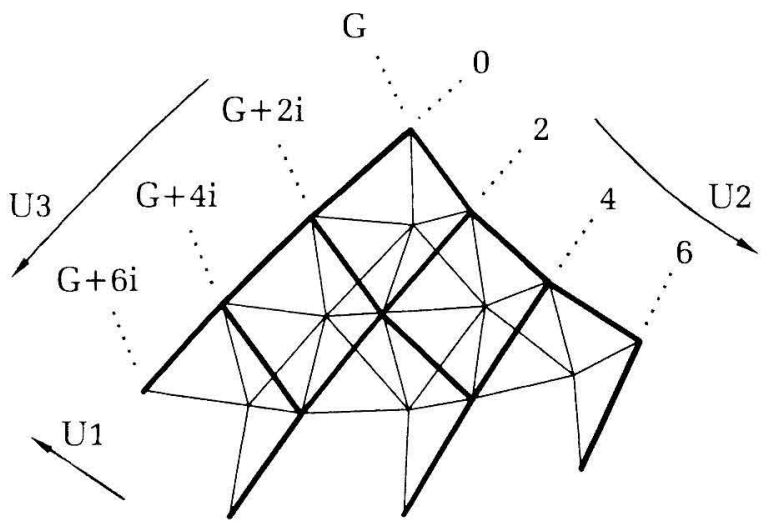

Fig 1.9.20 Spherical normat for the formulation of the compret of the double layer dome of Fig 1.9.17

The formulation of the formex variables TOP, BOT and WEB in the scheme of Fig 1.9.19 is in terms of the actual dimensions in the first direction and actual angular values in the third direction. However, in the second direction the normat coordinates are given in terms of the simple graduation shown in Fig 1.9.20. Consequently, in the basispherical retronorm given in the scheme of Fig 1.9.19, namely,

$$
\text { bs }(1,360 /(2 * M), 1)
$$

only the normat coordinates in the second direction need scaling. The (angular) scale factor in this direction is

\section{$360 / 2 \mathrm{M}$}

Thus, with $M$ members on a ring and with each member involving two divisions, the angles in the second direction will add up to $360^{\circ}$ and the rings will close.

\section{ACKNOWLEDGEMENTS}

The early work in formex configuration processing was greatly helped by substantial donations from a group of Iranian Engineers. These are A. Sarshar, A. Jahanshahi, C. G. Abkarian, G. A. Mirzareza, M. S. Yazdani and J. Hassanein and their contributions are gratefully acknowledged. In the early nineties, the Taiyo Kogyo Corporation of Japan played a crucial role in supporting research in formex configuration processing and, more recently, the Tomoe Corporation of Japan has been instrumental in supporting research in this field. Their generous help is gratefully acknowledged.

\section{REFERENCES}

1. Nooshin, H. Algebraic Representation and Processing of Structural Configurations, International Journal of Computers and Structures, Vol. 5, 1975, 119-130.

2. Nooshin, H. Formex Formulation of Double Layer Grids, This work was presented at a short course on 'Analysis, Design and Construction of Double Layer Grids' at the University of Surrey, UK, in September 1978 and subsequently published as chapter four in: Analysis, Design and Construction of Double Layer Grids, Edited by Z. S. Makowski, Applied Science Publishers, London, 1981, 119-183.

3. Nooshin, H. Formex Configuration Processing in Structural Engineering, Elsevier Applied Science Publishers, London, 1984.

4. Disney, P. and El-labbar, O. An Introduction to Formian, Proceedings of the $3^{\text {rd }}$ International Conference on Space Structures, Edited by $\mathrm{H}$. Nooshin, Elsevier Applied Science Publishers, 1984.

5. Disney, P. Formian: The Programming Language of Formex Algebra, Proceedings of the IASS Symposium on Membrane Structures and Space Frames, Edited by K. Heki, Elsevier Science Publishers, 1986.

6. Nooshin, H. and Disney, P. Elements of Formian, International Journal of Computers and Structures, Vol. 41, No. 6, 1991, 1183-1215.

7. Nooshin, H., Disney, P. and Yamamoto, C. Formian, Multi-Science Publishing Co. Ltd., 1993. 